\title{
Report of the Task Force \\ on Low-Temperature Magnet Operation
}

\section{DISCLAIMER}

This report was prepared as an account of work sponsored by an agency of the United States Government. Neither the United States Government nor any agency thereof, nor any of their employees, makes any warranty, express or implied, or assumes any legal liability or responsibility for the accuracy, completeness, or usefulness of any information, apparatus, product, or process disclosed, or represents that its use would not infringe privately owned rights. Reference herein to any specific commercial product, process, or service by trade name, trademark, manufacturer, or otherwise does not necessarily constitute or imply its endorsement, recommendation, or favoring by the United States Government or any agency thereof. The views and opinions of authors expressed herein do not necessarily state or reflect those of the United States Government or any agency thereof.

\section{July 2,1985}




\section{DISCLAIMER}

Portions of this document may be illegible in electronic image products. Images are produced from the best available original document. 


\section{Sum mary:}

The task force has studied two options for an $8 \mathrm{I}$ ring operating at $2 \mathrm{~K}$. In the first of these the synchrotron light load is taken at $2 \mathrm{~K}$, and in the second it is intercepted on a bore liner at $4.5 \mathrm{~K}$. The possibility of staged construction of the $20 \mathrm{Teq}, 8 \mathrm{~T}, 2 \mathrm{~K}$ ring with initial operation at $15 \mathrm{Te}, 6 \mathrm{~T}$ and $4.5 \mathrm{~B}$ has also been considered.

A set of dimensions and specifications has developed for each of the two $8 \mathrm{I}$ options in the thres categories: magnets, cryostat, and refrigeration system with the object of providing for a detailed cost comparison with the $6 \mathrm{~T}$, design $D$ ring. Cost information for refrigeration systems that are not strictly comparable to design $D$ have ben developed from component quotations. $A$ pery preliminary discussion of costs is included in the report.

A summary of the principal findings of the task force is as follows:

- The temperature at which a $6 \mathrm{~T}, 4.5 \mathrm{~K}$ magnet will operate at $8 \mathrm{~T}$ with the same critical current safety margin is found to be $2 \mathrm{~K}$.

- An increase of $0.5 \mathrm{~cm}$ in the magnet inner diameter is tound to be sufficient to accomodate a fluid-cooled bore liner.

- The most important change in going from the design $D$ magnet to a magnet suitable for operation at $8 \mathrm{~T}, 2 \mathrm{~K}$ is an increase of about 108 in the superconductor and 608 in the iron per unit length.

- The cryostat for $2 \mathrm{~K}$ is fundamentally the same as for design $\mathrm{D}$.

- For the same load ratings complete refrigeration system for the $2 \mathrm{R}$ ring costs about 1.5 times as much as a system for a $4.5 \mathrm{~B}$ ring and uses twice the power.

- Two ideas have come up in the investigations that clearly have merit and deserve further study independent of the choice of magnet style. These are the bore liner for synchrotron radiation interception and the ESCAR or pool-boiling cooling system. 


\section{Contents}

\section{Summary}

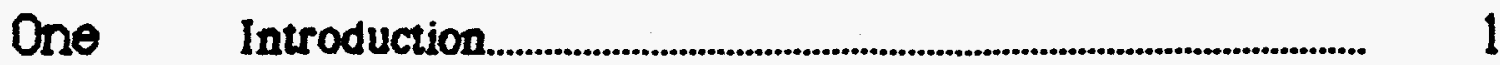

Two Special Problems of Low-Temperature Operation................. 3

Three Operating Temperature and Heat Loads...................................... 5

A) Operating Temperature.................................................. 5

B) Expected Heat Lords............................................................. 6

Four Reference Specifications.................................................................... 7

A) Description of Reference System Features............... 7

B) Magnet Specifications.......................................................... 8

C) Cryostat.......................................................................... 11

D) Refrigeration System Specifications............................. 12

Five Discussion of Specifications and Other Issues.......................... 17

A) Bore Liner.................................................................. 17

B) Pool Boiling................................................................ 18

C) Refrigeration Issues...................................................... 19

Six Staged Construction......................................................... 21

Seven. Preliminary Discussion of Costs............................................. $\quad 23$

A) Capital Costs......................................................... 23

B) Operation at a Lower Temperature............................. $\quad 25$

C) Operating Costs.............................................................. 26

\section{Appendices}

Appendix A 40 and $45 \mathrm{~mm}$ Bore Dipoles

Operated at 1.8 and $4.2 \mathrm{~K} \ldots \ldots \ldots \ldots \ldots$

Appendiz B Magnet Operation at 2.0 K............................................... Bl

Appendiz C Synchrotron Radiation Heat Removal from SSC Magnets and Beam Tube Isolation with Liners................ Cl

Appendix D Trial Helium-Cooled Bore Liner......................................... D1

Appendiz E Membership of Task Force on Low Temperature Operation 


\section{One: $\quad$ Introduction}

\section{A) General:}

It is a fundamental property of superconductors that the critical field is a function of temperature, rising as the temperature decreases. This has the effect in the extreme type two superconductors that the critical current increases with decreasing temperature in a significant way. The data quoted in Appendix A shows the critical current at constant field of a $\mathrm{Nb}-\mathrm{Ti}$ conductor increasing by about a factor of 1.9 as the temperature falls from $4.5 \mathrm{R}$ to $2 \mathrm{R}$. There is, therefore, the opportunity in designing a superconducting magnet system of trading off current density and field against temperature. It is the job of this task force to begin to examine this trade-off for the SSC.

The relevance of low temperature operation in the case of a $3 \mathrm{I}$ magnet is to be doubted. The field is limited by the iron and the coil geometry, and the saving associated with increasing the current density at constant machine radius would not be compelling. Somewhat the same argument applies to a $6 \mathrm{~T}$ magnet operated at the higher current density allowed by low temperature. Assuming the conductor cost to be .43 of the cost of a completed magnet (this is a current estimate for design D), the $2 \mathrm{~K}$, high current density magnet would cost 0.8 of the $4.5 \mathrm{~B}$ magnet. This is a significant saving, but the greatest pay-off for the lowtemperature operation comes when it is used to make magnets at the higher field of $8 \mathrm{~T}$. In this case the machine radius can smaller, reducing all of the sizedependent costs to $3 / 4$. In addition, such a machine can be designed to operate at $15 \mathrm{Tev}$ at $6 \mathrm{~T}$ and $4.5 \mathrm{I}$ with the expectation of an upgrade to 20 Tev at $8 \mathrm{~T}$ and $2 \mathrm{~g}$. This staged construction, with the possibility of reducing the front-end costs, is an important advantage of the low-temperature option. Of course it is understood that against any of these potential savings or advantages, the increased costs and complexity of refrigeration must be balanced. 


\section{B) Charge to the Task Force:}

The task force is charged with the following scope of work: To study both the $6 \mathrm{~T}$, high current density and the $8 \mathrm{~T}$ options both with and without synchrotron light shield at $4.5 \mathrm{~K}$, and to describe quantitatively the implied changes from the $\mathrm{D}$ designs in the magnets, the cryostats and the refrigeration system. The ultimate goal is to provide the basis of arriving at cost increments or decrements in the overall tacility cost if one of these low-temperature options is adopted. In addition some analysis of the special operational and reliability aspects of low-temperature operation needs to be made.

\section{C) Aims and Contents of the Report:}

Reeping in mind the arguments in the second paragraph above, the task force decided to concentrate its major effort on the $8 \mathrm{~T}$ system, and four reports were comissioned. These appear as Appendices A through D below. Two of these deal with the bore liner. Because of the complex nature of the liner problem, the interaction with problems of vacuum and of bore impedance, a complete treatment was not attempted. Enough was done, however, to show the nature of the cryogenic problems involved, and to suggest ideas for their solution. The other two reports deal with magnet designs for an $8 \mathrm{~T}$ ring and with cryostat and refrigerator designs for $2 \mathrm{~B}$ operation.

Drawing on the work in these appendices, the task force has assembled sets of dimensions and specifications for each of the two $8 \mathrm{~T}$ systems and comparisons are made wherever possible with design $D$ values. In cases such as in the refrigeration plants where direct comparison is not possible, cost estimates based on quotations for the major purchased components are provided. The task force is relying on work subsequent to this report for the assembly of the detailed cost figures, however some very preliminary discussions of cost are have been made. 
Two:

\section{Special Problems of Low Temperature Operation}

A discussion about the large-scale use of supertluid cooling rarely occurs without the question being raised about superleaks. This is really not a serious question, but it raises the issue of wheather or not there is an adequate background of technology to support a program of the scale and complexity of a superfluid-cooled SSC. Is there, perhaps, some basic research that neds to be undertaken? This topic is discussed under several headings below:

1) Thermophysical and heat transport properties of helium:

It is true that the large tabulations of the properties of hellum do not extend into the superfluid region. There are in the literature, however, adequate measurements of the saturated properties, and it is straightforward from these to compute thermodynamic quantities down to the lowest temperatures.

In the last decade an adequate formulation of superfluid heat transport has come together. There is not so adequate an understanding of the practical aspects of the Rapitza resistance, but this not a problem at temperatures as high as $2 \mathrm{~B}$.

\section{2) Superfluidity:}

Under this heading comes super leakage, super heat conductivity, and the creeping film. Any component that depends on stratification in the liquid will not work in the superfluid. Aside from this, experience has shown that in large systems superfluidity in practice has very little effect. All sealing and joining systems and valyes should characterized in superfluid before becoming part of a large design, but there is no mystery in the way that most things behave.

3) Refrigeration and systems questions:

It is interesting that superfluid plants were among the first large cryogenic refirgerators constructed for use in physics research laboratories. In the period between 1966 and 1972 four 300 watt, $1.8 \mathrm{X}$ plants were constructed: one at 
4

Stanford; two at Karlsruhe and one at CERN. These were all built to cool superconducting $R F$ systems. The plants have accumulated many tens of thousands of operating hours, not without incident, and there is roughly as much operating experience now with superfluid plants as there was with $4.5 \mathrm{~B}$ plants when the Tevatron was planned.

The real question is whether a large number of complex magnets can be manufactured, assembled, brought into service, and kept in service without a tremendous number of difficulties due in some way to superfluid. This problem has ben confronted in the course of construction and operation of such systems as the Stanford superconducting lina and the CERN separator, not on the scale of the SSC, of course, but on a scale adequate to show the complete range of difficulties. The task force feels confident that the use of superfluid cooling in the SSC program will not present problems that are qualitatively different from those that have ben encountered on the Tevatron. 


\section{Three: $\quad$ Operating Temperature and Heat Loads}

\section{A) Operating Temperature:}

The first question to be answered is at what temperature can a $6 \mathrm{~T}, 4.5 \mathrm{R}$ magnet be expected to operate at the specified $8 \mathrm{~T}$ with the same critical current safety margin? In Appendix A, Figure 2, are plotted short sample critical current curpes and load lines for a design D model magnet. It can be sen that a shift of 3 $T$ from the critical current curve at $4.4 \mathrm{~K}$ is required for safe $8 \mathrm{~T}$ operation. The experimental work indicates that for various conductors, none identical to the specific conductor used in the model dipoles, at $1.8 \mathrm{~K}$ a shift of $3.0-3.17 \mathrm{~T}$ is observed. Translating this range by means of the curves of Figure 3 of the Appendix into a temperature range, another way of expressing this is that the available data indicate that the required $3 \mathrm{~T}$ shift in the critical current curve will be reached at a temperature between 1.8 and $2.1 \mathrm{~K}$. Additional improvement in critical current can be expected from optimizing the conductor heat treatment for $8 \mathrm{~T}$, and perhaps by optimizing the conductor composition. Therefore the task force reccomends that for the present an operating temperature of $2 \mathrm{~B}$ be chosen for the $8 \mathrm{~T}$ ring.

Figure 1 of the Appendix shows the training behavior of several model dipoles at 6.4 and $1.8 \mathrm{~K}$. In general there is an increase of perhaps a little less than $2 \mathrm{~T}$ in going to the lower temperature, but the situation is complicated by the fact that these magnets do not have sufficient preload compression in the coils or sufficient iron for operation at $8 \mathrm{~T}$. 


\section{B) Expectod Heat Loads:}

The synchrotorn radiation power from an $8 \mathrm{I}$ ring at $20 \mathrm{Tev}$ and $70 \mathrm{~mA}$ circulating current is 0.392 watts $/ \mathrm{m}$ for both beams ${ }^{*}$. The bending radius of the beam is $8.37 \mathrm{~km}$. If the circumference of the ring is assumed to be $67 \mathrm{~km}$, then the synchrotron radiation power is 0.308 watts $/ \mathrm{m}$ on the average.

For the present purposes the heat leaks can be taken as the same as for design $D$. The heat leak into $4.5 \mathrm{~B}$ in design $D$ is estimated as 9,663 watts. If this ring has a circumference of $100 \mathrm{~km}$, then the arerage is .096 watts $/ \mathrm{m}$. Thus the total heat load at $2 \mathrm{~B}$ can be assumed to be 0.4 watts $/ \mathrm{m}$ average for the $8 \mathrm{~T}$ rings. Likewise the $10 a d$ at $20 \mathrm{~K}$ can be found to be 0.288 watts/m average.

Calculated from the data in Table 4.7-1 of the SSC Reference Designs Study 


\section{Four: Reference Specifications}

\section{A) Description of Reference System Features:}

Two major options are to bonsidered: Option 1 is to the $2 \mathrm{~K}, 8 \mathrm{I}$ ring without synchrotron light interception, and option 2 is to have the synchrotron light power intercepted at $4.5 \mathrm{R}$. Table I lists basic parameters chosen for the two systems.

Table I

Basic Parameters of the Two Reference Systems

Option

Ring circumference

Magnet bore diameter

Average heat load $2 \mathrm{~K}$

$4.5 \mathrm{~B}$

$20 \mathrm{~K}$
1

$67 \mathrm{KM}$

$4.0 \mathrm{~cm}$.

$0.4 \mathrm{~W} / \mathrm{M}$

0

$0.4 \mathrm{~W} / \mathrm{M}$
2

$67 \mathrm{KM}$

$4.5 \mathrm{~cm}$.

$0.13 \% / M$

$0.27 \mathrm{~T} / \mathrm{M}$

$0.4 \% / M$

In addition, basic choices for the cryogenic system are: to require subcooled liquid in the magnet windings; to require that the system work at least in principle at all temperatures between 2 and $4.5 \mathrm{~K}$; and to use a cold gas pump in the lowpressure cycle.

With these choices, a set of reference specifications for the major components of the two $8 \mathrm{I}$ ring options are worked out in the appendices for comparison to the $D$ design, and the results are summarized below. Following in Section Five is a discussion of parious issues raised in the course of the calculations. 


\section{B) Magnet Specifications:}

Table II lists dimensions of the $8 \mathrm{~T}$ magnets for the two options and gives a comparison to the $6 \mathrm{~T}$ case. These figures are calculated in Appendix $A$ and listed there in Tables I and III. The letters A through $F$ refer to the cross section Figure I.

\section{Table II}

Summary of Magnet Dimensions (diameters in $\mathrm{mm}$.)

Option

Magnet field, T

Cryostat bore i.d., A

Coil layer 1 i.d., B 40.00

Coil layer $10 . d$.

Coil layer 2 i.d.

Coil tayer 2 o.d.

collar i.d.

Iron i.d.

Iron $0 . d$. (design D)

6

59.24

C $\quad 59.74$

79.86

D 81.18

E 111.18

F $\quad 266.70$
6

38.00

45.00

64.24

64.74

84.86

86.18

118.78

289.36
1

8

33.00

40.00

62.52

63.02

87.22

88.54

128.54

330.76
2

8

38.00

45.00

67.52

68.02

92.22

93.54

136.84

357.88

Also from these tables and from Table IV of the Appendix comes information about the quantities of the various materials required. This is shown in Table III. Other than these changes in cross section, the magnets for the various cases are assumed to be the same. 


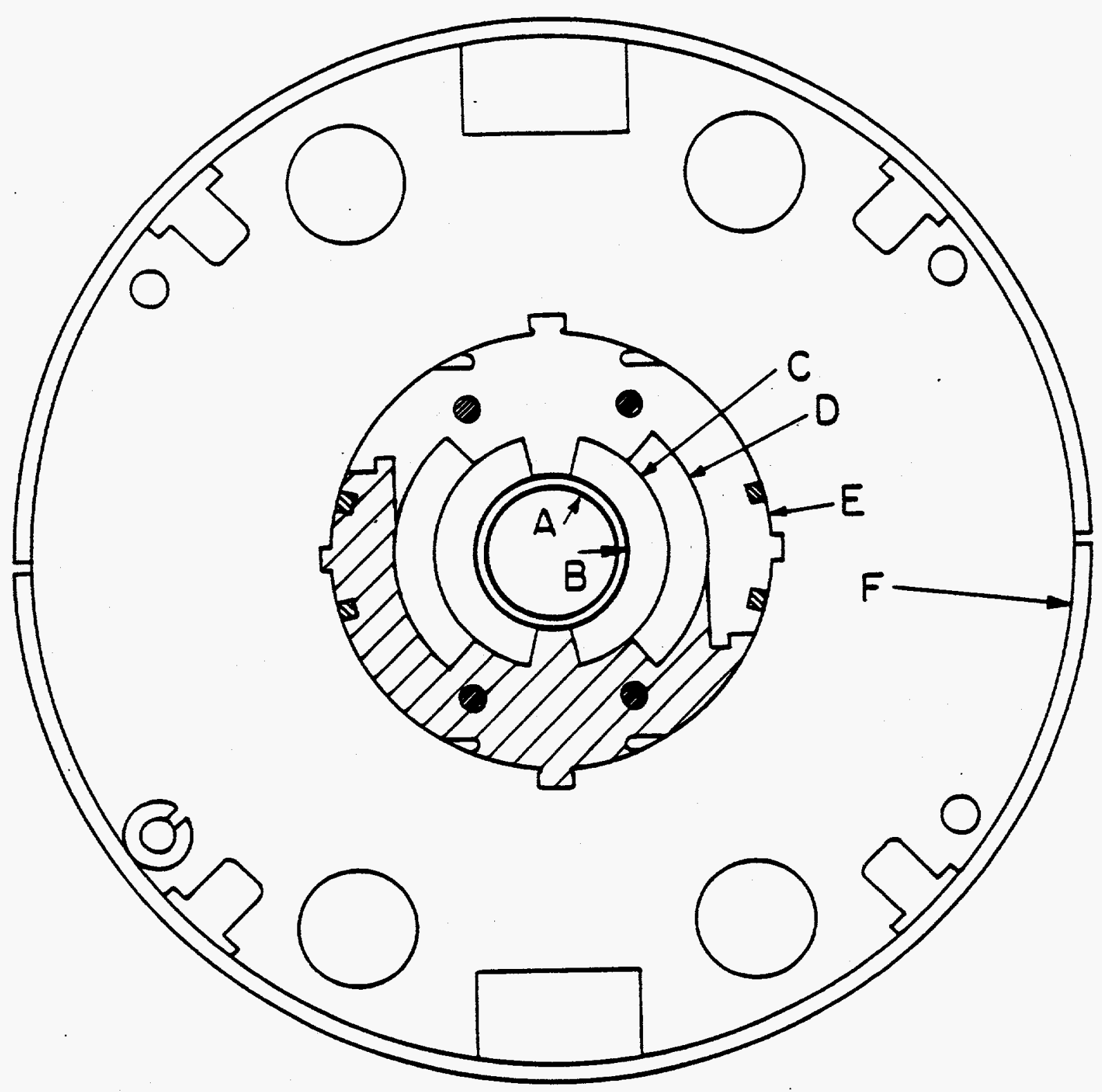

Figure 1

Magnet Cross Section 
Table III

Summary of Relative Total Material Requirements

For Unit Length of Magnet

$\begin{array}{lcccc}\text { Option } & \text { (design D) } & & 1 & 2 \\ \text { Magnet field, T } & 6 & 6 & 8 & 8 \\ \text { Magnet i.d., cm. } & 4.0 & 4.5 & 4.0 & 4.5 \\ \text { Layer 1 Cu } & 1 & 1.10 & 1.37 & 1.50 \\ \text { SC } & 1 & 1.10 & 1.07 & 1.16 \\ \text { Cu/SC ratio } & 1.30 & 1.30 & 1.73 & 1.73 \\ \text { Layer 2 Cu } & 1 & 1.07 & 1.43 & 1.52 \\ \text { SC } & 1 & 1.07 & 1.15 & 1.22 \\ \text { Cu/SC ratio } & 1.80 & 1.80 & 2.40 & 2.40 \\ \text { Collar S } & 1 & 1.16 & 1.50 & 1.72 \\ \text { Iron } & 1 & 1.18 & 1.58 & 1.86 \\ \text { Cold Mass } & 1 & 1.18 & 1.54 & 1.80\end{array}$

It is important to recognize explicitly the steps that lead to this model. At a givn field of $8 \mathrm{~T}$ choosing a temperature fixes the critical current density. This is chosen on the criterion that a $6 \mathrm{~T}$ magnet, that is, one designed for $6 \mathrm{~T}$, should operate at the $8 \mathrm{I}$ with the same safety margin as at the lower field. Once the critical current density is chosen, then the requirement is applied that the current density in the copper be the same in the properly designed $8 \mathrm{~T}$ magnet as the one designed for $6 \mathrm{~T}$, so the amount of copper must be increased. Because this makes the windings thicker, the load line shifts and it is necessary to somewhat increase the amount of superconductor to keep the current density margin the same. It is argued in Appendix A that the increase in the amount of superconductor required at the higher field is slightly overestimated by this procedure. 


\section{c) Cryostat:}

The concept that is being persued here is similar to that of the Tevatron cooling system. The magnet iron is wrapped in a stainless stel skin. inside the skin is pressurized superfluid at $0.6 \mathrm{~atm}$. Outside is a coaxial jacket $1 \mathrm{~cm}$. in radial thickness that contains the two-phase, saturated superfluid. A longitudinal section of such a magnet is sketched in Figure 10 of Appendix B. Figure 14 of this appendix shows in section the comparison of a cryostat for a jacketed magnet with the SSC Type D Cost Design Cryostat (reference Fermilab drawing number $0101-\mathrm{ME}-212229$ ). Table IV below summarizes the relevant dimensions. The designators $D_{1}$ through $D_{8}$ refer to Figure 14 and Table $X I$ of the appendix.

Table IV

Comparison of Pipe and Vessel Diameters between

Design $D$ and $2 \mathrm{~K}$, Option 1 and 2 Cryostats

(diameters in $\mathrm{cm}$.)

Option

Magnet jacket o.d.

LHe line o.d.

GHe line $0 . d$.

IN shield line $0 . d$.

$20 \mathrm{~B}$ shield line $0 . \mathrm{d}$.

$20 \mathrm{~K}$ shield $0 . \mathrm{d}$.

LN shield $0 . d$.

Envelope 0.d.

Cold mass (rolative)

*Located within the iron envelope

**Is now part of the magnet pessel (design D)

$D_{1}$

$D_{2}$

$D_{3}$

$D_{4}$

$D_{5}$

$D_{6}$

$D_{7}$

$D_{8}$

27.3
3.89
6.88
5.72
7.62
40.64
50.53
60.96

1
1.54

1.80

2

38.4

$\star$

*

5.72

5.08

48.57

57.46

67.62

64.91

45.86

Attention should be called to the fact that there are two pipes not shown on the drawing running inside the iron of the magnet each about $3 \mathrm{~cm}$ diameter. One of these carries liquid helium from the liquifiers around the ring. The other carries 
single phase $0.6 \mathrm{~atm}$. superfluid out from the refrigerators to the end of the string. Both of these pipes must be thermally insilated from the iron, but the temperature differences are small.

The only other changes assumed in the cost Design Cryostat is an increase in the strength of the vertical support members in order to hold the increased weight. This will increase the conduction heat leaks by a proportional amount, but the radiation heal leaks will be very little affected. It is possible that the greater stiffness of the larger magnet will allow a simpler support system.

The most important change to the design D cryostat in order to accomodate $2 \mathrm{~K}$ operation is the addition of the jacket around the magnet. This construction complication is not without compensations, however. It is true that the magnet supports must be brought through the jacket and that the jacket will probably have to corrugated in bands in order to provide for differential thermal contraction during cool-down. But the single-phase heat exchangers, which for 2 $\mathrm{B}$ are uncomfortably large, their control systems, and the helium gas pipe all disappear from the cryostat. Also it is not necessary with a jacket to circulate the single-phase helium in the magnet. For the small temperature rises allowable at the lower temperature the circulation rates become inconyeniently large.

\section{D) Refrigeration System Specifications:}

The refrigeration system for the two $8 \mathrm{~T}$ options are described in Appendix $B$, beginning in Section IV. The system consists of 32 refrigerators, 4 liquifiers and 2 nitrogen plants distributed around the ring as shown in Figure 5 of the appendix. The flow schematic for one of the refrigerators is given in Figure 6 with process points and pump data in Tables I - III. Figure 11 shows the lowtemperature coolant flow pattern in one string of magnets, and Figure 13 shows an equipment layout for one refrigerator.

In Tables V - VII to follow there is a comparison of the cooling system for the two $8 \mathrm{~T}$ options with the design D system. 
Table V

Refrigerator Steady-State Operation Comparison

Low Temperature Parameters

Option

1. Synchrotron Radiation $W / m$

2. Heat Leak

3. Total for 2 rings

4. Heat Load per Refrigerator

5. Refrigerator Capacity

6. Refr. Liq. Helium Cap. liters/hr

7. Number of Refrigerators

8. Number of Parallel Systems

9. Liquid Helium Storage Capacity gallons $\times 10^{-3}$

10. Liquid He Volume liters $\times 10^{-6}$

11. Lead Flow total liters/hr

12. Total Amp. of Leads (main power leads) AX 10-6

13. I phase He Flow Rato g/sec

14. Temperature Rise Dotween Exchangers ${ }^{\circ} \mathrm{K}$

15. I phase He Flow Pressure ata.

16. I phase He Flow delta $\mathrm{p}$ ata.

17. Number of Exchangers

18. Distance between 1 phase

Heat Exchangers

m.

19. I phase Heat Exchanger duty (design D)

14

$2^{\text {B }}$

.194

.267

.267

$2 \times .056$

26.4

2200

3300

680

12

48

$12 \times 30$

1.2

4080

1.15

1.15

$2 \times 100$

noned

.07

$4.0-3.7$

.22

864

none

200

n.a.

30.6

n.a.
1.15

noned

n.a.

n.a.

28.067

26.4

825

1237

$\alpha$

32

64

$32 \times 8$

.96

4080

OE

6

0

none

a. 
Table $V$ (continued)

Option

(design D)

1 A

20. He Temperature at the Coil

${ }^{\circ} \mathrm{B}$

4.55

2.14

2.07

21. Highest Temperature

$$
1 \text { phase (last cell) }
$$

$\circ \mathrm{K}$

4.46

2.14

2.07

22. Lowest Temperature

1 phase (last cell)

$\circ \mathrm{K}$

4.40

2.09

2.02

23. Thermal Mass per Refrigerator $\int \times 10^{-9}$

455

196

196

24. Cold Mass $\mathrm{kg} / \mathrm{m}$

$2 \times 373$

$2 \times 572$

$2 \times 572$

25. Surface Area $\mathrm{ft}^{2} / \mathrm{m}$

$2 \times 9.5$

$2 \times 12.06$

$2 \times 12.96$

26. Pipe Size (ID)

inches

1.53-2.71

1.315

1.315

27. Number of Pipes (excluding magnet)

2

1

1

\section{Notes for Table $\mathbf{V}$}

A. Option 1 magnets operate at a nominal $2 \mathrm{R}$, with heat leak and synchrotron radiation removed at $2 \mathrm{~K}$.

B. Option 2 magnets operate at a nominal $2 \mathrm{~B}$, with synchrotron radiation removed at $4.5 \mathrm{~K}$.

C. Liquid Helium for leads is supplied from separate liquefiers.

D. With the Tevatron-type system and separate liquid helium supply line, there is no need for flow of single-phase fluid.

E. Heat transfer takes place continually along the magnets, hence temperature increase is zero. 


\author{
Table VI \\ Refrigerator Steady-State Operation Comparison \\ Intermediate Shield Parameters
}

Option

28. Heat Leak

29. Total for Ring

30. Snield Flow Rato

31. Temperature in

32. Temperature out

33. Pressure drop

34. Pressure in

35. Pressure out

36. Cold Mass

37. Thermal Mass per Refrigerator

38. Surface Area

39. Pipe Size (ID)

40. Number of Pipes (design D)

$W / m$

KW

g/soc

- $\mathrm{K}$

- $\mathrm{B}$

ata.

ata.

ata.

$\mathrm{kg} / \mathrm{m}$

J $\times 10^{-9}$

$\mathrm{ft}^{2} / \mathrm{m}$

inches

28.80

0.5

3.5

3.0

$2 \times 12.1$

29.0

3.0
$2 \times .181$

100

15

18

9.4

$2 \times 16.5$

2.0

1

1

$2 \times 2$

26.4

$2 \times 9.78$

11.2

18

1.0

7.97

7.97

$2 \times 13.7$

$2 \times 14.6$

1
2

$2 \times 2$

26.4

$2 \times 9.78$

11.2

18

1.0

7.0

7.0

$2 \times 13.7$

9.4

$2 \times 16.5$

2.0

1 


\section{Table VII}

Refrigerator Steady-State Operation Comparison

$80 \mathrm{~K}$ Shield Parameters

Option

41. Heat Leak

42. Total for Ring

43. Fluid for Snield Cooling

44. Flow Rate

45. Temperature in

46. Temperature out

47. Pressure in

48. Pressure out

49. Pressure drop

50. Number of Parallel Shield Circuits

51. Number of Liquid $\mathrm{N}_{2}$ pumps

52. Number of Heat Exchangers

53. Heat Exchange Duty KW

54. Cold Mass

55. Thermal Mass per Refrigerator

56. Surface Area

57. Number of $\mathrm{N}_{2}$ Plants

58. $\mathrm{N}_{2}$ Plant Capacity

59. Pipe Size (ID)

60. Number of Pipes $\mathrm{kg} / \mathrm{m}$

(design D)

$\mathrm{W} / \mathrm{m}$

$\mathrm{K}$

$g / s \propto c$

- $\mathrm{K}$

- $\mathrm{X}$

ata.

ata.

ata.

24

24

12

$2 \times 1.67$

288

$\mathrm{N}_{2}$

$300-600$

74

89

5

4

1

12

24

24.0

$2 \times 14.3$

J $\times 10.9$

35.2

$2 \times 12.0$

2

tons/day

inches

170

2.25

1
1

$2 \times 2.25$

297

$\mathrm{N}_{2}$

$200-400$

74

85

5

4

1

64

32

32

9.28

$2 \times 19.3$

13.6

$2 \times 16.2$

2

170

2.25

1
2

$2 \times 2.25$

297

$\mathrm{N}_{2}$

$200-400$

74

85

5

4

1

64

32

32

9.28

$2 \times 19.3$

13.6

$2 \times 16.2$

2

170

2.25

1 
Five:

Discussion of Specifications and Other Issues

\section{A) Bore Liner:}

Although a complete consideration of the problems of a bore liner has not been made here, enough has been done to show several interesting things clearly. The work that appears in Appendices $C$ and $D$ indicates that $0.5 \mathrm{~cm}$ increase in the cryostat diameter is enouth to accomodate a liner. Also fluid cooling seems to be the most attractive alternative. The fluid can be either two-phase saturated nitrogen or helium gas, and the temperature can be anywhere between 4.5 and $80 \mathrm{~B}$. There is, moreover, a considerable variety of ways that the liner can constructed and integrated into the refrigeration system.

In deciding on a temperature of operation, the problem of supporting the liner. which is greater about as the square of the temperature, must be weighed against the saving and simplicity associated with providing refrigeration at a higher temperature. The cost of propiding this refrigeration falls about linearly with increasing temperature to reach the negligible level before LN temperature is reached. A very important issue is the question of operload capability. If in the course of time it becomes desirable to operate the rings at a higher current, with a LN-cooled liner, the refrigeration system would not notice the difference. The optimum operating point will have to be decided by detailed design, but it seems likely that the result will be around $20 \mathrm{R}$.

A refrigeration cycle capable of taking the synchrotron light load at the 20 $\mathrm{R}$ level can easily be constructed. If in the cycle shown in Figure 12, Appendix B, the flow in the expander E-3 is eliminated and the flow in the dry expander E-2 is doubled, the result will as desired. The capital cost of this machine will be only slightly less than that of Case 2, Table VII of the appendix. but there will be operating cost savings. In the simple model in which input power is a linear function of refrigeration power divided by refrigeration temperature:

Input Powr $=(\mathrm{A} \cdot 2 \mathrm{~K}$ POWT $/ 2+\mathrm{B} \cdot 4.5 \mathrm{~K}$ POWT $/ 4.5)$ 
the constants $A=2.16$ and $B=1.68$ can be determined from the information in Table IX of Appendix B. The difference in A and B expresses the difference in efficiency of the processes at the two temperature levels. If, as is very likely, the $20 \mathrm{~K}$ process has the same efficiency as the $4.5 \mathrm{~K}$ one, then a load of 275 watts at $2 \mathrm{~K}$ and a load of 550 watts at $20 \mathrm{~K}$ will require an input power of $344 \mathrm{KW}$. This is a saving of $159 \mathrm{KW}$ per station or $5 \mathrm{MW}$ for the whole ring over taking the $\mathrm{SR}$ light load at $4.5 \mathrm{~K}$.

Care must be exercised in this matter, however. It is likely that the sizing the refrigeration at $2 \mathrm{~K}$ will be determined by quench recovery time rather than steady-state load. In Appendix $B$ it is estimated that for a refrigeration power of 825 watts at $2 \mathrm{~B}$, the recovery time from a 6 magnet quench will $1-1.5$ hours, probably the maximum tolerable. Thus getting the full advantage of the powar sayings of a liner may depend on haying a good turn-down capability the refrigeration plant.

It is clear that everything said here about the $20 \mathrm{~B}$ or higher liner applies equally well to the design $D$ machine. There it is a matter of trading increased magnet cost for reduced operating cost. The task force reccomends, therefore, that the fluid-cooled bore liner merits further study independent of the choice of magnet style.

\section{B) Pool Boiling Spstem:}

Another interesting thing that has come up in this study is the pool boiling or ESCAR cooling system described in Appendix A. The behavior of magnets in saturated liquid over a wide range operating conditions is not very well known. One might expect that $4.5 \mathrm{~B}$ systems and superfluid systems would operate; but would they train and how would they react to beam loss heating? What about operation at $2.5 \mathrm{~B}$ ? The task force felt that the uncertainties are too great for this system to adopted in the $2 \mathrm{~B}$ reference systems, which must be able to operate over the full range from 2 to $4.5 \mathrm{~B}$. However, particularly at $4.5 \mathrm{~K}$ the system is very attractive for its simplicity of operation and tolerance to transients during a quench. No relief or control valyes are needed in the system outside of the refrigerators. The task force reccomends that the ESCAR system should be further studied. The first thing to do in this respect is some pool-boiling magnet testing. 


\section{c) Refrigeration Issues:}

\section{1) Number of units:}

It is always possible to trade off yessel sizes in the cryostat against number of units in a distributed system. With larger vessels it is possible to transport refrigeration greater distances with the same pressure drop. Therefore the number of units proposed for the $2 \mathrm{~K}$ reference systems is largely arbitrary. Instead of 32 the number could have been 24 or fewer, perhaps with some overall cost advantages. This optimization, however, belongs in a later stage of the design development than the one underway here.

2) Low pressure pumping and cold compressor:

The machines chosen and costed for the $P_{1}$ and $P_{2}$ low-pressure pumps of the refrigerator are oil-flooded screw compressors operating in a single stage to 1 atmosphere. The machines are operated in parallel where the capacity demands it. These compressors have excellent reliability and durability and will handle the operload conditiond required during quench recovery. They are also expensive and not very efficient. In Table II of Appendix B compressor $P_{1}$ operates at $17 \%$ of isothermal.

Table III of the appendix shows what $P_{1}$ would look like if no cold gas compressor is used in the cycle. It is clear that although it is possible to plan a plant with these machines in this service, it is on the edge of the tolerable from the point of view of both capital and power cost. There are alternatives to the screw machine for the low-pressure end in this application, and a complete study will have to made to compare all of the possibilities including the cold gas recompression cycles. The task force has chosen the cycle and the machinery that it has because of the belief that this choice will provide a realistic cost estimate for the final refrigerator.

Attention should called to the use of a cold gas pump in the refrigeration cycle for the Tore-Supra. The capacity of this plant is 300 watts at $1.75 \mathrm{~K}$, and the cold gas pump is to be a two-stage centrifugal compressor operating 10 and 60 torr. This is more severe duty than the pump needed for the $8 \mathrm{~T}$ relrigerators. At the present time the cold box for this plant has been delivered, and the cold gas compressor has been developed and is undergoing tests at L'Air Liquide in Grenoble.

3) Pressure and Temperature Drops at Low Temperature:

In thermal conduction entropy is generated at a rate proportional to the temperature gradient divided by $\mathrm{T}^{2}$. It is very important for the efficiency of a

G. M. Gistau and G. Claudet; The Design of the Helium Refrigerator for ToreSupra"; Procedings of ICEC 10 , Helsinki 1984 
process, therefore, that the temperature gradients at the lowest temperature be kept to a minimum. This is doubly important when the vapor pressure of the refrigerant is very low. In this case temperature drops are associated with pressure drops that may be a significant fraction of the working pressure. This is the reason that the Tevatron cooling system with the jacketed magnet is attractive for the $2 \mathrm{~K}$ systems under discussion here. The jacket provides not only a large passage for the refrigerant flow and a large surface area for the heat exchange, but also it eliminates the need for heat to be carried by the convection of the single-phase magnet coolant, a process in which a temperature rise is essential.

\section{4) Quench Recovery:}

Quench recovery is discussed in Appendix B, beginning on page 24. The essential features of this process are mentioned briefly in the following sentences: First, relief valves are neded between the single-phase and the two-phase polumes, but the equlibrium pressure after the quench is onip a few tenths of an atmosphere. Thus all of the gas and all of the heat remains within the cryostat. Second, the energy deposited during the quench all must be removed at the temperature that is in equilibrium with the cryostat pressure, that is, below $3.5 \mathrm{~B}$. Third, essential to getting recovery fron quench conditions in a reasonable time is the ability to increase the flow through the refrigerator by a factor of 2 to 3 when the system pressure rises. All of the components must be selected with these transient operating conditions in mind.

5) Operation at Higher Temperature:

Section X of Appendix B takes a first look at what a refrigerator for $2.5 \mathrm{X}$ operation might look like. This anticipates the stage in the development of these ideas in which final cost optimizations are made (see section Seven B below). 
This subject is discussed in Appendix B, Section VII. The concept that is explored is staging by constructing the 15 Tey ring with half the number of refrigerators and expanding to $20 \mathrm{Tev}$ by adding pumping to those refrigerators and adding the rest of the 32 neded for $2 \mathrm{~K}$ operation. The 15 Tev ring would have no synchrotron radiation and reduced lead cooling flow, and it appears feasable to use the same cold box as would eventually be used for the 20 Tev ring with doubled up compressors and expanders. The cryostat could be the same as well.

In the appendix it is argued that such a refrigerator would cost about 0.8 M\$. If it is assumed that safety margin could be supplied by the four liquifiers, the 15 Ter system would consist of 16 refrigerators, four liquifiers and two air plants. If as in section Seven $\mathrm{C}-3$ below a factor of 2.73 is used to relate the equipment cost of the 16 refrigerators to their total cost, and if the liquifiers are assumed to be the same as those costod in this section as well, then the result is about $80 \mathrm{M} \$$ for the whole system. Included is $10 \%$ for items in addition to the plants alone. 


\section{Seven: Preliminary Discussion of Costs}

\section{A) Capital Costs:}

The task force does not want to prejudice any detailed cost camparisons with design $D$ that will go on after the submission of this report. However it adds to the usefulness of the report, and it helps to tie the work together to make some general estimates. It is to be understood that these are strictly back-of-theenvelope.

Drawing upon Table 8.2-1 of the SSC Reference Designs Study, estimates will be made in three areas: Collider Facilities; Collider Magnets; and Collider Cryogenics.

\section{1) Collider Facilities:}

If a straight line is fit to the figures under this heading for designs $A$ and $B$ the result is:

$$
\text { Cost }(\mathrm{M} \$)=17.57+4.235 \cdot \text { Circumference }(\mathrm{Rm})
$$

If design $D$ is assumed to be $100 \mathrm{~km}$ in circumference and the $8 \mathrm{~T}$ options 67 , the cost decrement from this formula is $139.8 \mathrm{M}$. The $8 \mathrm{~T}$ options require more cryogenic sites and utilities distribution, however. Table 5.3-6 of the Design Studies puts the cost of construction of cryogenic facilities at $8 \mathrm{M} 5$, so if this is roughiy doubled for the $8 \mathrm{~T}$ ring, the cost decrement can be put at $130 \mathrm{M} \$$.

2) Collider Magnets:

The first two columns in Table VIII give a relative cost model for the design $D$ magnet. The accuracy of this model may well be questioned as it is assembled mostly from hearsay, however it provides a basis for correction at least. The third and fourth columns are constructed from the second by multiplying by the relative material factors in Table III abope. The multipliers 
for the cryostat are 1.2 for Option 1 and both the 1.2 and another 1.2 for the liner in Option 2.

\begin{tabular}{|c|c|c|c|}
\hline \multicolumn{4}{|c|}{$\begin{array}{l}\text { Table VIII } \\
\text { Relative Costs of } 8 \text { T Magnet Options } \\
\text { (per unit length) }\end{array}$} \\
\hline Option & (design D) & 1 & 2 \\
\hline Layer 1 SC & .22 & .235 & .255 \\
\hline Layer $2 \mathrm{Cl}$ & $\begin{array}{l}.01 \\
21\end{array}$ & $\begin{array}{l}.014 \\
.242\end{array}$ & $\begin{array}{l}.015 \\
.256\end{array}$ \\
\hline Lagle & .01 & .014 & .015 \\
\hline Collar & .06 & .090 & .103 \\
\hline Iron & .07 & .111 & .130 \\
\hline cryostat & .15 & .180 & .216 \\
\hline Other & .27 & .27 & .27 \\
\hline Total & 1 & 1.16 & 1.26 \\
\hline Total $\times .75$ & & .87 & .95 \\
\hline
\end{tabular}

If the cost basis of the magnets in the design $\mathrm{D}$ ring is $800 \mathrm{M}$ then the decrements for the two $8 \mathrm{I}$ options are $104 \mathrm{M} \$$ and $40 \mathrm{M} \$$ respectively.

3) Collider Cryogenics:

The refrigerator costs listed in Table VII of Appendix B provide the basis for the construction of the following model for the total installed costs of cryogenics for the two $8 \mathrm{~T}$ options.

Option 1:

Total Cost $(M \$)=A \cdot\left(.711 \cdot\left(\mathrm{P}_{2 \mathrm{X}} / 825\right) \cdot 7+.377 \cdot\left(\mathrm{P}_{2 \mathrm{X}} / 825\right)\right)$

Option 2:

Total Cost $(\mathrm{M} \$)=\mathrm{A} \cdot\left(.783 \cdot\left(\mathrm{P}_{2 \mathrm{~K}}+4.5 \mathrm{~K} / 825\right) \cdot 7+.156 \cdot\left(\mathrm{P}_{2 \mathrm{R}} / 275\right)\right)$

Here $A$ is a constant relating equipment cost to total installed cost, and $P_{2 X}$ is the refriigeration load at $2 \mathrm{~K}$. The first term in parenthesis represents the cost of the conventional part of the refrigerator and the second term the costs of the lowpressure pumps. These are assumed to consist of parallel units, so that their cost scales linearly with capacity. 
All that is necessary now is to find a value for $A$. This can be done by the lollowing argument. Assume that the collider cryogenics cost for the $D$ design is the same as that for the $A$ and $B$ systems, namely $120 \mathrm{M} \$$. Assume also that 908 of this pays for the 12 refrigeration plants and the other 108 is fixed independent of scale. This means that one of the 12 refrigerators costs a total of $9 \mathrm{MS}$. Assume further that of this $60 \%$ or $5.4 \mathrm{M} \$$ buys the refrigeration capacity (3300 watts) and the rest, $3.6 \mathrm{M}$, buys the liquification capacity $(680 \mathrm{l} / \mathrm{hr}$ ). The refrigeration capacity of this plant is exactly 4 times that of the Option 1 refrigerator. Scaling the conventional part of the Option 1 plant according to the above expression and setting the cost at $5.4 \mathrm{M} \$$ allows the reasonable value $A=$ 2.73 to be derived. This is the same reasoning used in Appendix B to produce Table VIII of normalized refrigerator costs.

From these figures a cost formula for liquifaction plant can also derived:

$$
\text { Liquifier Cost (M\$) }=3.6 \cdot(\text { Cap } / 680) .7
$$

Here the capacity Cap is in $1 / \mathrm{hr}$. According to this the Fermilab central liquifier $(4,000 \mathrm{l} / \mathrm{hr})$ would cost $12.5 \mathrm{Ms}$.

As is mentioned in Appendix $B$, page 43 , operating margin in a system with a central liquifier can smaller because local requirements for extra refrigeration can be met by providing more liquid. Margin is neded, however, and in order provide a fair comparison with the design D costs, it should be roughly the same in both cases. Therefore what is neded for the $8 \mathrm{~T}$ options are 32 plants of 1,200 watts each and 4 liquifiers of $2,5001 / \mathrm{hr}$ each. For this the formulas above yield the cost for Option 1 of $176.5 \mathrm{MS}$ and for Option 2 of 156.5 $M \$$. Here the $12 \mathrm{M} 5$ of unscaled costs have ben added in again. Thus the cost increments for the two cases are $56.5 \mathrm{M} \$$ and $36.5 \mathrm{M}$.

\section{4) Conclusions:}

Adding all of the numbers in the thre sections above, the result is for Option 1 a decrement of $178 \mathrm{M} \$$ or $13 \%$, and for Option $2134 \mathrm{M} \$$ or $10 \%$, on a cost basis of $1,360 \mathrm{M}$.

\section{B) Operation at Lower Temperature:}

According to Appendix A, Figure 3, a variation of $0.1 \mathrm{~B}$ produces a 1.58 change in the critical current. Therefore reducing the operating temperature from $2 \mathrm{R}$ to $1.9 \mathrm{~K}$ would allow a reduction of $1.5 \%$ in the amount of conductor in the magnet keeping the field constant. If the conductor is 438 of the total cost of $800 \mathrm{M} \$$, then this reduction would yield a saving of $5.16 \mathrm{M \$}$. Now if it is assumed that the capital cost increase in a refrigerator at $1.9 \mathrm{~K}$ over one at $2 \mathrm{~K}$ consists of 
increasing the capacity of P1 (see Appendix B. Table VII) by the ratio of the Yapor pressure of helium at the two temperatures (1.4), then the equipment cost increase of one refrigerator is $0.164 \mathrm{M} \$$ and for $32,5.25 \mathrm{M} \$$. Using the factor 2.73 to get the total installed cost increase, the result is $14.3 \mathrm{MS}$. It would seem that operation at a higher temperature with more superconductor might be a saving, however a much more detailed cost model is needed to draw any conclusions.

c) Operating Costs:

Power requirements are estimated in Appendix B, Table IX and Figure 5. These are summarized in Table IX below.

Table II

Summary of Power Requirements (MW)

Option

32 Refrigerators

4 Liquifiers

2 Air Seperation Plants

Totals (design D)

1

43.2

7.2

4.4

27.3

54.8
2

24.0

7.2

.4 .4

35.6

The 50.5 operating margin is included in these figures. 


\section{Appendi $\mathrm{A}$}

40 AND $45 \mathrm{~mm}$ BORE DIPOLES OPERATED

AT 1.8 AND 4.2K

by

W.V. Hassenzah1

Lawrence Berkeley Laboratory

University of California

Berkeley, California 94720 
40 and $45 \mathrm{~mm}$ Bore Dipoles Operated at 1.8 and $4.2 K^{*}$

\author{
W.V. Hassenzahl \\ Lawrence Berkeley Laboratory \\ University of California \\ Berkeley, California 94720
}

\title{
Introduction
}

During tests of superconducting model dipoles at LBL we have observed an increase in operating field of $2 \mathrm{~T}$ for SSC model dipoles that were tested at $4.5 \mathrm{~K}(\sim 6 \mathrm{~T})$ and subsequently at $1.8 \mathrm{~K}(\sim 8 \mathrm{~T})$. The training curve for three magnets designed to operate at $6 \mathrm{~T}$ are given in Fig. 1. Fig. 2 shows the short sample critical current curve at $4.2 \mathrm{~K}$ and the "load line" for one of these model magnets. The $1.8 \mathrm{~K}$ curve is an extrapolation based on a shift of $3 \mathrm{~T}$ for a change of operating temperature from 4.2 to 1.8 K. Note that the operating temperature for the magnet in Fig. 1 is about $4.4 \mathrm{~K}$ and the planned operating temperature for the SSC is $4.5 \mathrm{~K}$.

No critical current data at $1.8 \mathrm{~K}$ exists on the specific conductors used in these magnets. Thus the extrapolation may be questioned. However, it is based on data from similar conductors and is in good agreement with the results of the magnet tests. Recent measurements by Larbalestier ${ }^{(1)}$ on a similar conductor and the measurements of Hudson ${ }^{(2)}$ et al. give an increase of 3.0 to $3.1 \mathrm{~T}$ where we have used $3.0 \mathrm{~T}$.

The variation of critical current near $2.0 \mathrm{~K}$ shown in Fig. 3, is based on the data of Hudson ${ }^{(2)}$ for a very different conductor. This curve may be used to estimate the variation in coil performance expected for a given variation of operating temperature, should a temperature other than $1.8 \mathrm{~K}$ be selected. The conductor used for the SSC dipoles is specifically designed for operation at 5 to $6 \mathrm{~T}$ at $4.4 \mathrm{~K}$.

\# This work was supported by the Director, Office of Energy Research, Office of High Energy and Nuclear Physics, High Energy Physics Division, U.S. Dept. of Energy, under Contract No. DE-ACD3-76SFDDO98. 
An optimized conductor has been obtained through a not so minor research program. The $3 \mathrm{~T}$ improvement mentioned above could likely be increased with some work on the material characteristics at $1.8 \mathrm{~K}$.

The operation of a magnet near $2.0 \mathrm{~K}$ can be either in saturated liquid helium at about 15 torr or in liquid helium at one atmosphere pressure. Little hard data is available to recommend one or the other in terms of performance once critical current has been reached. However, because of the greater energy absorbing capability of the pressurized helium, it has been observed that magnets will train faster in this medium than in a saturated liquid.

This result implies that more energy can be absorbed in a small region by pressurized liquid helium $\mathrm{He}$ than by saturated $\mathrm{He}$ at the same temperature. Experiments on pulsed heat input to small channels confirmed this impression. However, the main cause of quenches in the magnets of the SSC will likely be beam loss, which is expected to occur on such a short time scale that the helium adjacent to the conductor may have little influence. This would suggest that the simplest cooling scheme be used. On the other hand, conductors operated below $T_{\lambda}$ in helium at 1 atmosphere have been observed to perform very well, both in terms of accelerated training and stability against moderately fast (tens of $\mathrm{ms}$ long) pulses. Some magnets have operated well in saturated liquid helium while others have performed quite poorly, having violent quenches at fields not appreciably higher than those reached at $4.2 \mathrm{~K}$.

This status of understanding (or lack thereof) suggests that some (at least one) S5C model dipole be tested in saturated liquid helium at a temperature below $T_{\lambda}$. At LBL we could test at 1 atmosphere at temperatures between 1.7 and $4.4 \mathrm{~K}$, if a circulating pump were installed in our cryostat. Testing in saturated liquid near $T_{\lambda}$ will be more difficult. 


\section{Estimates of Material Requirements}

In this section we ignore the general discussion presented above and simply estimate the change in total material required in the magnets if the field is changed from 6 to $8 T$ and the accelerator is shortened by 1/4. Changes in tunnel, cryostat, refrigerator, power supply, etc. are not considered.

\section{Layer 1 - $40 \mathrm{~mm}$ Bore - $8 \mathrm{~T}$}

We begin with the inside of layer 1 . The reference diameter for the inside of the colls will remain at $40.0 \mathrm{~mm}$ for the first set of calculations. The coil dimensions will stay roughly the same except we assume it is necessary to increase the quantity of copper to maintain stable and safe operation. The current density at $8 \mathrm{~T}$ is arbitrarily set equal to the current density at $6 T, J_{8 T}=J_{6 T}$, thus the copper area must increase by $33 \%$. This choice is debatable, but probably correct for safety considerations. The dimensions of the various components of the $40 \mathrm{~mm}$ bore, $6 \mathrm{~T}$ dipole are given in Table I for reference.

The thickness of the layer will increase due to the extra copper. Neglecting any increase in the amount of superconductor, the new thickness will be:

$$
t_{\text {new }}=t_{\text {old }}\left\{\frac{\sum A+A_{c u} \times .333}{\sum A}\right\}
$$

where $\sum A$ is the total area in the original conductor.

The original percentage of copper in the cross section was 48 , thus:

$$
t_{\text {new }}=t_{\text {old }}\{1+.48 \times .333\}=t_{\text {old }} \times 1.1584=11.14 \mathrm{~mm}
$$


Table I

Parameters for 6 and $8 T, 40 \mathrm{~mm}$ bore, design $D$ magnets

\begin{tabular}{|c|c|c|c|c|}
\hline & \multirow{2}{*}{$\begin{array}{r}6 T \\
20.0\end{array}$} & \multirow{2}{*}{$\begin{array}{r}8 T \\
20.0\end{array}$} \\
\hline Layer & i.d. $/ 2$ & $(\mathrm{~mm})$ & & \\
\hline & o.d./2 & $(\mathrm{mm})$ & 29.62 & 31.26 \\
\hline \multicolumn{2}{|c|}{ Thickness } & $(\mathrm{mm})$ & 9.62 & 11.26 \\
\hline \multicolumn{2}{|c|}{$\mathrm{Cu} / \mathrm{Sc}$} & & 1.30 & 1.73 \\
\hline \multicolumn{2}{|c|}{ Cu Area } & (relative) & 1.0 & 1.37 \\
\hline \multicolumn{2}{|c|}{ S.C. Area } & (relative) & 1.0 & 1.06 \\
\hline \multirow[t]{2}{*}{ Layer } & i.d. $/ 2$ & $(\mathrm{~mm})$ & 29.87 & 31.51 \\
\hline & $0 . d . / 2$ & $(\mathrm{~mm})$ & 39.93 & 43.61 \\
\hline \multicolumn{2}{|c|}{ Thickness } & $(\mathrm{mm})$ & 10.06 & 12.10 \\
\hline \multicolumn{2}{|c|}{ Cu/SC ratio } & & 1.80 & 2.40 \\
\hline \multicolumn{2}{|c|}{ Cu Area } & (relative) & 1.0 & 1.43 \\
\hline \multicolumn{2}{|c|}{ SC Area } & (relative) & 1.0 & 1.15 \\
\hline \multirow[t]{2}{*}{ Collar } & i.d./2 & $(\mathrm{mm})$ & 40.59 & 44.27 \\
\hline & $0 . d . / 2$ & $(\mathrm{~mm})$ & 55.59 & 64.27 \\
\hline \multicolumn{2}{|c|}{ Thickness } & $(\mathrm{mm})$ & 15.00 & 20.00 \\
\hline \multicolumn{2}{|c|}{ Area } & (relative) & 1.0 & 1.50 \\
\hline \multirow[t]{2}{*}{ Iron } & i.d. $/ 2$ & $(\mathrm{~mm})$ & 55.59 & 64.27 \\
\hline & $0 . d . / 2$ & $(\mathrm{~mm})$ & 133.35 & 165.38 \\
\hline \multicolumn{2}{|c|}{ Thickness } & $(\mathrm{mm})$ & 77.78 & 101.11 \\
\hline \multicolumn{2}{|c|}{ Area } & (relative) & 1.0 & 1.58 \\
\hline
\end{tabular}


Because the superconductor is on the average further from the bore, the total volume of superconductor must also be increased. For simplicity we assume in addition that the effectiveness is inversely proportional to the radius, as this is not a major effect. Results will be presented in the summary for a less severe fall off.

$$
\begin{aligned}
t_{\text {new }}^{\prime} & =t_{\text {new }}\left\{1+A_{s c}\left[\frac{r_{i}+t_{n} / 2}{r_{i}+t_{0} / 2}-1\right]\right\}=11.14\left\{1+.37\left[\frac{20+11.14 / 2}{20+4.62}-1\right]\right\} \\
& =11.14\{1+.37 \times 0.003\} \\
t_{\text {new }}^{\prime} & =11.266 \mathrm{~mm}
\end{aligned}
$$

The quantity of copper required is simply the increased copper to superconductor ratio times the increase in the mean radius. These are 1.333 and 1.03 respectively, giving 1.37. The quantity of superconductor increase by $1.03^{2}=1.06$. The new and old parameters are given in Table 1.

\section{Layer $2-40 \mathrm{~mm}$ Bore - $8 \mathrm{~T}$}

The thickness of layer 2 is found using the same relationship as for layer 1 .

$$
\begin{aligned}
t_{\text {new }} & =t_{01 d}\left\{\frac{\sum A+A_{C u} \times .333}{\sum A}\right\}=10.06\{1+.53 \times .3333\} \\
& =11.84 \mathrm{~mm} \\
t_{\text {new }}^{\prime} & =t_{\text {new }}\left\{1+.3\left[\frac{31.5+\frac{11.84}{2}}{29.17+\frac{10.06}{2}}-1\right]\right\}=11.841+.30 .072 \\
& =12.097 \mathrm{~mm}
\end{aligned}
$$

The increases in amounts of $\mathrm{Cu}$ and superconductor are calculated as above for layer 1 , and are given in Table I. 


\section{Collars - $40 \mathrm{~mm}$ Bore $-8 \mathrm{~T}$}

The collars for these coils are assumed to increase in thickness linearly with the field. Thus a $15 \mathrm{~mm}$ collar will increase to $20 \mathrm{~mm}$. We have tested coils with $15 \mathrm{~mm}$ stainless steel collar to $8 \mathrm{~T}$. However, it is not clear that they could withstand thousands of cycles to this level. The increase from 15 to $20 \mathrm{~mm}$ maintains a fixed margin of safety.

To calculate the relative areas of the collars the following formula was used.

$$
\frac{A_{\text {new }}}{A_{\text {old }}}=\frac{r_{0 \text {-new }}^{2}-r_{j-\text { new }}^{2}}{r_{0-01 d}^{2}-r_{j-01 d}^{2}}=1.50 \text {. }
$$

where 5 -new is the new outer radius, etc.

\section{Iron $40 \mathrm{~mm}$ Bore $-8 \mathrm{~T}$}

The thickness of the iron is determined by the flux that passes through it, assuming the saturation level will be the same for the two operating fields. The major contributor to this will be the bore where the field is at its peak, but the first layer and the region of the collars also contribute. The estimates below are based on observing some plots of field in the $6 \mathrm{~T}$ design and could be refined with a little effort.

$$
t_{\text {iron-n }}=t_{\text {iron-0 }} \frac{r_{\text {bore }} B_{n}+t_{1-n e w} \frac{2 B_{n}}{3}-t_{\text {collar-n }} \frac{B_{n}}{3}}{r_{\text {bore }} B_{0}+t_{1-0 \text { ld }} \frac{2 B_{0}}{3}-t_{\text {collar-o }} \frac{B_{0}}{3}}
$$

where rbore is the bore radius, $t_{1-n e w}$ is the new thickness of layer $1, B_{n}$ is the new field, etc.

$$
\begin{aligned}
& =1.30 \mathrm{t} \text { iron-0 } \\
& =101.11 \mathrm{~mm}
\end{aligned}
$$


The relative area is found as above for the collars.

$$
\frac{A_{\text {iron }-n}}{A_{\text {iron-0 }}}=1.58
$$

In Table II The local increase in material requirements is combined with the material reduction because the accelerator is shorter. Two $8 \mathrm{~T}$ cases are considered here: one where the superconductor effectiveness drops off inversely with radius (the calculation above), and another where it drops off $1 / 2$ as fast.

The only material requirement that decreases is the superconductor. If the current density in the copper were allowed to increase then the total quantity of copper could also decrease. This condition may in fact be allowed by safety considerations, because the quench velocity may increase. However, at present, this cannot be calculated with any certainty so a conservative approach has been taken here.

\section{Table II}

Relative total material requirements for the magnets in 6 and 8T accelerators

$\begin{array}{lllll} & & 6 \mathrm{~T} & 8 \mathrm{~T}^{\mathrm{a}} & 8 \mathrm{~T}^{\mathrm{b}} \\ \text { Layer 1 } & \mathrm{CU} & 1 & 1.03 & 1.02 \\ \text { Layer 1 } & \mathrm{SC} & 1 & 0.80 & 0.78 \\ \text { Layer 2 } & \mathrm{CU} & 1 & 1.07 & 1.04 \\ \text { Layer 2 } & \mathrm{SC} & 1 & 0.86 & 0.83 \\ \text { Collar } & & 1 & 1.12 & 1.12 \\ \text { Iron } & & 1 & 1.18 & 1.17\end{array}$

a as calculated in the text.

b with radial effectiveness of superconductor increased. 


\section{Effect of Bore Diameter on Material Requirements}

The synchrotron radiation from high energy protons will be a major source of heat input to the low temperature $(4.5 \mathrm{~K}$ or $1.8 \mathrm{~K})$ bath. As a result several proposals have been made to place $a$ thermal shield inside the bore to remove this energy at some intermediate temperature. These shields will occupy some space and so will cause the bore tube and the coil to be moved outward. An additional argument for placing the coil at a larger radius is to reduce the random errors that will be introduced due to construction tolerances. Here we estimate the effect on material requirements of increasing the bore radius by $2.5 \mathrm{~mm}$.

All the conductor of layer 1 is moved outward by $2.5 \mathrm{~mm}$, giving a net material increase of $2.5 / 24.88$ and $2.5 / 25.63$ or 10 and $9.75 \%$ respectively for the 6 and $8 T$ magnets. A similar calculation holds for layer 2.

The collars move out by $2.5 \mathrm{~mm}$ on the inside and increase in thickness by the ratio of the mean radii of the conductor for the two different cases. The iron calculation is as above for the 6 and $8 T$ cases.

The results are summarized in Table III, which is similar in form to Table II.

The relative material requirements for the different 40 and $45 \mathrm{~mm}$ and 6 and $8 \mathrm{~T}$ cases are compared in Tables IV and V. 
Table III

Parameters for 6 and $8 T$ design $D$ magnets $45 \mathrm{~mm}$ bore

\begin{tabular}{|c|c|c|c|c|}
\hline \multirow{2}{*}{ Layer 1} & \multirow[b]{2}{*}{ i.d. $/ 2$} & \multicolumn{2}{|r|}{$6 T$} & 8T \\
\hline & & $(\mathrm{mm})$ & 22.5 & 22.5 \\
\hline & o.d./2 & $(\mathrm{mm})$ & 32.12 & 33.76 \\
\hline \multicolumn{2}{|c|}{ Thickness } & $(\mathrm{mm})$ & 9.62 & 11.26 \\
\hline \multicolumn{2}{|c|}{$\mathrm{Cu} / \mathrm{Sc}$} & & 1.30 & 1.73 \\
\hline \multicolumn{2}{|c|}{ Cu Area } & (relative) & 1.10 & 1.50 \\
\hline \multicolumn{2}{|c|}{ S.C. Area } & (relative) & 1.10 & 1.16 \\
\hline \multirow[t]{2}{*}{ Layer 2} & i.d. $/ 2$ & $(\mathrm{~mm})$ & 32.37 & 34.01 \\
\hline & $0 . d . / 2$ & $(\mathrm{~mm})$ & 42.43 & 46.11 \\
\hline \multicolumn{2}{|c|}{ Thickness } & $(\mathrm{mm})$ & 10.06 & 12.10 \\
\hline \multicolumn{2}{|c|}{ Cu/SC ratio } & & 1.8 & 2.40 \\
\hline \multicolumn{2}{|c|}{ Cu Area } & (relative) & 1.07 & 1.52 \\
\hline \multicolumn{2}{|c|}{ SC Area } & (relative) & 1.07 & 1.22 \\
\hline \multirow[t]{2}{*}{ Collar } & i.d. $/ 2$ & $(\mathrm{~mm})$ & 43.09 & 46.77 \\
\hline & $0 . d . / 2$ & $(\mathrm{~mm})$ & 55.39 & 68.42 \\
\hline \multicolumn{2}{|c|}{ Thickness } & $(\mathrm{mm})$ & 16.30 & 21.65 \\
\hline \multicolumn{2}{|c|}{ Area } & (relative) & 1.16 & 1.72 \\
\hline \multirow[t]{2}{*}{ Iron i.d./2 } & $(\mathrm{mm})$ & 59.39 & 68.42 & \\
\hline & $0 . d . / 2$ & $(\mathrm{~mm})$ & 144.68 & 178.94 \\
\hline \multicolumn{2}{|c|}{ Thickness } & $(\mathrm{mm})$ & 85.29 & 110.52 \\
\hline \multicolumn{2}{|c|}{ Area } & (relative) & 1.18 & 1.86 \\
\hline
\end{tabular}




\section{Table IV}

Relative total material requirements for the 6 and $8 T$ and 40 and $45 \mathrm{~mm}$ bore coils

\begin{tabular}{lccccc} 
& & & $40 \mathrm{~mm}$ bore & \multicolumn{2}{c}{$45 \mathrm{~mm}$ bore } \\
& & $6 \mathrm{~T}$ & $8 \mathrm{~T}$ & $6 \mathrm{~T}$ & $8 \mathrm{~T}$ \\
Layer 1 & $\mathrm{Cu}$ & 1 & 1.03 & 1.1 & 1.12 \\
Layer 1 & SC & 1 & 0.80 & 1.1 & 0.87 \\
Layer 2 & Cu & 1 & 1.07 & 1.07 & 1.14 \\
Layer 2 & SC & 1 & 0.86 & 1.07 & 0.92 \\
Collar & & 1 & 1.12 & 1.16 & 1.29 \\
Iron & & 1 & 1.18 & 1.18 & 1.40
\end{tabular}

Table V

Relative total material requirements for the 6 and $8 \mathrm{~T}$ and 40 and $45 \mathrm{~mm}$ bore coils with an optimistic estimate of superconductor effectiveness

\begin{tabular}{lccccc} 
& \multicolumn{7}{c}{$40 \mathrm{~mm}$ bore } \\
& & $6 \mathrm{~T}$ & $8 \mathrm{~T}$ & \\
Layer 1 & $\mathrm{Cu}$ & 1 & 1.02 & 1.1 & 1.12 \\
Layer 1 & $\mathrm{SC}$ & 1 & 0.78 & 1.08 & 0.85 \\
Layer 2 & Cu & 1 & 1.04 & 1.05 & 1.10 \\
Layer 2 & SC & 1 & 0.83 & 1.04 & 0.90 \\
Collar & & 1 & 1.12 & 1.16 & 1.28 \\
Iron & & 1 & 1.17 & 1.18 & 1.38
\end{tabular}




\section{References}

1. D. Larbalestier, private communication.

2. P.A. Hudson, F.C. Yin, and H. Jones, "Evaluation of the Temperature and Magnetic Field Dependerice of Critical Current Densities of Multifilamentary Superconducting Composites," IEEE Transactions on Magnetics, Vol. MAG-17, No. 5 , September 1981. 
TRAINING LBL-SSC DIPOLE MODELS

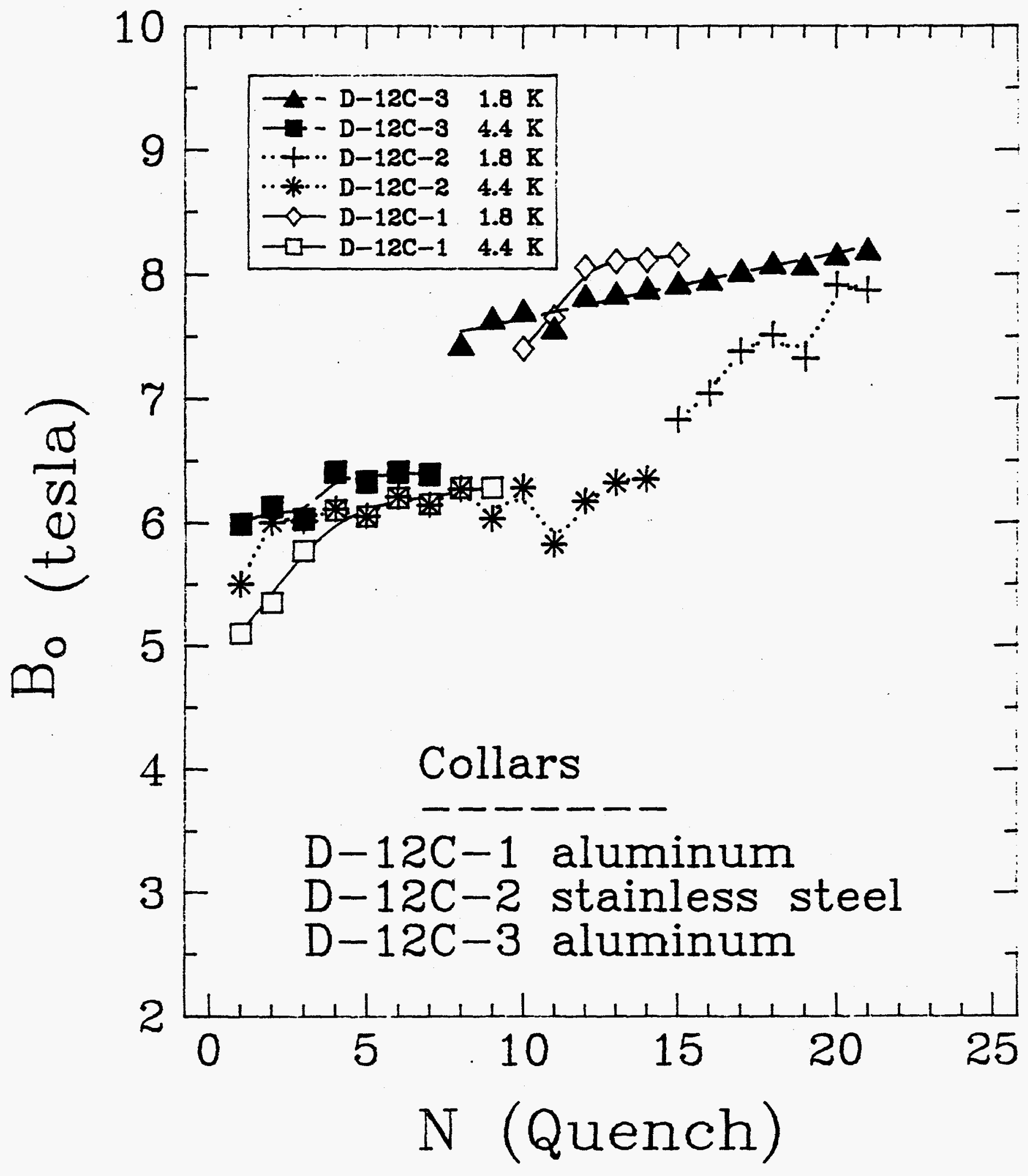

Fig. 1 
LOAD LINES/SHORT SAMPLE CURVES LBL-SSC DIPOLE
D-12C-1 Layer 1

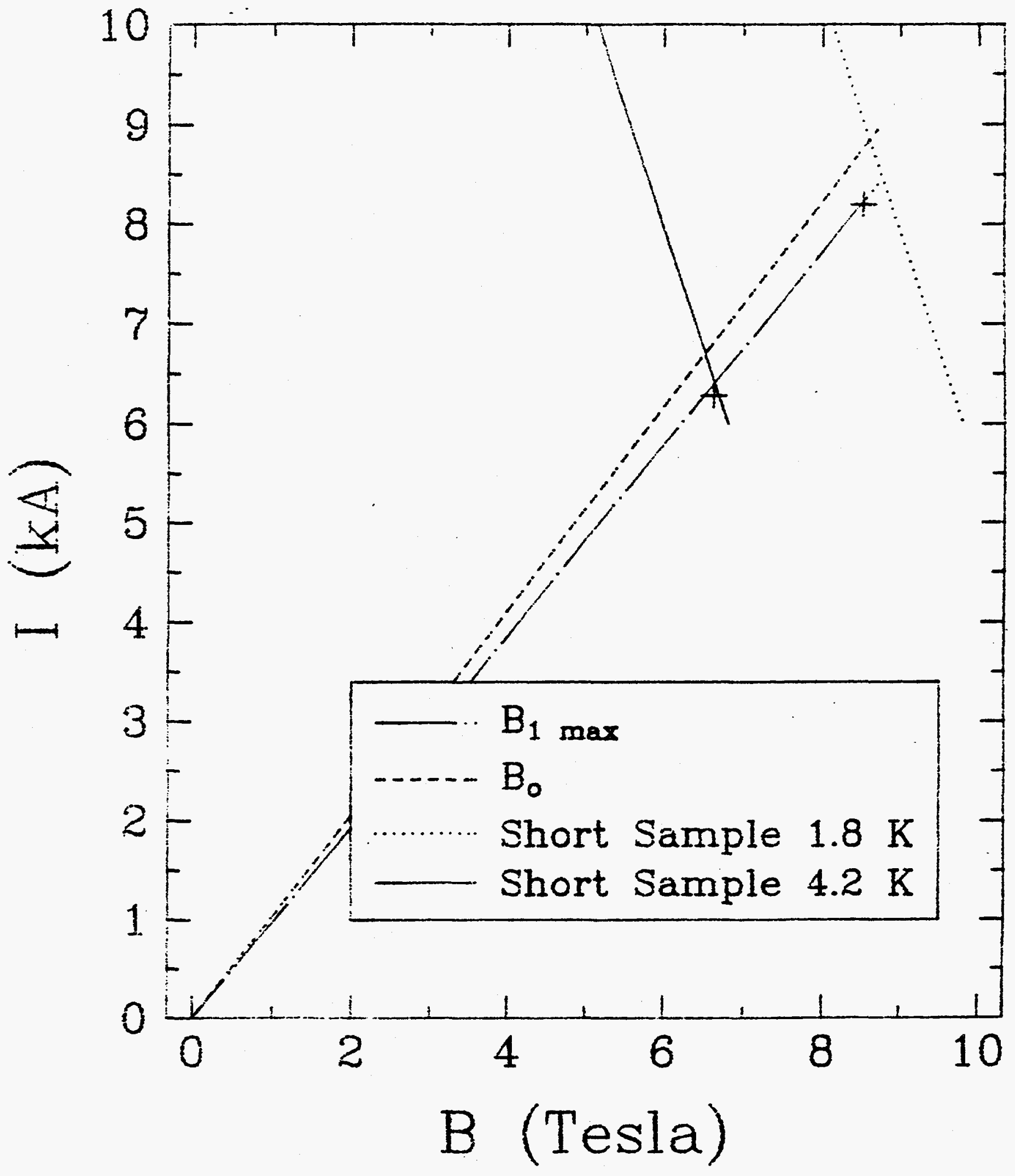

Fig. 2 


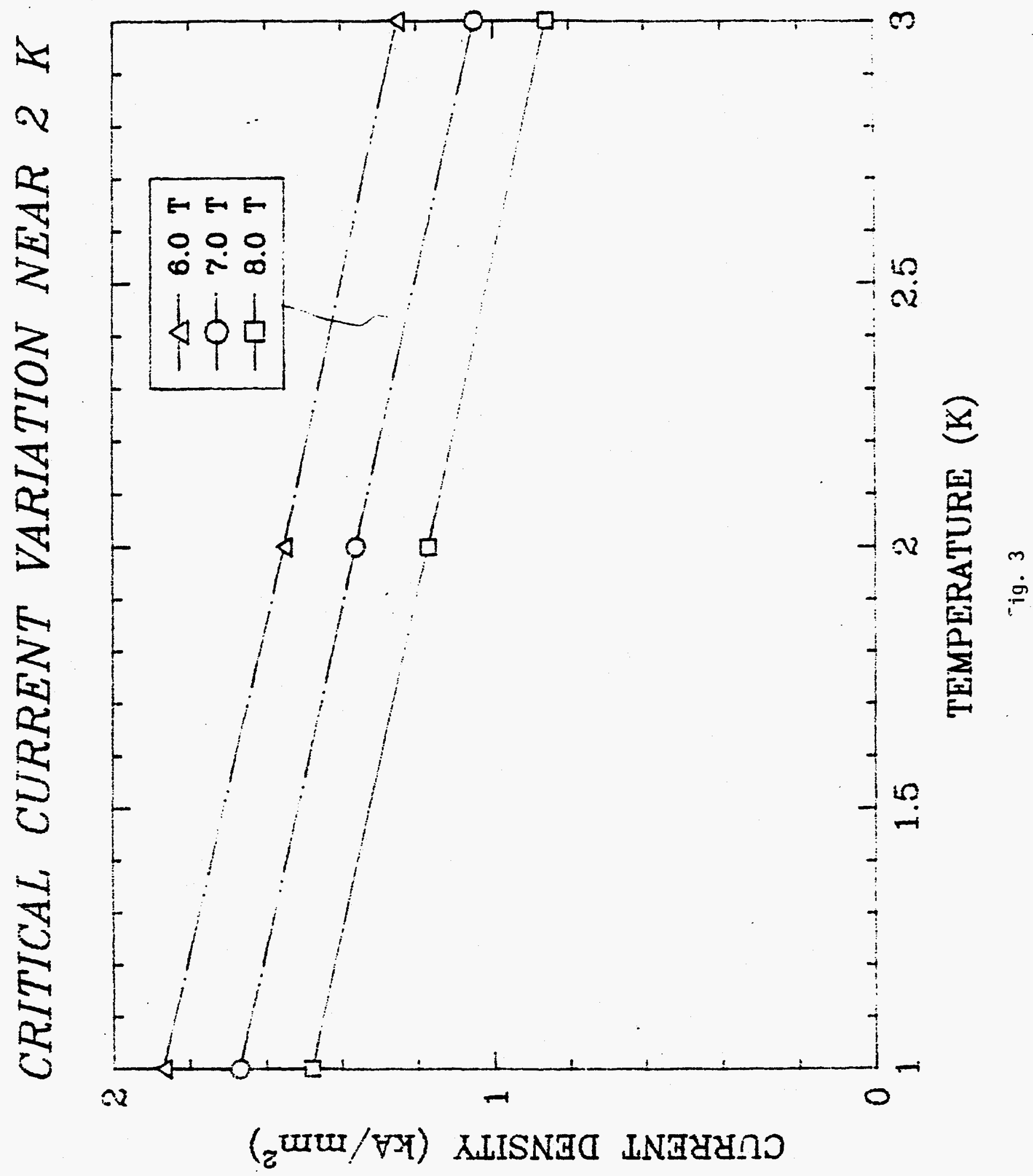




\section{Appendix $\mathrm{B}$}

MAGNET OPERATION AT $2.0^{\circ} \mathrm{K}$

By

Cryogenic Consultants, Inc.

Allentown, Pennsylyania 18103

For

Superconducting Super Collider

Universities Research Association

Under Subcontract SC-94362

Task Order No. 593-5 


\section{IABLE OF CONTENTS}

SECTION

$\begin{aligned} \text { I } & \text { INTRODUCTION } \\ \text { II } & \text { SUMMARY } \\ \text { III } & \text { POOL BOILING MAGNET COOLING SYSTEM } \\ \text { IV } & \text { REFRIGERATOR SYSTEM } \\ V & \text { HELIUM LIQUEFIERS } \\ \text { VI } & \text { NON-STEADY STATE MAGNET OPERATION } \\ \text { VII } & \text { MAGNET COOLING SYSTEM WITH PRESSURIZED } \\ \text { VIII } & \text { SUPER FLUID } \\ \text { IX } & \text { OPERATING AT } 4-4.5^{\circ} \mathrm{K} \\ & \text { MAGNET OPERATION WITH SYNCHROTRON } \\ X & \text { RADIATION REMOVED AT } 4.5^{\circ} \mathrm{K} \\ \mathrm{XI} & \text { MAGNET OPERATION AT } 2.5^{\circ} \mathrm{K} \\ & \text { COST DATA } \\ & \text { REFERENCES } \\ & \text { APPENDIX }\end{aligned}$

PAGE NO.

B-1

B-2

B-5

B-10

B-19

B-20

B-26

$B-30$

B-32

B-37

B-41

B-51

B-53 


\section{LISI OE TABLES}

IABLE

PAGE NO.

I

PROCESS POINTS FOR AN $825 \mathrm{~W} 2.0^{\circ} \mathrm{K}$ HELIUM

REFRIGERATOR AT STEADY STATE OPERATION

B-14

VACUUM PUMP DATE FOR AN $825 \mathrm{~W} 2.0^{\circ} \mathrm{K}$ HELIUM

REFRIGERATOR (WITH COLD GAS COMPRESSOR)

B-16

II

III

VACUUM PUMP DATA FOR AN $825 \mathrm{~W} 2.0^{\circ} \mathrm{K}$ HELIUM

B-17

REFRIGERATOR (WITH COLD GAS COMPRESSOR)

IV

PROCESS POINTS FOR AN 825W HELIUM

B-33

REFRIGERATOR AT STEADY STATE OPERATION

SYNCHROTRON RADIATION REMOVED AT $4.5^{\circ} \mathrm{K}$

$V$ POWER REQUIREMENTS IN KW FOR PROCESSES

$B-36$

REMOVING SYNCHROTRON RADIATION AT

2 AND $4.5^{\circ} \mathrm{K}$

VI

PROCESS POINTS FOR MAGNET OPERATION

B-39 AT $2.5^{\circ} \mathrm{K}$

VII

PURCHASED COST OF A SINGLE REFRIGERATOR

B-42

VIII

NORMALIZED REFRIGERATOR COSTS FOR D MAGNETS

B-43 OPERATING AT $4.5^{\circ} \mathrm{K}$ AND $2.0^{\circ} \mathrm{K}$

IX

POWER REQUIREMENTS (KW/REFRIGERATOR)

B-44

$x$

COOLING WATER REQUIREMENTS (GPM)

B- 45

$X I$

COMPARISON OF PIPE AND VESSEL DIAMETERS

FOR $6 \mathrm{~T}-4.5^{\circ} \mathrm{K}$ AND $8 \mathrm{~T}-2.0^{\circ} \mathrm{K}$ MAGNETS (IN CM)

B-50 


\section{LISI OF EIGURES}

EIGURE

1

2

3

4

5

6

7

8

9

10

11

12

13

14
CROSS-SECTION OF DIPOLE CRYOSTAT

MAGNET CRYOSTAT TO CRYOSTAT OPERATION

BAKER PLOT FOR MAGNET OPERATION

MAGNET COOLING SYSTEM

ARRANGEMENT OF REFRIGERATION EQUIPMENT AROUND THE RING

FLOW SCHEMATIC OF AN 825W HELIUM REFRIGERATOR

HEAT EXCHANGER FOR AN 825W HELIUM REFRIGERATOR

CRYOSTAT CROSS-SECTION DESIGN INCORPORATING UNIFORM COOLDOWN AND LOW LIQUID INVENTORY

PUMPDOWN TIME VS PRESSURE FOR A I KM MAGNET STRING

MAGNET ENCLOSED BY PRESSURIZED SUPERFLUID

MAGNET COOLING SYSTEM FOR MAGNETS WITH PRESSURIZED SUPERFLUID

FLOW SCHEMATIC OF AN 825W HELIUM REFRIGERATOR-SYNCHROTRON RADIATION REMOVED AT $4.5^{\circ} \mathrm{K}$

CASE 1 EQUIPMENT LAYOUT

COMPARISON OF $6 \mathrm{~T}-4.5^{\circ} \mathrm{K}$ AND $8 \mathrm{~T}-2.0^{\circ} \mathrm{K}$ MAGNET CRYOSTATS 


\section{INTRODUCTION}

During a workshop held at LBL on April 11, 1985, it was decided to study the requirements for a refrigeration system capable of cooling SSC magnets to a temperature of the order of $2^{\circ} \mathrm{K}$. The magnets to be considered are the "one-in-one" D type, which at present are to operate at $6 \mathrm{~T}$ at $4.5^{\circ} \mathrm{K}$. Heat load and synchrotron radiation for this magnet are approximately $.056 \mathrm{~W}$ and .097 Watts per meter respectively at $6 \mathrm{~T}$ and $4.5^{\circ} \mathrm{K}$.

Without exact before-hand knowledge of the system, it has been assumed that the refrigeration system has to remove $.4 \mathrm{~W} /$ meter at steady state operating conditions.

Two refrigeration systems are proposed for $2^{\circ} \mathrm{K}$ operation. One is the Escar system, which has been operated at $4.5^{\circ} \mathrm{K}$ on a small scale at LBL during the 1970's. The Escar system employs pool boiling with the magnet windings submersed in liquid helium. Both helium liquid and vapor flow in the same direction through the magnets. Velocities are low so that liquid will settle out. Weirs are used between magnets to make sure that each magnet is submersed in liquid.

The other system is the Tevatron system in which the magnets are cooled by superfluid under pressure. Heat transfer between the pressurized superfluid and boiling superfluid will remove the synchrotron heat load. 


\section{SUMMARY}

1) The report evaluates the requirements of a refrigeration system maintaining magnets at as low as $2.0^{\circ} \mathrm{K}$. Two types of cooling systems have been analyzed. One of these is the Escar system, which was developed and tested on a string of 12 magnets at Lawrence Berkeley Laboratory (ref. 1). The other system is the Tevatron cooling system, in use at Fermilab (ref. 2).

The Escar type system requires that the magnets operate in boiling liquid helium. This works quite well at $4.2^{\circ} \mathrm{K}$. At the very low vapor density at $2.0^{\circ} \mathrm{K}$, heat transfer between magnet winding and boiling liquid may be reduced sufficiently to impair the stability of the conductor near its operating point.

In order to get around this problem, magnets have been operated in pressurized superfluid. Heat transfer then occurs through a wall separating the pressurized fluid from boiling liquid.

Use of this system incurs a penalty since some temperature difference is required to transport heat.

The Tevatron cooling system has been chosen over the cooling systems presently being considered for the $3 \mathrm{~T}$ and $6 \mathrm{~T} C$ and $D$ type magnets. This has been done to basically provide a uniform temperature along the string of magnets independent of specific heat of the liquid helium. The temperature gradient along the string of magnets is now related to the pressure drop in the two phase flow system, which by definition is kept at a very low value.

2) It appears that from a cryogenic standpoint there are no fundamental problems for realizing and maintaining temperatures as low as $2.0^{\circ} \mathrm{K}$. It also appears feasible to upgrade the cryogenic system from initial operation at $4.5^{\circ} \mathrm{K}$ to final operation at $2.0^{\circ} \mathrm{K}$. It is of course necessary to recognize the features which need to be built into magnets, magnet cryostats and refrigeration systems to allow the upgrading at a later date. 
In the case of the cryogenic system, upgrading most likely will consist of:

a) Doubling or tripling the number of refrigerators.

b) Provide warm vacuum pumps.

c) Provide a cold gas compressor for each refrigerator.

d) Provide the utilities during the initial installation of $1 / 2$ or $1 / 3$ of the refrigerator stations for the final requirements of the $2.0^{\circ} \mathrm{K}$ system.

3) The study also has brought out some features, which possibly should be considered in the case that a temperature level of $2.0^{\circ} \mathrm{K}$ is not chosen. These are:

a) The Escar system with a small liquid volume and large vapor volume is capable of making quenches essentially non-events. This deletes the requirements for many relief valves.

b) The number of cryogenic valves required to operate either the Escar or Tevatron type systems is reduced by at least one order of magnitude over that of the presently proposed systems.

c) Liquid helium inventory of the systems is low compared to that of the presently considered systems.

4) The refrigerators do not have any unusual features, with the exception of a cold gas pump desirable for operation at $2.0^{\circ} \mathrm{K}$. Since the refrigeration system can be upgraded, development of a cold gas compressor does not appear to be a critical path item.

5) The number of refrigerators was chosen at 32 . This was an arbitrary choice based on a 2.06 kilometer length of magnet string to be served by one refrigerator. The calculations made so far, indicate that the number may be reduced to 24 and possibly lower (the refrigeration system also has not been optimized at this time). 
6) It is feasible to operate both Escar and Tevatron systems with a sloping collider. The number of weirs (dams) to provide pools of liquid will only have to be adjusted as a function of the angle of the slope.

7) Power requirements for the $2.0^{\circ} \mathrm{K}$ operation are approximately 50 \% higher than those for the $4.5^{\circ} \mathrm{K}$ system. If synchrotron radiation can be removed at a higher temperature level, very considerable savings will be achieved. Removal of synchrotron radiation at a higher temperature level may be coupled with efforts to improve the vacuum pumping capability of the beam tubes. 


\section{POOL BOILING MAGNET COOLING SYSTEM}

Figure 1 shows the cross-section of a dipole magnet cooled by boiling superfluid. The arrangement of Figure 1 is carried out without a skin surrounding the iron. Without a skin, boiling superfluid is in direct contact with the windings of the magnet and makes possible the lowest possible temperature in the magnet.

Figure 2 shows the manner in which magnet cryostats are connected. The connecting pipes carry both liquid and vapor. Location of the pipe determines the liquid level in the magnet cryostat. Boiling superfluid is also located in the space between windings and beam tubes.

In order for the cooling system to work satisfactorily, it is necessary that the liquid separate from the vapor in each magnet. The Baker plot was used to determine the various flow regimes. Figure 3 shows a Iine representing flow at varying quality used for calculating the flow regimes. The plot shows that regardless of magnet location, flow is in the transition region between the stratified region and the slug/plug. The distinct division between flow regimes as shown in Figure 3 does not occur in actual practice. The boundaries are gradual and in the case shown on Figure 3 would in all probability represent a stratified flow, with vapor and liquid separated.

Figure 4 shows schematically the steady state magnet cooling system represented by one refrigerator. It has been assumed that one refrigerator handles a total of $2 \mathrm{~km}$ of magnet string. Each refrigerator then handles 4 magnet subsystems of $1.03 \mathrm{~km}$ length. The refrigerator supplies liquid to an insulated pipe which runs through the magnets to the end of each magnet string. Flow direction is reversed at the end of the string, with vapor and liquid flow cocurrent to the refrigerator. The refrigerator also supplies the coolant fluid (pressurized helium gas) to the intermediate temperature shield.

To provide extra refrigeration when needed, a liquid helium transfer line supplies liquid helium to the refrigerator. Warm helium gas is returned to the helium liquefiers. 
$-86-$

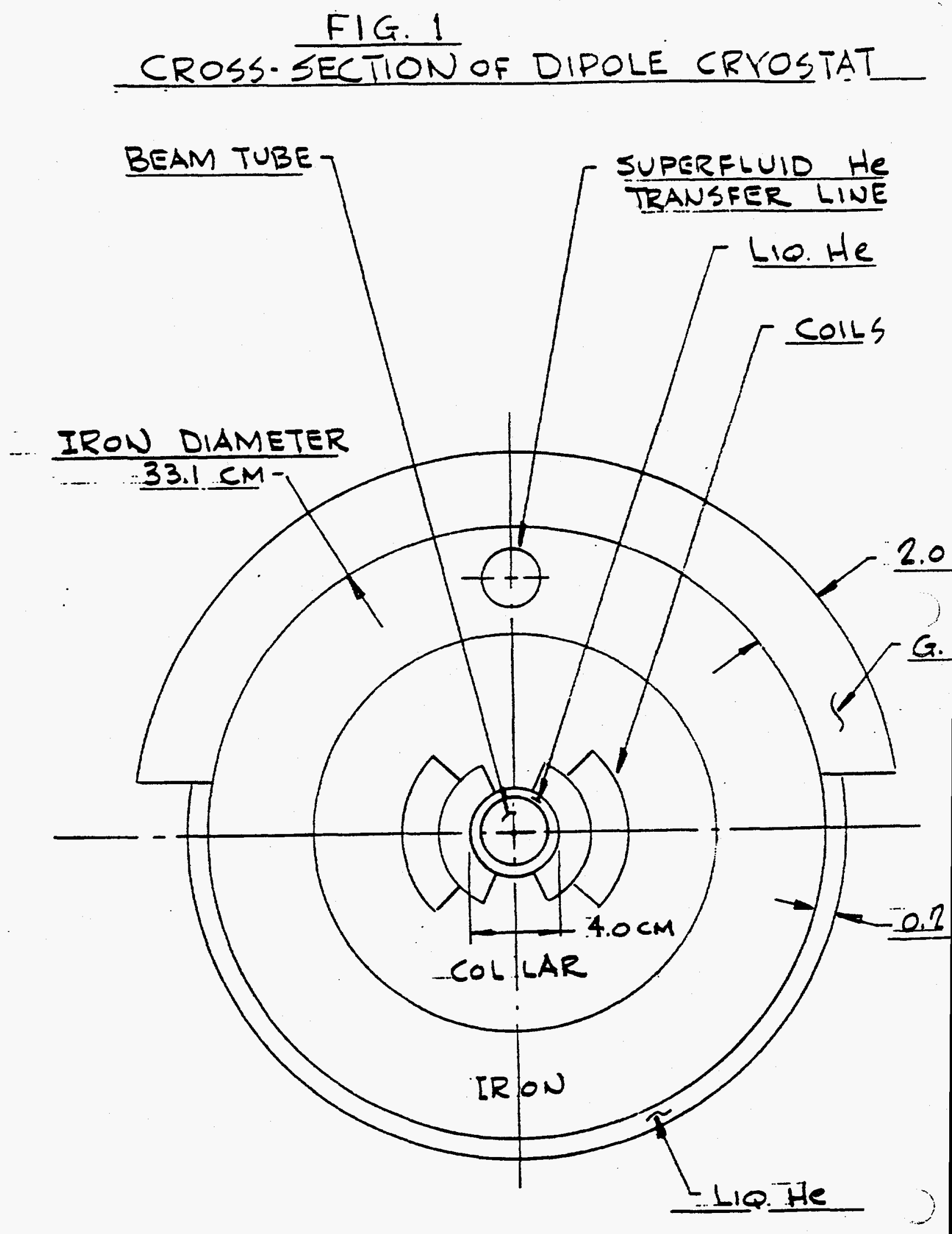


$F \mid G .2$

MAGNET CRYOSTAT-TO-CRYOSTAT CONNECTIO

\section{LIQUID LEVEL}

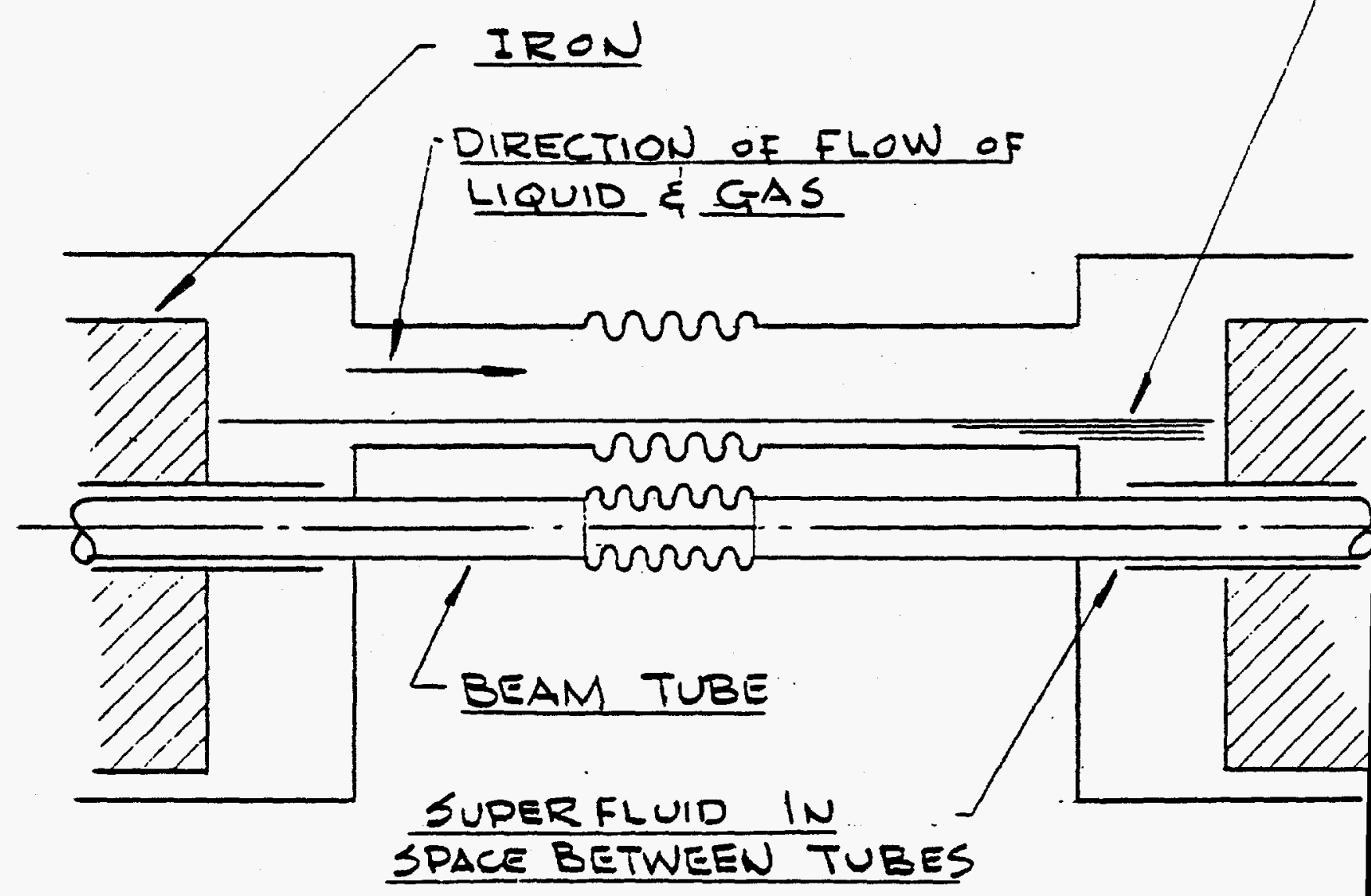




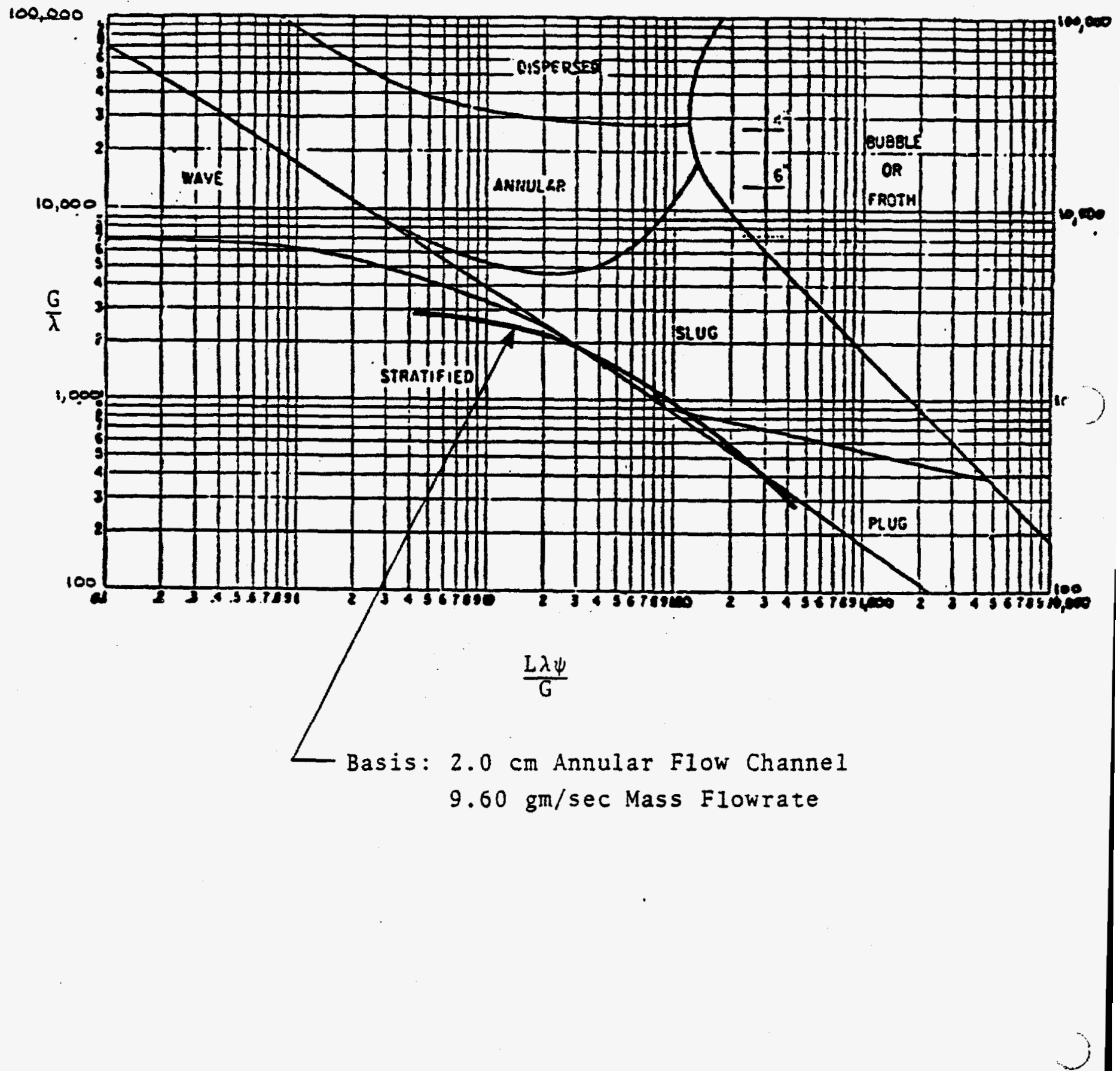




\section{FIG 4 \\ MAGNET COOLING SYSTEM}

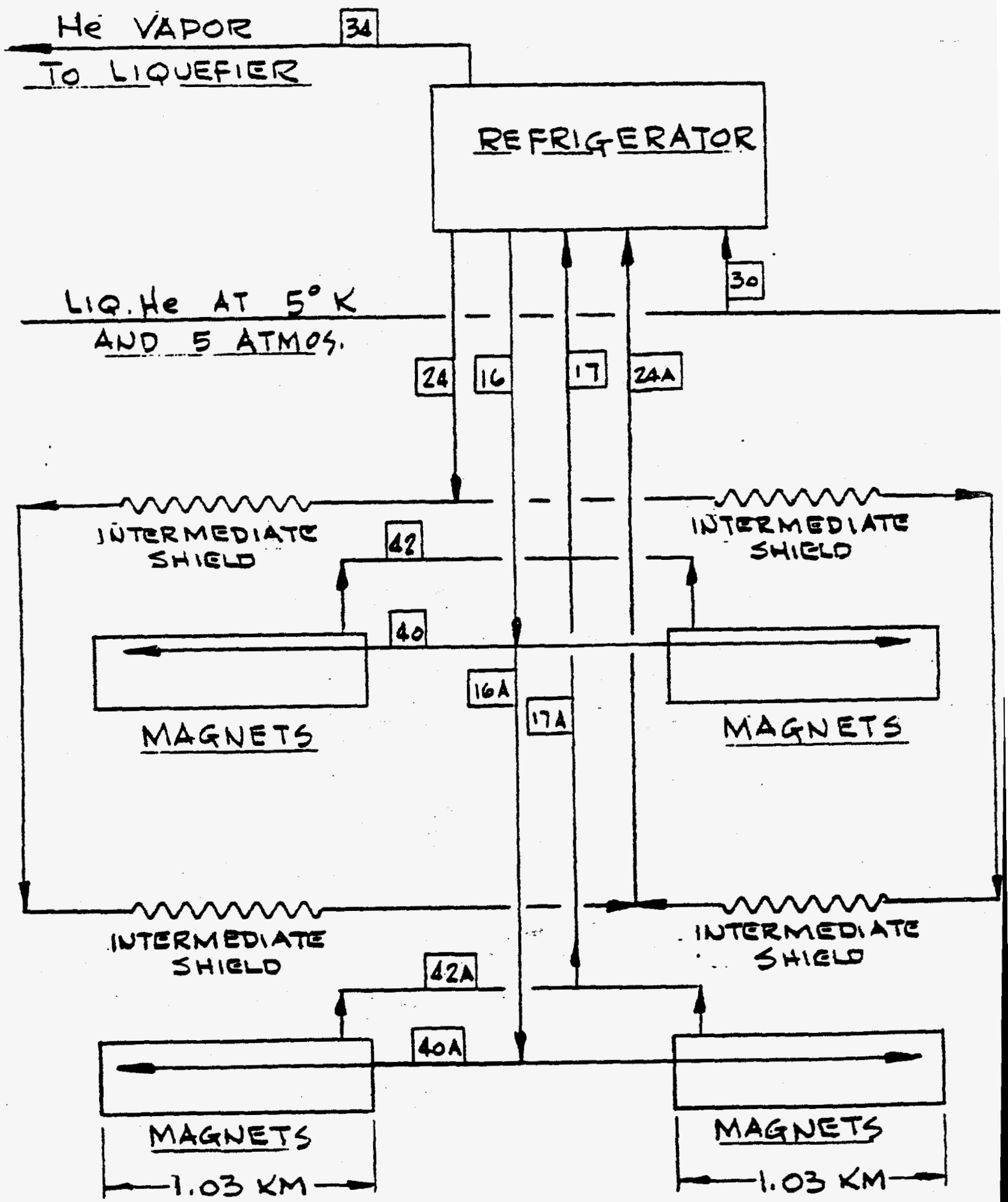

SCHEMATIC OF $2^{\circ} \mathrm{K}$. REFRIGERATION SYSTEM 


\section{REFRIGERATION SYSTEM}

Figure 4 shows that the refrigerator handles a length of $2.06 \mathrm{~km}$ of magnets. With magnet operating at $8 \mathrm{~T}$ it turns out that a total of 32 refrigerators is required. Figure 5 shows schematically the arrangement of refrigeration equipment associated with the total ring. In addition to the 32 refrigerators, there are 4 helium liquefiers equally spaced. These liquefiers provide liquid helium for lead cooling and supply liquid to each one of the refrigerators upon demand. The demand will vary as a function of operating conditions. To provide the capability of supplying high instantaneous flow rates, each refrigerator station is equipped with liquid and gaseous helium storage.

Figure 6 shows the flow schematic of one of the 32 refrigerators proposed for the system. The schematic shows two expanders: Expander EI provides refrigeration at the lowest temperature level, and Expander E2 generates refrigeration for the intermediate temperature magnet shield.

Cold compressor C2 may or may not be used. When used, it will reduce the number of low pressure warm vacuum pumps but will increase the flowrate to wet Expander EI.

Compression equipment consists of a number of vacuum pumps operating at a suction pressure determined by the magnet temperature. Liquid bath 51 operates at a pressure of approximately 0.1 ata in order to reduce the number of low pressure suction vacuum pumps.

High pressure of the system has been chosen at approximately 8 ata. Expander El operates at an inlet pressure of almost 8 ata, while Expander E2 operates at an inlet pressure of 7 ata. This allows the intermediate shield to be cooled with pressurized helium gas between 8 and 7 ata.

The liquid helium supplied to the system is at 5 ata and $4.5-5 \circ \mathrm{K}$. In warmup, its pressure is preserved and it is used to drive the warm vapor to the helium liquefiers. The process also shows a nitrogen circuit which may or may not be used. 
FIG 5

ARRANGEMENT OF REFRIGERATION

EQUIPMENT AROUND THE RING

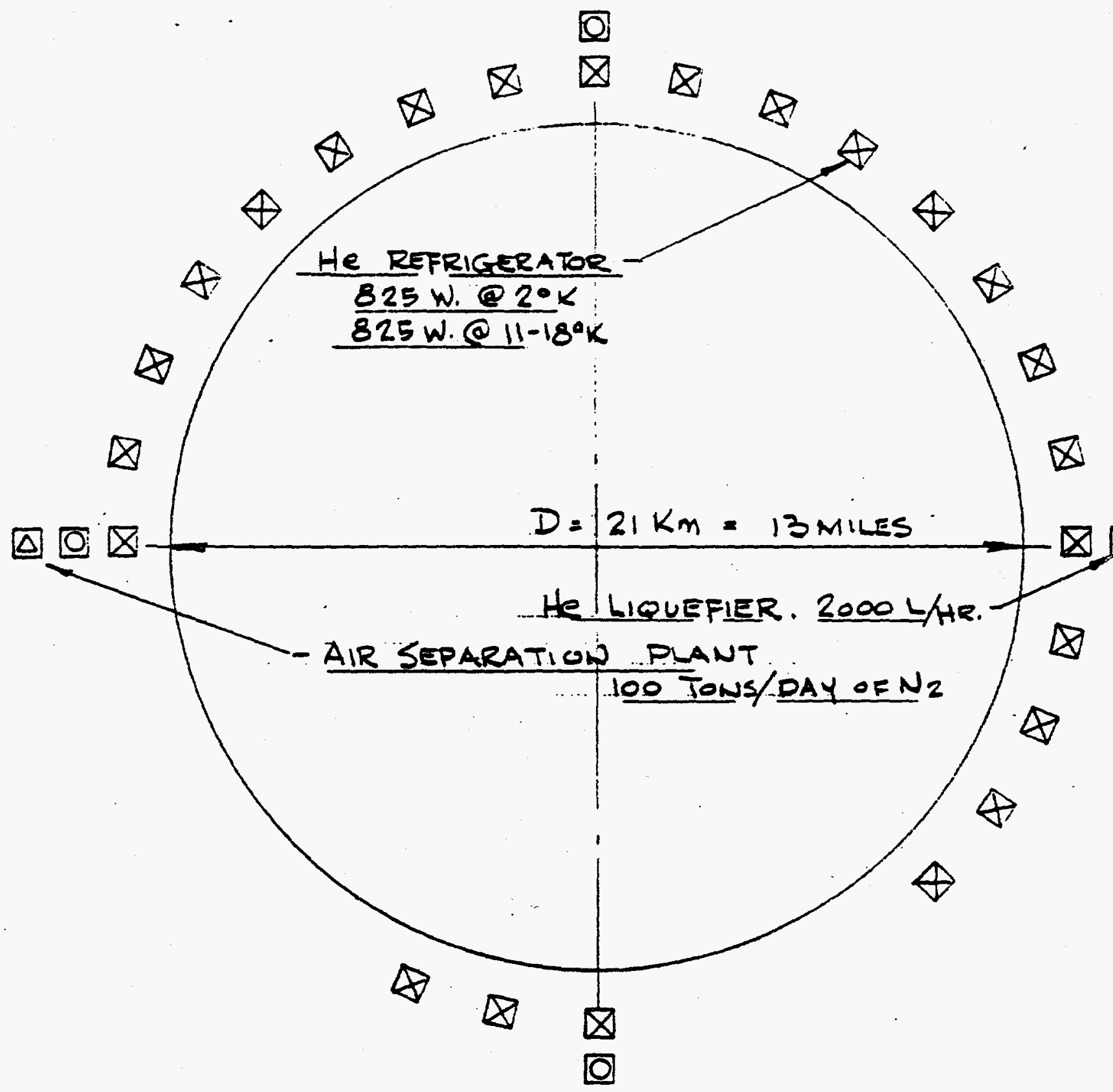

* 50\% larger capacity

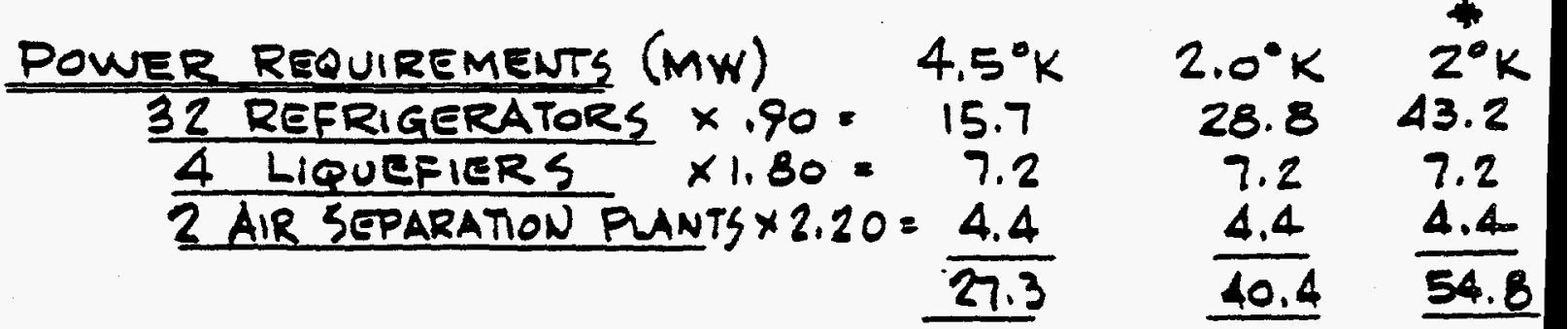




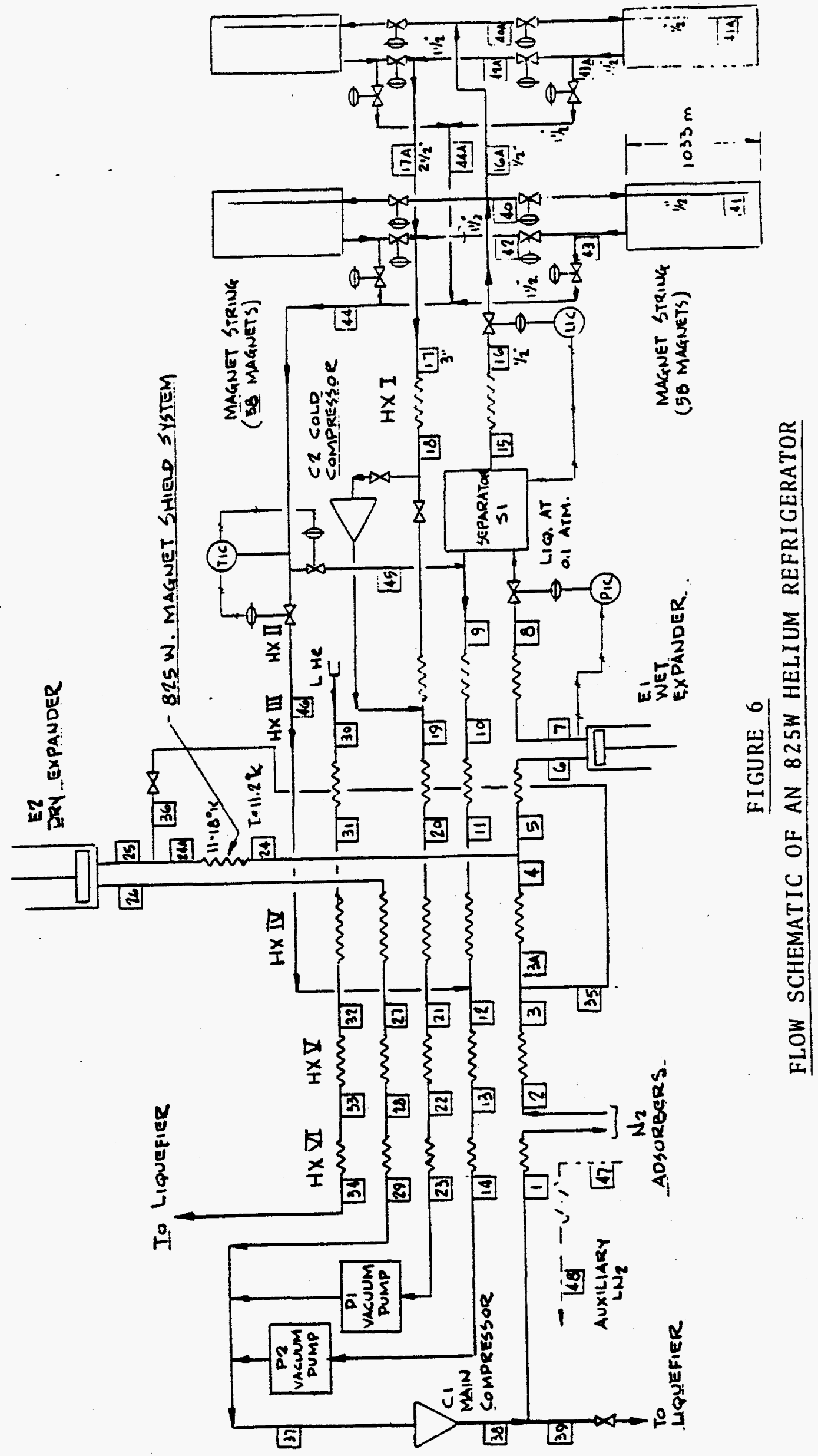


Process points for the steady state operation of the schematic of Figure 6 are given in Table I. The numbers are based on providing $825 \mathrm{~W}$ of refrigeration (.4W/meter) at approximately $2^{\circ} \mathrm{K}$ and $825 \mathrm{~W}$ to the intermediate magnet shield. Shield temperature has been chosen to be between 11 and $18^{\circ} \mathrm{K}$.

Table II provides the vacuum pump data for the process of Figure 6, operating with a cold compressor, C2. Table III shows vacuum pump data for the process without the cold compressor as a function of magnet operating temperature. It is obvious that operation of the magnets below $2.0^{\circ} \mathrm{K}$ without the aid of a cold compressor becomes quite expensive in terms of power. Cost of a system without cold gas compressor is also considerably higher, as shown in Section XI of the report.

The bottom line of Tables II and III indicates the size of the warm lines representing flow points 14 and 23 . The selected size is based on a pressure drop of a small fraction of one Torr in these lines.

The compressor selected to compress from 1.0 ata to 8.0 ata is a screw compressor of modest size. Required bhp for this machine is 420 bhp.

Figure 7 shows the main heat exchanger assembly of the $825 \mathrm{~W}$ refrigerator. The exchanger is a socalled plate fin exchanger in which a number of parallel streams may be accomodated. The exchanger will be mounted vertically. In addition to the plate fin exchanger there will be two small finned tube and shell Exchangers, I and II. 


\section{TABLE I}

PROCESS POINTS FOR AN $825 \mathrm{~W}, 2.0^{\circ} \mathrm{K}$ HELIUM REFRIGERATOR AT STEADY STATE OPERATION

\begin{tabular}{|c|c|c|c|c|}
\hline Point & $\begin{array}{c}\text { Pressure } \\
\text { ata } \\
\end{array}$ & $\begin{array}{l}\text { Temperature } \\
{ }^{\circ} \mathrm{K} \\
\end{array}$ & $\begin{array}{l}\text { Enthalpy } \\
\mathrm{J} / \mathrm{gr}\end{array}$ & $\begin{array}{c}\text { Flow Rate } \\
\mathrm{g} / \mathrm{sec} \\
\end{array}$ \\
\hline 1 & 8.00 & 300.00 & 1575.00 & 110.85 \\
\hline 2 & 7.99 & 70.00 & 379.70 & 110.85 \\
\hline 3 & 7.98 & 18.10 & 103.20 & 110.85 \\
\hline $3 A$ & 7.98 & 18.10 & 103.20 & 81.88 \\
\hline 4 & 7.97 & 11.20 & 61.30 & 81.88 \\
\hline 5 & 7.97 & 11.20 & 61.30 & 62.33 \\
\hline 6 & 7.96 & 6.00 & 20.07 & 62.33 \\
\hline 7 & 0.60 & 3.72 & 14.51 & 62.33 \\
\hline 8 & 0.59 & 3.72 & 12.84 & 62.33 \\
\hline 9 & 0.100 & 2.50 & 26.66 & 24.26 \\
\hline 10 & 0.098 & 3.26 & 30.95 & 24.26 \\
\hline 11 & 0.096 & 10.70 & 70.10 & 24.26 \\
\hline 12 & 0.094 & 16.43 & 99.82 & 24.26 \\
\hline 13 & 0.092 & 68.00 & 367.80 & 24.26 \\
\hline 14 & 0.090 & 291.50 & 1528.73 & 24.26 \\
\hline 15 & 0.100 & 2.50 & 4.036 & 38.07 \\
\hline 16 & 0.100 & 2.20 & 3.196 & 38.07 \\
\hline $16 \mathrm{~A}$ & 0.100 & 2.20 & 3.196 & 19.04 \\
\hline 17 & 0.030 & 1.99 & 24.87 & 38.07 \\
\hline $17 \mathrm{~A}$ & 0.030 & 1.99 & 24.87 & 19.04 \\
\hline 18 & 0.029 & 2.25 & 25.71 & 38.07 \\
\hline 19 & 0.060 & 3.40 & 31.04 & 38.07 \\
\hline 20 & 0.058 & 10.70 & 70.10 & 38.07 \\
\hline 21 & 0.056 & 16.43 & 99.82 & 38.07 \\
\hline 22 & 0.054 & 68.00 & .367 .80 & 38.07 \\
\hline 23 & 0.052 & 291.50 & 1528.73 & 38.07 \\
\hline 24 & 7.97 & 11.20 & 61.00 & 19.55 \\
\hline $24 \mathrm{~A}$ & 7.00 & 18.00 & 103.20 & 19.55 \\
\hline 25 & 7.00 & 18.00 & 103.20 & 48.52 \\
\hline 26 & 1.03 & 10.70 & 68.80 & 48.52 \\
\hline 27 & 1.02 & 16.43 & 99.06 & 48.52 \\
\hline
\end{tabular}


TABLE I continued. . .

\begin{tabular}{|c|c|c|c|c|c|}
\hline Point & $\begin{array}{l}\text { Pressure } \\
\text { ata } \\
\end{array}$ & $\begin{array}{c}\text { Temperature } \\
{ }^{\circ} \mathrm{K} \\
\end{array}$ & $\begin{array}{l}\text { Enthalpy } \\
\mathrm{J} / \mathrm{gr} \\
\end{array}$ & $\begin{array}{c}\text { Flow Rate } \\
g / \text { sec } \\
\end{array}$ & \\
\hline 28 & 1.01 & 68.00 & 368.00 & 48.52 & \\
\hline 29 & 1.00 & 291.50 & 1528.73 & 48.52 & \\
\hline 30 & 5.00 & 5.00 & 14.32 & 3.29 & \\
\hline 31 & 4.99 & 10.70 & 62.33 & 3.29 & \\
\hline 32 & 4.98 & 16.43 & 95.77 & 3.29 & \\
\hline 33 & 4.97 & 68.00 & 368.70 & 3.29 & \\
\hline 34 & 4.96 & 291.50 & 1529.73 & 3.29 & \\
\hline 35 & 7.98 & 18.10 & 103.20 & 28.97 & \\
\hline 36 & 7.00 & 18.00 & 103.20 & 28.97 & \\
\hline 37 & 1.00 & 300.00 & 1573.00 & 110.85 & \\
\hline 38 & 8.00 & 300.00 & 1575.00 & 110.85 & \\
\hline 39 & - & - & - & 0 & \\
\hline 40 & 0.100 & 2.20 & 3.196 & 9.52 & \\
\hline $40 A$ & 0.100 & 2.20 & 3.196 & 9.52 & \\
\hline 41 & 0.035 & 2.04 & 3.196 & 9.52 & \\
\hline $4 I A$ & 0.035 & 2.04 & 3.196 & 9.52 & \\
\hline 42 & 0.030 & 1.99 & 24.87 & 9.52 & \\
\hline $42 \mathrm{~A}$ & 0.030 & 1.99 & 24.87 & 9.52 & \\
\hline 43 & - & - & - & $0)$ & \\
\hline $43 A$ & - & - & - & 0 & \\
\hline 44 & - & - & - & 0 & Quench \\
\hline $44 \mathrm{~A}$ & - & - & - & 0 & Recovery \\
\hline 45 & - & - & - & 0 & \\
\hline 46 & - & - & - & 0 & \\
\hline 47 & - & - & - & 0 & $\mathrm{~N}_{2}$ \\
\hline 48 & - & - & - & 0 & $\mathrm{~N}_{2}$ \\
\hline
\end{tabular}

Notes:

Efficiency of Cold Gas Compressor C2 is $70 \%$ Efficiency of Expander E1 is $72 \%$ Effieiency of Expander 
TABLE II

VACUUM PUMP DATA FOR AN $825 \mathrm{~W} 2.0^{\circ} \mathrm{K}$ HELIUM REFRIGERATOR (WITH COLD COMPRESSOR C2)

Pump Designation

Fluid

Flowrate, gm/sec

Suction Temperature, ${ }^{\circ} \mathrm{K}$

Suction Pressure, Ata

Torr

Discharge Pressure, Ata

Inlet Flow, ACFM

No. of Parallel Machines

Horsepower/Machine

Total Horsepower

Number of Skids

Dimensions (per Skid)

Header Line Size

Magnet Operating

Temperature Range, ${ }^{\circ} \mathrm{K}$

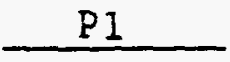

Helium

38.07

291.5

0.052

39.52

1.0

9257

3

175

525

$\mathrm{H}, \mathrm{ft}$

$W, f t$

$L, f t$

ID, in

12

$1.99-$

2.04
$P 乏$

Helium

24.26

291.5

0.090

68.40

1.0

3410

1

250

250

1

9

8

18

8 
TABLE III

VACUUM PUMP DATA FOR AN $825 \mathrm{~W} 2.0^{\circ} \mathrm{K}$ HELIUM REFRIGERATOR

(WITHOUT COLD COMPRESSOR)

Pump Destination

Fluid

Flowrate, $\mathrm{gm} / \mathrm{sec}$

Inlet Temperature, ${ }^{\circ} \mathrm{K}$

Suction Pressure, Ata Torr

Discharge Pressure, Ata

Inlet Flow, ACFM

No. of Parallel Machines

Horsepower/Machine

Total Horsepower

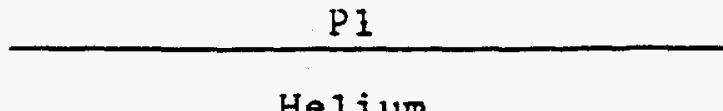

Helium

38.07

291.5

0.0103

7.05

1.0

44100

15

90

1350

20.0

$1.86-$

1.92
16.0

12.0

$1.99-$

0.0207

15.00

1.0

22050

8

100

800

0.0310

22.50

1.0

14700

6

110

660

2.04

$2.09-$

2.13
P2

Helium

12.12

291.5

0.090

67.50

1.0

1710

3

65

195

6.0
Magnet Operating

Temperature Range, ${ }^{\circ} \mathrm{K}$ 
FIG. 7

HEAT EXCHANGER FOR AN $825 \mathrm{~W}$. REFRIGERATOR

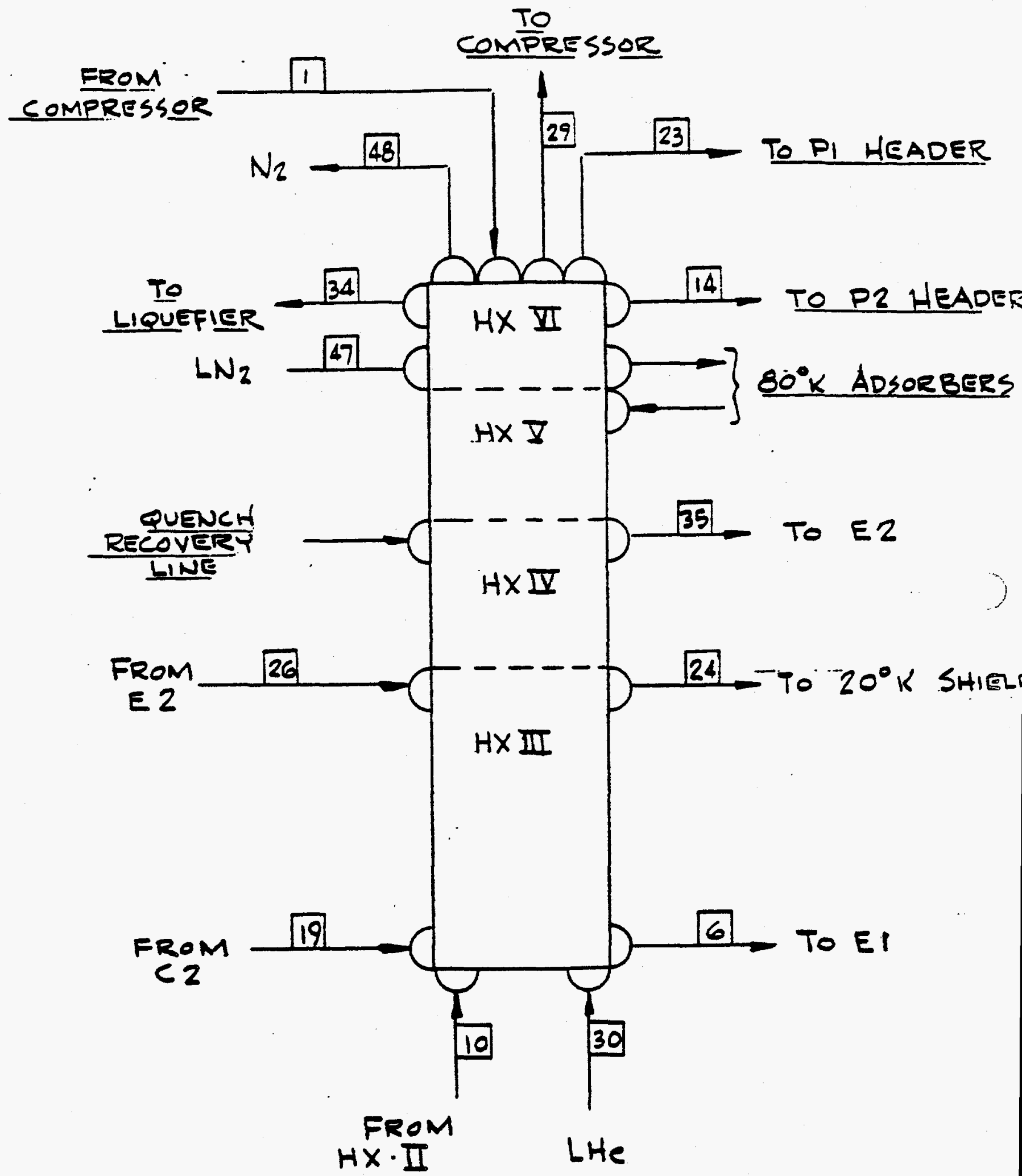

HX.II LHE

OVERALL DIMENSIONS $30^{\circ} \times 30^{\circ} \times 180^{\circ}$ 


\section{HELIUM LIQUEFIERS}

The Tevatron at Fermilab has demonstrated that liquid helium can be distributed through a $6 \mathrm{~km}$ long transfer line. If we assume a more or less similar length as the maximum distance over which liquid will be transported, the number of helium liquefiers will be 4 . This yields a maximum distance of $8.25 \mathrm{~km}$ for liquid helium flow from a liquefier. The total quantity of helium used for the ring (not including flow to the electrical leads) is 2500 liters per hour. We will assume that the liquid helium for electrical leads is the same as for the $D$ magnet. This amounts to $5440 \mathrm{l} / \mathrm{hr}$. Total liquid helium capacity is then $8000 \mathrm{l} / \mathrm{hr}$ or $2000 \mathrm{l} / \mathrm{hr}$ per liquefier.

In comparison the central helium liquefier at Fermilab generates approximately $4000 \mathrm{l} / \mathrm{hr}$ of liquid. 
VI. NON-STEADY STATE MAGNET OPERATION

The following non-steady state conditions need to be taken care of:
a) Cooldown of the magnets.
b) Warmup of the magnets.
c) Recovery from a quench.

Cooldown of Magnets

In general, a string of magnets will be cooled by flowing cold helium gas into the end near the refrigerator and return the stream through a second string back to the refrigerator. Because of the large cross-section of the flow passages, pressure drop is not a major problem. Highest pressure drop occurs at time zero, when all of the magnets are at ambient temperature. In order to reduce the pressure drop at this time, a bypass between the two magnet strings halfway between refrigerator and turnaround point may be required.

The main problem during cooldown from ambient temperature is the non-uniform cross-section of the flow path and the non-uniform distribution of mass. The skin of the cryostat has as much surface area as the iron, but represents a very small part of the mass. Consequently the cryostat wall will quickly cool to the gas temperature. In order to accomodate the difference in temperature between shell and iron, the beam tube needs to be fastened to the cryostat wall by means of a bellows capable of accomodating at least one inch in differential contraction.

A more serious problem of the section shown in Figure 1 is the large flow of coolant in the upper half of the cryostat relative to the bottom half. Fast cooling of the upper half of the iron may lead to bowing of the complete magnet assembly during the cooldown process. This would possibly break the beam tube at both ends of the cryostat. 
To avoid the problem of non-uniform cooldown the arrangement of the gas and liquid channels in the cryostat as shown in Figure 8 may be used. The vapor flows primarily through the jacket outside the skin surrounding the iron. Liquid level in the cryostat is determined by the elevation of supply and discharge tube at either end of the magnet.

Total time required to cool one string of $1 \mathrm{~km}$ length can be estimated roughly by assuming a flowrate through the string and comparing this with the amount of heat to be removed. If we assume a flowrate of $110 \mathrm{~g} / \mathrm{sec}$ (which is roughly the flowrate of which the refrigerator compressor is capable) and a magnet mass of 1260 lbs per meter, cooldown to $80^{\circ} \mathrm{K}$ should take some 77.5 hours. To this needs to be added the cooldown, filling with liquid He and pumpdown from $4.5^{\circ} \mathrm{K}$ to $2.0^{\circ} \mathrm{K}$. Cooldown and filling will take another 35 hours, while pumpdown is a function of total liquid inventory of the string. However, cooldown at $4.5^{\circ} \mathrm{K}$ and filling of one string should be accomplished in some 120 hours.

We can reduce this period of time by supercharging the compressor of the refrigerator to a suction pressure $50 \%$ over the normal pressure. In order to be able to do this, sufficient motor horsepower needs to be provided. If the extra power is available, cooldown and filling of one string should be accomplishable in a period of 80 hours. To put 4 magnet strings compressing $2.06 \mathrm{~km}$ of each ring will then take some 320 hours or roughly two weeks.

Figure 9 shows that pumpdown of one string of magnets from 1.2 ata and $4.5^{\circ} \mathrm{K}$ to operating conditions requires roughly 3500 seconds. The starting condition is represented by a total fluid inventory of approximately 336000 grams, of which $57 \%$ is vapor. Actual liquid and vapor volumes are 1200 and 9300 liters per string respectively.

During the cooldown to $2^{\circ} \mathrm{K}$ mass is removed from the magnet system. Mass in the vapor space is reduced from 190965 to 7280 grams. Liquid added is $29715 \mathrm{grams}$. If a liquid helium storage tank is present at the refrigerator station, cold vapor removed from the magnet system may be liquefied and put in storage as excess $4.5^{\circ} \mathrm{K}$ liquid. 
$-B 22-$

FIG 8

$\frac{\text { CRYOSTAT CROSS-SECTION INCORPORATING UNIFUR }}{\text { COOLDOWN AND LOW LIQUID INVENTORY }}$

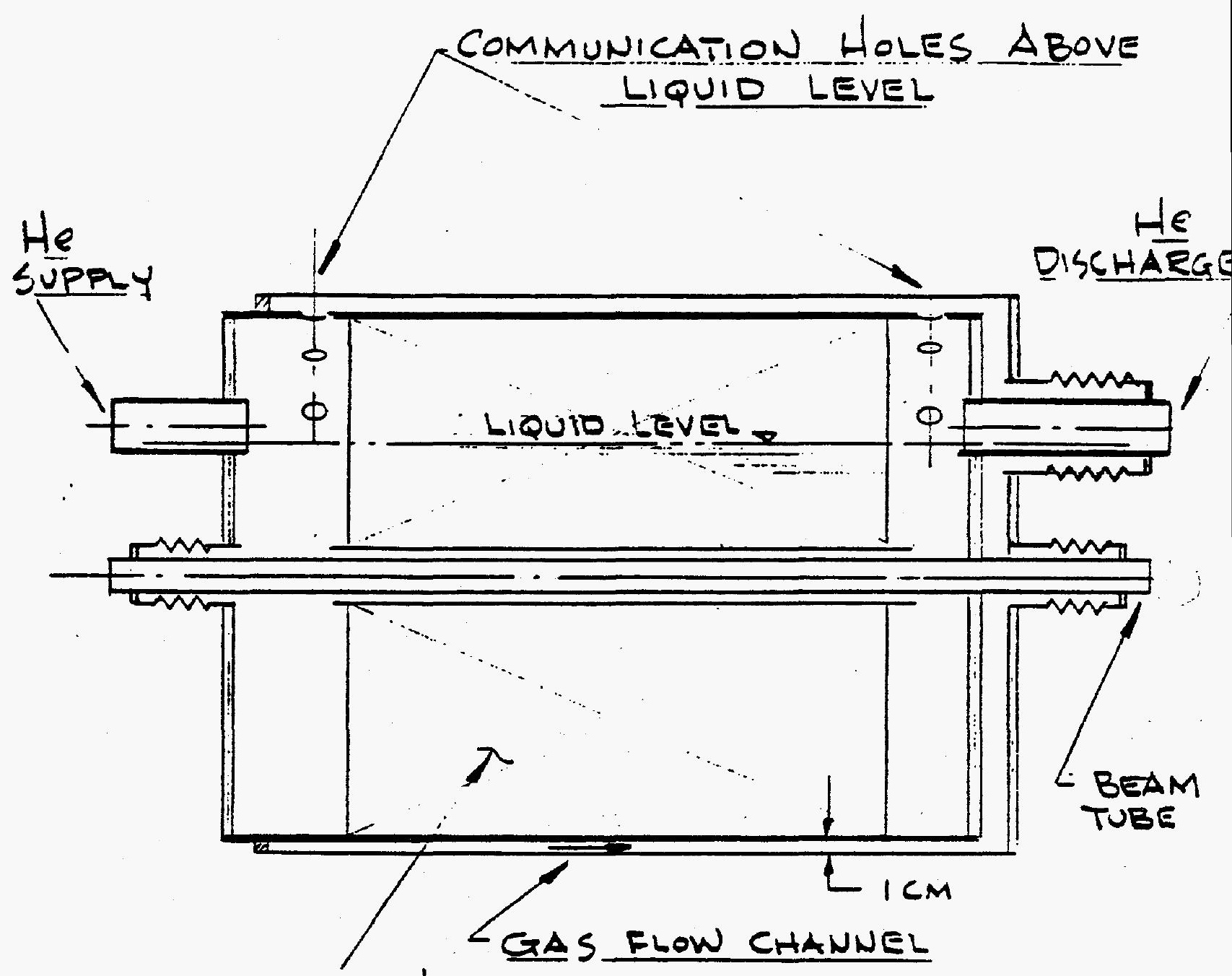

COILS, COLLAR Er IRON 


\section{FIGURE 9}

PUMPDOWN TIME VS PRESSURE FOR A ONE KILOMETER MAGNET STRING

(Based on compressor (Cl) flow of $110 \mathrm{gm} / \mathrm{sec}$. Pumpdown rate decreases from 76 to $67 \mathrm{gm} / \mathrm{sec}$ as pressure decreases from 1.2 ata to 0.053 ata and thereafter decreases linearly with pressure to $38 \mathrm{gm} / \mathrm{sec}$ at 0.03 ata)

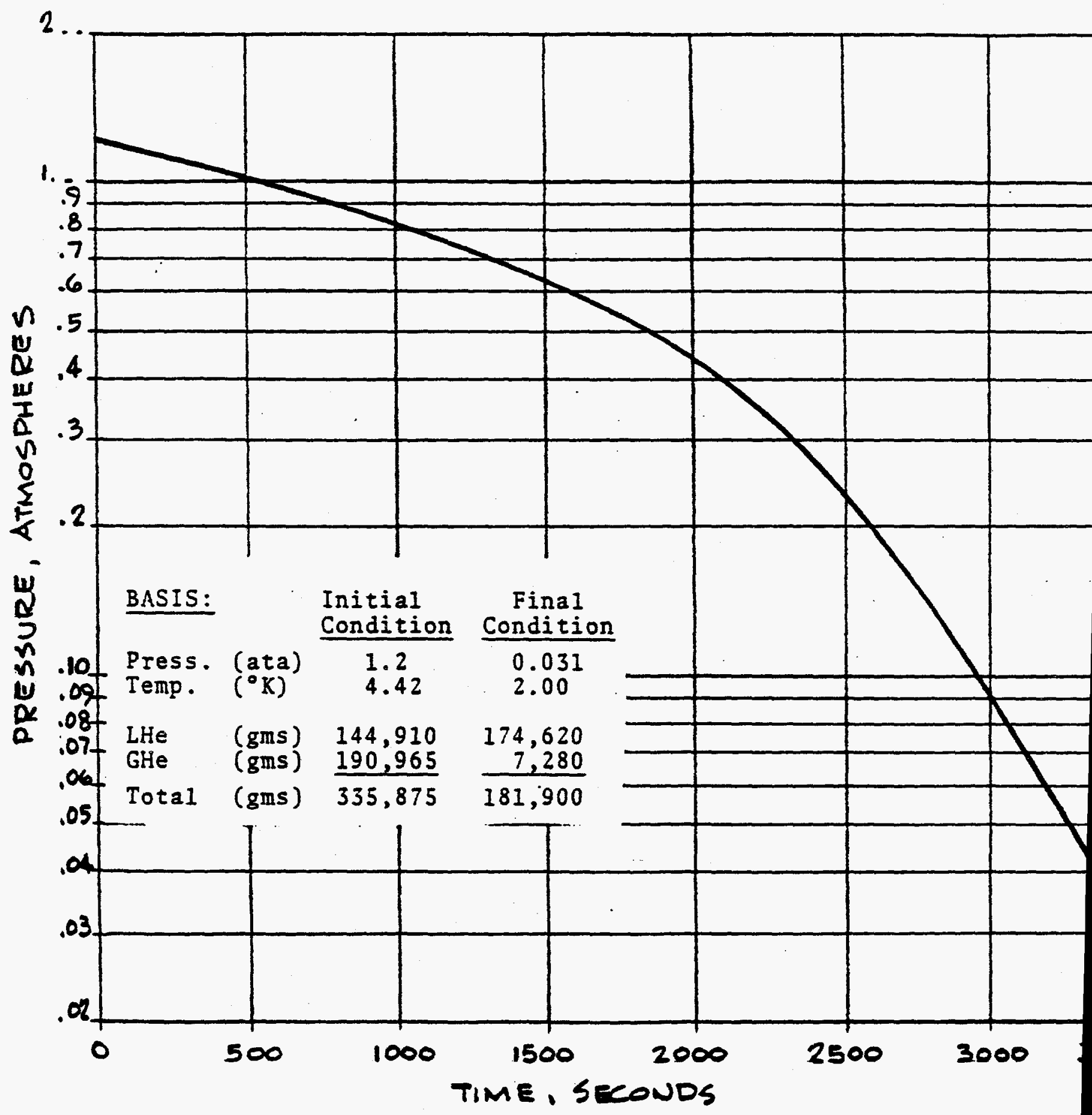


Warmup of Magnets

The warmup of the magnets is independent of the temperature at which the magnets ultimately operate, since there is no specific heat between 2 and $4.5^{\circ} \mathrm{K}$. Warmup by electric heaters has been proposed for the $D$ magnet. This method is perfectly alright for the superfluid system.

\section{Recovery from a Quench}

It is assumed that the onset of a quench will be detected and used to drive 6 dipoles simultaneously to the normal state. The amount of energy deposited in the winding of these six (6) magnets has been assumed to be $9 \times 10^{6}$ Joules. The following sequence of events will occur:

a) 6 magnets will be driven normal and heat will be deposited in windings, collar and iron. The string will be isolated from the refrigerator and other magnet strings by closing valves.

b) Liquid in the 6 quenching magnets will be vaporized. Gas will flow into the adjacent magnets and compress low pressure cold vapor. The newly generated vapor is assumed to have had insufficient time to come to temperature equilibrium with the warming iron of the quenching mangets.

c) The compressed gas will have warmed some. Heat will be transmitted to the iron which in turn will warm the liquid in the non-quenched magnets to the new vapor pressure present.

d) In case some extra superheat is left, liquid in the non-quenched magnets will vaporize and raise the pressure in the string.

e) Finally al1 non-quenched magnets will have an equilibrium temperature determined by heat contents of iron, collars, windings, and liquid present. 
Recovery from the quench may now begin. The lowest pressure circuit of the refrigerator will keep operating at the lowest pressure and will maintain 3 of the 4 strings at operating temperature. The quenched string vapor return will be switched to the .l ata circuit of the refrigerator. Possibly to obtain more capacity the pressure level of this circuit will be allowed to rise to .15 or .2 ata. liquid from the separator vessel operating at .6 ata will be forced into the string with the quenched magnets. Liquid will spili into the first quenched cryostat, where it will vaporize.

This vapor will flow along 5 more "warm" magnets and will start cooling these magnets. The warm vapor will then pass along cold magnets and vaporize liquid present in these magnets.

The net refrigeration obtained is the mass flowrate times the enthalpy difference between liquid and returning vapor. With a flowrate of $100 \mathrm{~g} / \mathrm{sec}$ at an enthalpy difference of $18 \mathrm{~J} / \mathrm{gram}$ refrigeration supplied is $1800 \mathrm{~W}$. To remove $9 \mathrm{x}$ $10^{6}$ Joules then should take approximately $5000 \mathrm{sec}$. The removal of heat all takes place at a pressure of . $1-.2$ ata and finally it will be necessary to reduce this pressure to the required operating pressure. According to Figure 9 this will require another 800 seconds to pumpdown from 0.2 ata to 0.03 ata.

Total time to recover from the quench will then be of the order of 5800 seconds.

Appendix A of this report contains some calculations for the postulated model of the quench and quench recovery. With some extra effort, it appears feasible to recover from a quench in a period of one hour. 
VII. MAGNET COOLING SYSTEM WITH PRESSURIZED SUPERFLUID

Most of the superfluid systems in operation today employ a pressurized liquid bath surrounding the magnet windings. Cooling and removal of heat from the magnet is achieved by boiling liquid helium receiving heat through a wall from the pressurized superfluid.

It appears reasonably simple to modify the cryostat shown in Figure 1 to one in which the magnets are surrounded by pressurized superfluid. Figure 10 shows the concept. The jacket contains the low pressure boiling fluid. Liquid level is controlled by location of the inlet and discharge pipes. The inner vessel containing the magnet, collar, and iron has its own entry and exit pipe. Location of these is not important since there is no liquid level to control. To maintain the smallest possible temperature difference between pressurized and boiling superfluid, heat exchange should be uniformly distributed along the magnet and surface area and thermal conductivity of the wall separating the pressurized and boiling superfluid should be large.

From a cryogenic standpoint a wall separating pressurized and boiling superfluid at the diameter of the magnet collar might be most advantageous. The outside diameter of the collar of a 8 . Tesla magnet may be of the order of $128.5 \mathrm{~mm}$ (see Reference 3 ). Total surface area of the wall outside the collar is then $68600 \mathrm{~cm}^{2}$ for a 17 meter long magnet. If all of this wall is used for heat transfer, heatflux will be approximately $3 x$ $10^{-5} \mathrm{~W} / \mathrm{cm}^{2}$. Even a thin walled stainless steel cylinder of $.040^{\prime \prime}$ thickness will be strong enough to contain a pressure of 10 ata in the pressurized superfluid region without support from the iron. Assuming a thermal conductivity of $7 \times 10^{-3}$ $\mathrm{W} / \mathrm{cm}^{\circ} \mathrm{K}$ for stainless steel at $2.0^{\circ} \mathrm{K}$, temperature gradient through the wall will be of the order of $.004^{\circ} \mathrm{K}$.

By putting the wall between iron and collar, inventory in the pressurized superfluid region will be small. This is advantageous in case of a quench.

The method by which a string of magnets is maintained in the steady state is shown in Figure 11. The superfluid leaves the refrigerator gas-liquid separator at approximately. 6 ata and is then further cooled in heat exchanger I by boiling superfluid, which is returned from the magnet string (stream 17). 
$-827-$

$$
\text { FIG .10 }
$$

MAGNET ENCLOSED BY PRESSURIZED SUPERFLUID

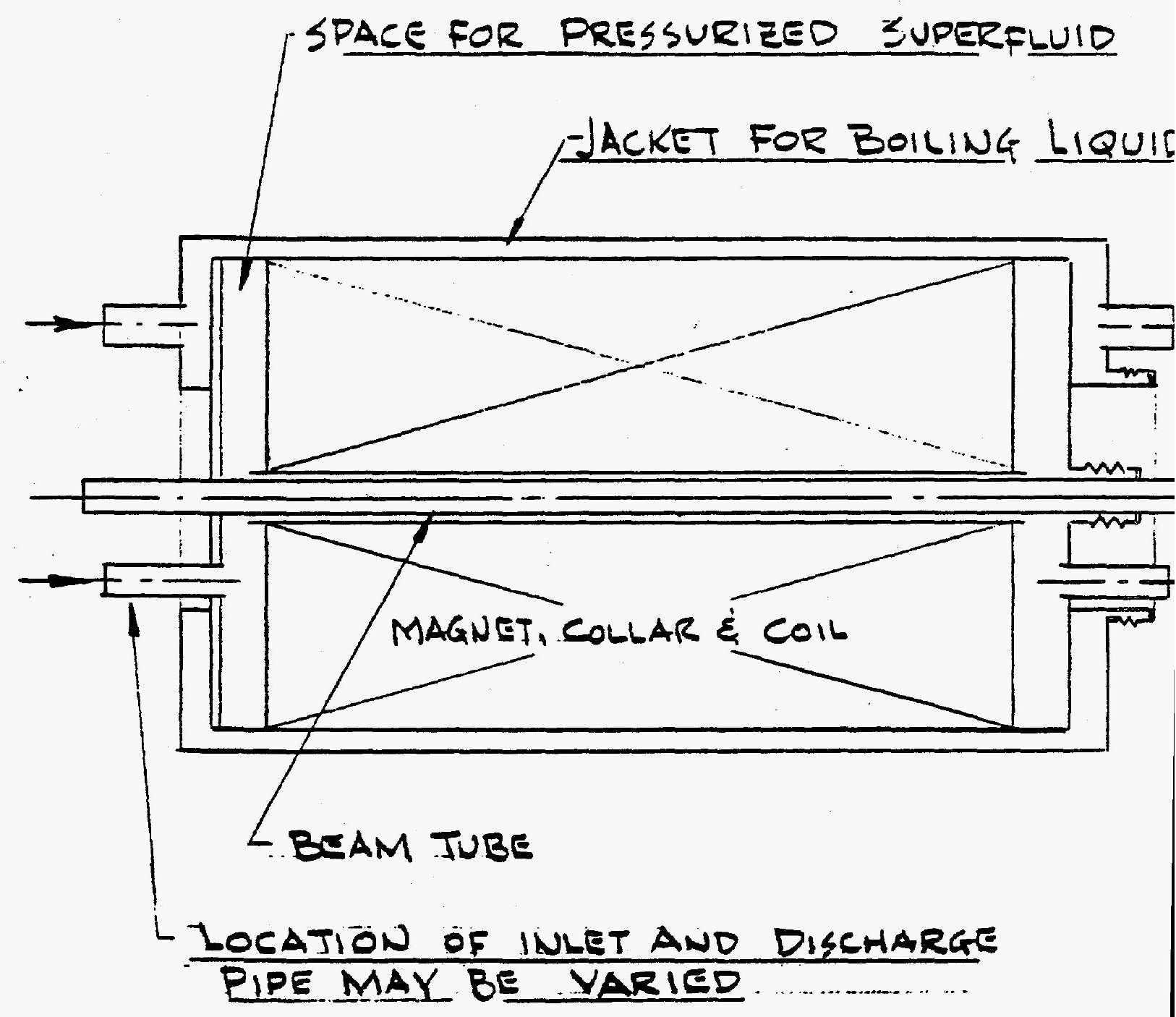


$-828-$

$$
\text { FIG } 11
$$

MAGNET COOLING SYSTEM FOR MAGNETS WITH PRESSURIZED SUPERFLUID

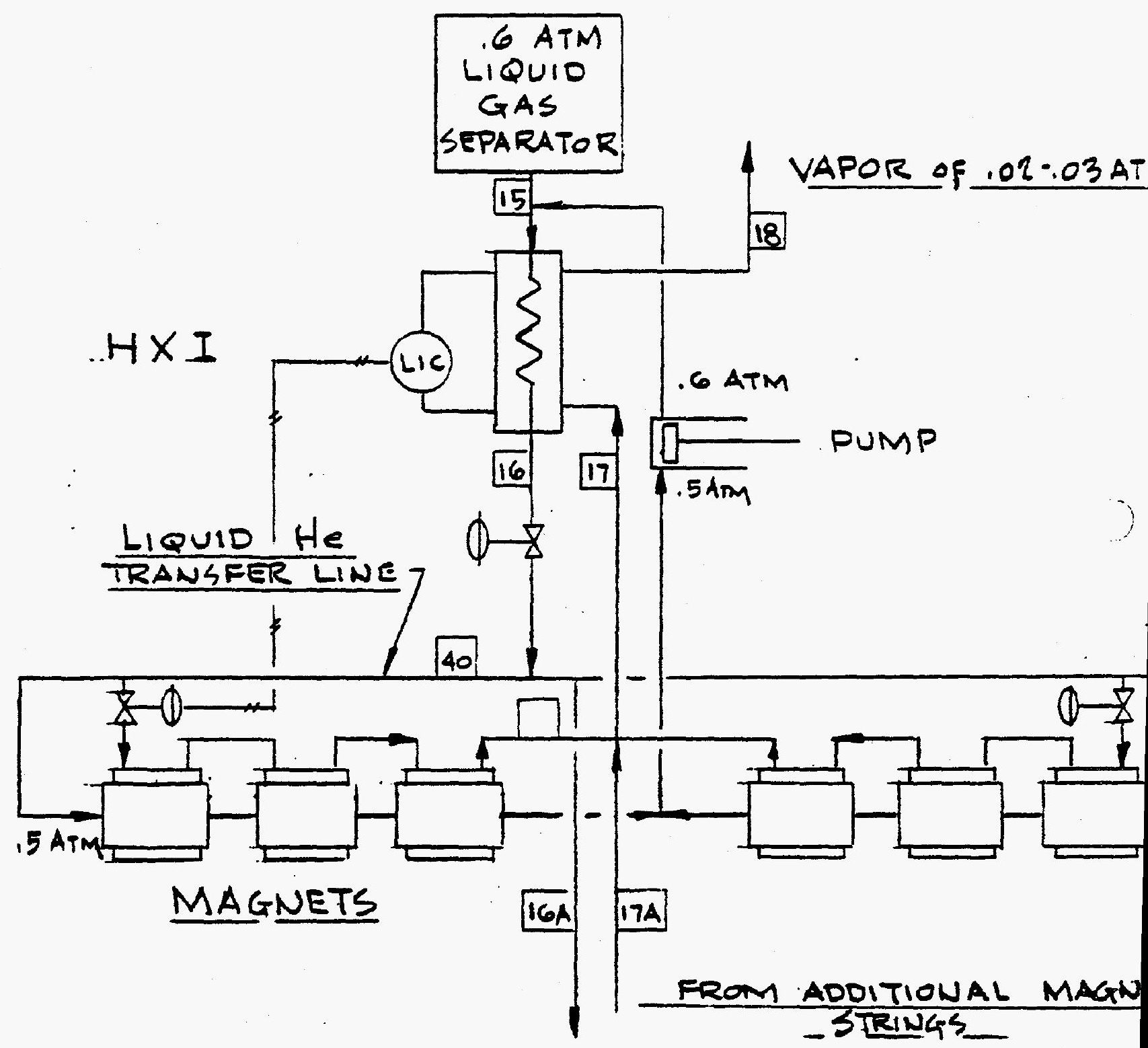

TO ADDITIONAL MAGNET STRINGS 
Flowrate into exchanger $I$ is controlled by a level indicatorcontroller, which provides a signal to the valve at the end of the magnet string.

A liquid helium pump may be used to generate some flow through the pressurized superfluid system. The pump only has to provide sufficient head to overcome pressure drop in the pressurized superfluid system.

The system as shown in Figure 11 is nearly identical to the system employed at the Tevatron. However, a liquid helium transfer line carrying stream 40 has been added to permit cooldown of the magnet string without need for a large warm gas collection header.

The refrigerators used to provide refrigeration to the system of Figure 11 are identical to those used for the system in which magnets are submerged in boiling liquid helium.

Cooldown of the magnet string may be carried out by flowing cold gas through one string and returning it through the second string. Or, the vacuum jacketed transfer line may be used to start flow of cold vapor to the end of the string and return it through the jackets of the magnets.

Quench behavior of the magnets is almost the same as that of the system employing boiling superfluid. However, the pressurized superfluid located in the magnets needs to be removed from the quenching magnets.

In all cases it will be advantageous to limit the inventory of the superfluid to be displaced in order to prevent propagation of the quench through warm fluid movement. A small inventory also would reduce the requirements for size and number of safety valves. 


\section{15 TEV OPERATION WITH MAGNETS OPERATING AT $4.5^{\circ} \mathrm{K}$}

It is assumed that the magnets are designed for $8 \mathrm{~T}$ and $2^{\circ} \mathrm{K}$ operation. However, during initial commissioning of the facility, one can envision operation at 15 TEV with magnets operating at $4.5^{\circ} \mathrm{K}$. The total heat load of the system at $4.5^{\circ} \mathrm{K}$ will reduce somewhat, because synchrotron radiation will drop. We will assume that refrigeration required at $4.5^{\circ} \mathrm{K}$ will be of the order of $.34 \mathrm{~W} /$ meter, rather than .4 W/meter when operating at $2^{\circ} \mathrm{K}$. We will also assume that only half of the refrigerators will be installed initially. Each refrigerator then serves $4.12 \mathrm{~km}$ of collider and the heat load at $4.5^{\circ} \mathrm{K}$ per refrigerator will be $1400 \mathrm{~W}$. This is roughly $70 \%$ more per refrigerator when compared with the 3.2 refrigerator case. Heat loads to be removed at the intermediate shield and $80^{\circ} \mathrm{K}$ temperature level will double.

Iransport of refrigeration now is carried over double the distance. At the $4.5^{\circ} \mathrm{K}$ temperature level there are no problems with pressure drop. This can be seen from the relationship:

$$
\Delta P=\frac{C G^{1 \cdot 8} \mathrm{~L}}{\rho}
$$

Operation at $2^{\circ} \mathrm{K}$ is accomplished with a pressure drop of .005 ata through a $1 \mathrm{~km}$ long string of magnets. At $4.5^{\circ} \mathrm{K}$ density of the gas is 26 times larger than at $2^{\circ} \mathrm{K}$, length doubles, and $G$ increases by a factor of 1.7. Then:

$$
\Delta P=\left(\frac{c G^{1 \cdot \theta} L}{\rho}\right)_{p} \times \frac{(1.7)^{1 \cdot 8} \times 2}{26}=.2\left(\frac{c G^{1 \cdot 8} L}{\rho}\right)_{0}
$$

The pressure drops of the shield cooling systems increase by a factor $2^{2}=6.96$ when operating at $2^{\circ} \mathrm{K}$. Since pressure drops in both intermediate and $\mathrm{N}_{2}$ cooled shields are low at $2^{\circ} \mathrm{K}$, we can operate with half the number of refrigerators. 
A reasonably accurate quick estimate may be made for the requirements of the larger refrigerator. When considering the flowsheet of Figure 6 and process data of Table $I$, we find that we have to increase compressor $\mathrm{Cl}$ flowrate from $110.85 \mathrm{~g} / \mathrm{sec}$ to $1.7 \times 62.33+2 \times(19.55+28.97)=203.00$ g/sec. Expander El needs to handle $70 \%$ more flow, while Expander E2 flowrate doubles. There is no need for a cold compressor $\mathrm{C} 2$.

The main heat exchanger has to handle more flow, which can be accomplished with the same passages for more pressure drop. This in turn requires somewhat more bhp to be used by the compressor motors. On the other hand, the passages designated for vacuum flow at a later date may be used.

Wet Expander El can be built to accomodate the extra $70 \%$ flowrate. Expander E2 either may be a larger turbine or two identical units may be used in parallel, if the expander is a reciprocating device.

If appears that the cost of the refrigerator will increase only slightly, since an extra compressor will offset the cost of the cold gas compressor. It is clear that the refrigerator for $4.5^{\circ} \mathrm{K}$ initial operation will cost considerably less than those for $2^{\circ} \mathrm{K}$ operation because of the absence of vacuum pumps. In Section XI, cost of a single $2^{\circ} \mathrm{K}$ refrigerator is estimated to be $\$ 1.09 \times 10^{6}$. This refrigerator costs approximately $\$ 735,000$ without vacuum pumps and we may assume that the refrigerators for initial operation at $4.5^{\circ} \mathrm{K}$ and 15 TEV will cost approximately $\$ 800,000$ each. Savings in capital investment for refrigerators will then be $32 \mathrm{x}$ $1.09-16 \times .80=\$ 22.1 \times 10^{6}$.

In addition to capital investment savings, only 16 of the 32 refrigerator facilities need to be put in. All costs associated with the furnishing of 16 buildings with utilities and site work can be postponed to a later date. 
IX. MAGNET OPERATION WITH SYNCHROTRON RADIATION REMOVED AT $4.5^{\circ} \mathrm{K}$

The synchrotron radiation which represents approximately twothirds of the refrigerator thermal load $(825 \mathrm{~W} \times 0.667=550 \mathrm{~W})$ could be removed at the $4.5^{\circ} \mathrm{K}$ temperature level rather than at the $2.0^{\circ} \mathrm{K}$ level. The process points and the flowsheet for this mode of operation are shown in Table IV and Figure 12 respectively.

Shifting the removal of the $550 \mathrm{~W}$ of synchrotron radiation to $4.5^{\circ} \mathrm{K}$ results in a $44 \%$ savings in power as shown in Table $V$. The large power saving results from a two-thirds reduction in flowrate through the low pressure vacuum pumps, P1. The major changes required to the process include the addition of a third expander, E3, and an additional heat transfer circuit to HX III. It should be noted that in an optimized process, Expander $E 1$ and $E 3$ will be combined in one machine. In addition, the magnet design would be modified to permit $4.5^{\circ} \mathrm{K}$ helium to circulate in a beam tube circuit.

Capital costs are discussed in Section XI. 


\section{IABLE IV}

PROCESS POINTS FOR REFRIGERATOR AT STEADY STATE OPERATION SYNCHROTRON RADIATION REMOVED AT $4.5^{\circ} \mathrm{K}$

\begin{tabular}{|c|c|c|c|c|}
\hline Point & $\begin{array}{c}\text { Pressure } \\
\text { ata } \\
\end{array}$ & $\begin{array}{l}\text { Temperature } \\
{ }^{\circ} \mathrm{K} \\
\end{array}$ & $\begin{array}{c}\text { Enthalpy } \\
\mathrm{J} / \mathrm{gr} \\
\end{array}$ & $\begin{array}{c}\text { Flowrate } \\
\text { g/sec }\end{array}$ \\
\hline 1 & 8.00 & 300.00 & 1575.00 & 107.71 \\
\hline 2 & 7.99 & 70.00 & 379.70 & 107.71 \\
\hline 3 & 7.98 & 18.10 & 103.20 & 107.71 \\
\hline $\mathrm{BA}$ & 7.98 & 18.10 & 103.20 & 78.74 \\
\hline 4 & 7.97 & 11.20 & 61.30 & 78.74 \\
\hline 5 & 7.97 & 11.20 & 61.30 & 59.19 \\
\hline 6 & 7.96 & 6.00 & 20.07 & 20.78 \\
\hline $6 \mathrm{~A}$ & 7.96 & 6.00 & 20.07 & 38.41 \\
\hline $6 \mathrm{~B}$ & 7.96 & 6.00 & 20.07 & 59.19 \\
\hline 7 & 0.60 & 3.72 & 14.51 & 20.78 \\
\hline $7 \mathrm{~A}$ & 1.20 & 4.42 & 15.62 & 38.41 \\
\hline 8 & 0.59 & 3.72 & 12.84 & 20.78 \\
\hline 9 & 0.100 & 2.50 & 26.66 & 8.09 \\
\hline 10 & 0.098 & 3.26 & 30.95 & 8.09 \\
\hline $10 \mathrm{~A}$ & 1.200 & 4.424 & 29.44 & 38.41 \\
\hline 11 & 0.096 & 10.70 & 70.10 & 8.09 \\
\hline $11 \mathrm{~A}$ & 1.100 & 10.70 & 68.55 & 38.41 \\
\hline 12 & 0.094 & 16.30 & 99.14 & 8.09 \\
\hline 13 & 0.092 & 67.64 & 365.93 & 8.09 \\
\hline 14 & 0.090 & 290.43 & 1523.34 & 8.09 \\
\hline 15 & 0.100 & 2.50 & 4.036 & 12.69 \\
\hline 16 & 0.100 & 2.20 & 3.196 & 12.69 \\
\hline $16 \mathrm{~A}$ & 0.100 & 2.20 & 3.196 & 6.35 \\
\hline 17 & 0.030 & 1.99 & 24.87 & 12.69 \\
\hline $17 \mathrm{~A}$ & 0.030 & 1.99 & 24.87 & 6.35 \\
\hline 18 & 0.029 & 2.25 & 25.71 & 12.69 \\
\hline 19 & 0.060 & 3.40 & 31.04 & 12.69 \\
\hline 20 & 0.058 & 10.70 & 70.10 & 12.69 \\
\hline 21 & 0.056 & 16.30 & 99.14 & 12.69 \\
\hline 22 & 0.054 & 67.64 & 365.93 & 12.69 \\
\hline 23 & 0.056 & 290.43 & 1523.34 & 12.69 \\
\hline 24 & 7.97 & 11.20 & 61.00 & 19.55 \\
\hline $24 \mathrm{~A}$ & 7.00 & 18.00 & 103.20 & 19.55 \\
\hline
\end{tabular}


TABLE IV continued...

\begin{tabular}{|c|c|c|c|c|c|}
\hline Point & $\begin{array}{c}\text { Pressure } \\
\text { ata } \\
\end{array}$ & $\begin{array}{c}\text { Temperature } \\
{ }^{\circ} \mathrm{K} \\
\end{array}$ & $\begin{array}{c}\text { Enthalpy } \\
\mathrm{J} / \mathrm{gr} \\
\end{array}$ & $\begin{array}{c}\text { Flowrate } \\
g / \text { sec } \\
\end{array}$ & $y$ \\
\hline 25 & -7.00 & 18.00 & 103.20 & 48.52 & \\
\hline 26 & 1.03 & 10.70 & 68.80 & 48.52 & \\
\hline $26 \mathrm{~A}$ & 1.03 & 10.70 & 68.69 & 86.93 & \\
\hline 27 & 1.02 & 16.30 & 98.37 & 86.93 & \\
\hline 28 & 1.01 & 67.64 & 366.12 & 86.93 & \\
\hline 29 & 1.00 & 290.43 & 1523.34 & 86.93 & \\
\hline 30 & 5.00 & 5.00 & 14.32 & 3.54 & \\
\hline 31 & 4.99 & 10.70 & 62.33 & 3.54 & \\
\hline 32 & 4.98 & 16.30 & 95.03 & 3.54 & \\
\hline 33 & 4.97 & 67.64 & 366.82 & 3.54 & \\
\hline 34 & 4.96 & 290.43 & 1524.34 & 3.54 & \\
\hline 35 & 7.98 & 18.10 & 103.20 & 28.97 & \\
\hline 36 & 7.00 & 18.00 & 103.20 & 28.97 & \\
\hline 37 & 1.00 & 300.00 & 1573.00 & 107.71 & \\
\hline 38 & 8.00 & 300.00 & 1575.00 & 107.71 & \\
\hline 39 & - & - & - & 0 & \\
\hline 40 & 0.100 & 2.20 & 3.196 & 3.17 & \\
\hline $40 \mathrm{~A}$ & 0.100 & 2.20 & 3.196 & 3.17 & \\
\hline 41 & 0.035 & 2.04 & 3.196 & 3.17 & \\
\hline $41 \mathrm{~A}$ & 0.035 & 2.04 & 3.196 & 3.17 & \\
\hline 42 & 0.030 & 1.99 & 24.87 & 3.17 & \\
\hline $42 \mathrm{~A}$ & 0.030 & 1.99 & 24.87 & 3.17 & \\
\hline 43 & - & - & - & 0 & \\
\hline $43 A$ & - & - & - & 0 & \\
\hline 44 & - & - & - & 0 & Quencin \\
\hline $44 A$ & - & - & - & 0 & Recovery \\
\hline 45 & - & - & - & 0 & \\
\hline 46 & - & - & - & 0 & \\
\hline 47 & - & - & - & 0 & $\mathrm{~N}_{2}$ \\
\hline 48 & - & - & - & 0 & $\mathrm{~N}_{2}$ \\
\hline
\end{tabular}




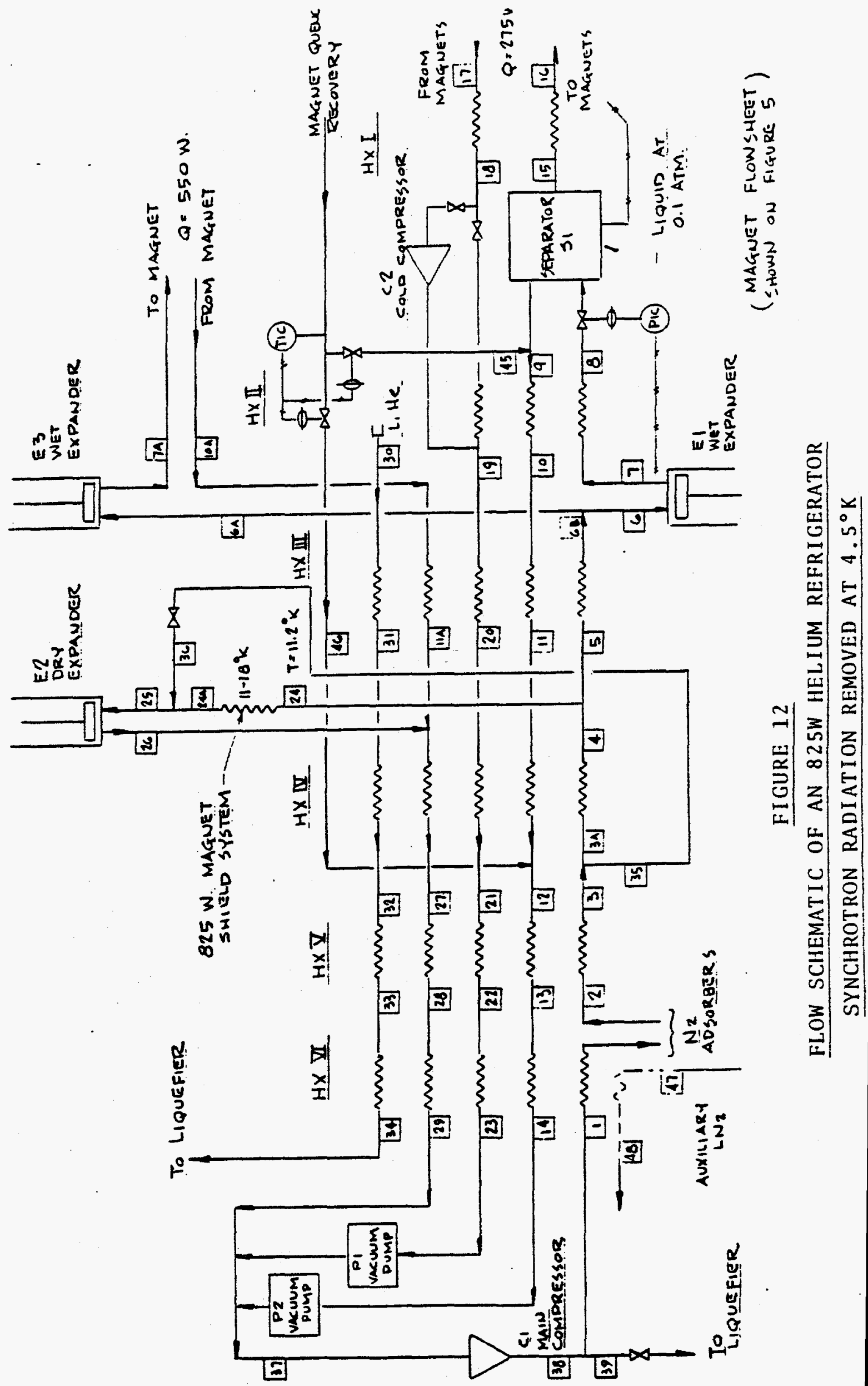


POWER REQUIREMENTS IN KW FOR PROCESSES REMOVING SYNCHROTRON RADIATION AT 2 AND $4.5^{\circ} \mathrm{K}$

Synchrotron Radiation Removed at

\begin{tabular}{cr}
$2^{\circ} \mathrm{K}$ & $4.5^{\circ} \mathrm{K}$ \\
\cline { 2 - 2 } 313 & 306 \\
391 & 131 \\
187 & 63 \\
3 & 3 \\
\hline 894 & 503
\end{tabular}

Total (KW)

Compressor, $\mathrm{Cl}$

Vacuum Pump, P1

894

503 
$X$. MAGNET OPERATION AT $2.5^{\circ} \mathrm{K}$

Assume that maximum magnet field strength of a $6 \mathrm{~T}$ magnet is a function of temperature as follows:

$$
H=8.0-.8(T-2.0) \text { Tesia }
$$

where $T=$ magnet temperature in ${ }^{\circ} \mathrm{K}$

Instead of operating at $2.0^{\circ} \mathrm{K}$ with the associated requirements of a large number of vacuum pumps and high power, it might be advantageous to consider operation at $2.5^{\circ} \mathrm{K}$. With a peak field of $7.6 \mathrm{~T}$ total length of the ring will be reduced very significantly.

Table VI shows the process points for a refrigerator system operating at $2.5^{\circ} \mathrm{K}$. The process points correspond to those shown on Figure 6 . The following should be noted:

a) The refrigerator operates with warm vacuum pumps only. A preliminary calculation showed that a cold gas pump operating at an inlet temperature and pressure of $4.25^{\circ} \mathrm{K}$ and .1 ata respectively puts in almost $600 \mathrm{~W}$ of heat in delivering gas at. 2 ata. All of this heat has to be removed at the $4^{\circ} \mathrm{K}$ temperature level, and it appears that the cold gas pump does not provide a significant advantage over a warm vacuum pump.

b) The refrigerator does not require Iiquid helium flow from a central liquefier. This is accomplished by increasing the compressor discharge pressure from 8 to 13.5 ata. This increase results in more power required locally, and less at the central liquefier.

c) The absence of liquid helium as auxiliary refrigeration requires an increase in flow to the warm Expander, E2. This increase will most likely make E2 a turbine. The assumed pressure levels of streams 25 and 26 are not optimum for a turbine and the process probably needs to be modified. 
d) Vacuum pump, P2, is not required.

e) Power required by the refrigerator is $740 \mathrm{KW}$. This is approximately $150 \mathrm{KW}$ less than the refrigerator supplying refrigeration at $2^{\circ} \mathrm{K}$ (Table $\mathrm{V}$ ). The total difference is greater by approximately $90 \mathrm{KW}$, since the $2^{\circ} \mathrm{K}$ refrigerator required approximately 100 liters per hour of liquid from a central liquefier. 
$\underline{\text { TABLE VI }}$

PROCESS POINTS FOR MAGNET OPERATION AT $2.5^{\circ} \mathrm{K}$ (HELIUM REFRIGERATOR FLOWSHEET FIGURE 5)

\begin{tabular}{|c|c|c|c|c|}
\hline Point & $\begin{array}{c}\text { Pressure } \\
\text { ata } \\
\end{array}$ & $\begin{array}{l}\text { Temperature } \\
{ }^{\circ} \mathrm{K} \\
\end{array}$ & $\begin{array}{c}\text { Enthalpy } \\
\mathrm{J} / \mathrm{gr} \\
\end{array}$ & $\begin{array}{c}\text { Flowrate } \\
\text { g/sec } \\
\end{array}$ \\
\hline 1 & 13.5 & 300 & 1577.0 & 149.19 \\
\hline 2 & 13.3 & 80 & 433.0 & 149.19 \\
\hline 3 & 13.2 & 18.05 & 99.9 & 149.19 \\
\hline $3 \mathrm{~A}$ & 13.2 & 18.05 & 99.9 & 88.44 \\
\hline 4 & 13.1 & 12.25 & 63.64 & 88.44 \\
\hline 5 & 13.1 & 12.25 & 63.64 & 65.69 \\
\hline 6 & 13.0 & 8.00 & 32.07 & 65.69 \\
\hline 7 & 2.0 & 5.047 & 23.91 & 65.69 \\
\hline 8 & 2.0 & 5.047 & 18.25 & 65.69 \\
\hline 9 & 1.2 & 4.42 & 29.94 & 27.78 \\
\hline 10 & 1.2 & 4.95 & 34.28 & 27.78 \\
\hline 11 & 1.18 & 10.7 & 68.40 & 27.78 \\
\hline 12 & 1.17 & 14.4 & 89.17 & 27.78 \\
\hline 13 & 1.15 & 78.5 & 422.6 & 27.78 \\
\hline 14 & 1.12 & 290.0 & 1521.0 & 27.78 \\
\hline 15 & 1.20 & 4.42 & 10.80 & 37.91 \\
\hline 16 & 1.20 & 2.60 & 4.90 & 37.91 \\
\hline $16 \mathrm{~A}$ & 1.20 & 2.60 & 4.90 & 18.96 \\
\hline 17 & 0.10 & 2.496 & 26.66 & 37.91 \\
\hline 18 & 0.10 & 4.25 & 32.56 & 37.91 \\
\hline 19 & 0.100 & 4.95 & 39.73 & 37.91 \\
\hline 20 & 0.096 & 10.70 & 70.09 & 37.91 \\
\hline 21 & 0.094 & 14.40 & 88.87 & 37.91 \\
\hline 22 & 0.093 & 78.50 & 422.30 & 37.91 \\
\hline 23 & 0.090 & 290.00 & 1521.0 & 37.91 \\
\hline 24 & 13.1 & 12.25 & 63.64 & 22.75 \\
\hline $24 \mathrm{~A}$ & 12.5 & 18.00 & 99.90 & 22.75 \\
\hline 25 & 12.5 & 18.00 & 99.90 & 83.50 \\
\hline 26 & 1.60 & 10.40 & 65.90 & 83.50 \\
\hline 27 & 1.40 & 14.40 & 89.17 & 83.50. \\
\hline 28 & 1.15 & 78.50 & 422.60 & 83.50 \\
\hline 29 & 1.10 & 290.00 & 1521.0 & 83.50 \\
\hline
\end{tabular}


TABLE VI continued..

\begin{tabular}{|c|c|c|}
\hline Point & $\begin{array}{c}\text { Pressure } \\
\text { ata }\end{array}$ & $\begin{array}{c}\text { Temperature } \\
{ }^{\circ} \mathrm{K}\end{array}$ \\
\hline 30 & - & - \\
\hline 31 & - & - \\
\hline 32 & - & - \\
\hline 33 & - & - \\
\hline 34 & - & - \\
\hline 35 & 13.2 & 15.05 \\
\hline 36 & 12.5 & 18.00 \\
\hline 37 & 1.0 & 300.00 \\
\hline 38 & 13.5 & 300.00 \\
\hline 39 & - & - \\
\hline 40 & 1.2 & 2.60 \\
\hline $40 \mathrm{~A}$ & 1.2 & 2.60 \\
\hline 41 & 0.11 & 2.536 \\
\hline $41 \mathrm{~A}$ & 0.11 & 2.536 \\
\hline 42 & 0.10 & 2.496 \\
\hline $42 \mathrm{~A}$ & 0.10 & 2.496 \\
\hline 43 & - & - \\
\hline $43 \mathrm{~A}$ & - & - \\
\hline 44 & - & - \\
\hline $44 \mathrm{~A}$ & - & - \\
\hline 45 & - & - \\
\hline 46 & - & - \\
\hline 47 & 1.14 & 78.5 \\
\hline 48 & 1.10 & 290.0 \\
\hline
\end{tabular}

Enthalpy
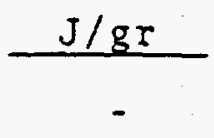

$-$

$-$

-

$\begin{array}{cc}99.90 & 60.75 \\ 99.99 & 60.75 \\ 1573.0 & 149.19 \\ 1577.0 & 149.19 \\ - & 0 \\ 4.90 & 9.48 \\ 4.90 & 9.48 \\ 4.90 & 9.48 \\ 4.90 & 9.48 \\ 26.66 & 9.48 \\ 26.66 & 9.48 \\ - & 0 \\ - & 0 \\ - & 0 \\ - & 0 \\ - & 0 \\ - & 0\end{array}$

32.78 16.2 451.74

Flowrate

$\mathrm{g} / \mathrm{sec}$

0

0

0

0

0

75

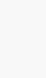


$X I$. COST DATA

A. Capital Investment

A cost analysis has been made for the following cases:

1) 32 refrigerator stations each capable of providing $825 \mathrm{~W}$ at $2.0^{\circ} \mathrm{K}$

2) 32 refrigerator stations providing $275 \mathrm{~W}$ at $2.0^{\circ} \mathrm{K}$ and $550 \mathrm{~W}$ at $4.5^{\circ} \mathrm{K}$

3) 32 refrigerator stations providing $825 \mathrm{~W}$ at $2.5^{\circ} \mathrm{K}$

It should be noted that case 3 above is not quite correct with respect to heatleak. At $2.5^{\circ} \mathrm{K}$, maximum field of the magnets is probably 7.5 Tesla and the ring then should be some $7 \%$ longer in length. If so, the 32 refrigerators should put out roughly $2.5 \%$ more refrigeration to pick up the additional heatleak from the longer ring. This effect has been ignored.

In order to arrive at a cost number for the refrigerators, quotes have been obtained for the major components. To arrive at the cost of the complete refrigerator, a multiplier of 1.80 has been used to account for all the other things necessary to provide a complete fabricated cold box.

This multiplier is a CCI experience number and may vary some for other vendors of helium refrigeration equipment. Included in this multiplier is profit, contingency, engineering, instrumentation, warm and cold piping, etc..

The same multiplier has not been used for the vacuum pumps necessary to generate the required low pressure, because cold box construetion is only slightly affected by the use of these pumps. Multiplier used for the acquired cost of the pumps is 1.3 .

Table VII shows the purchased cost in thousands of dollars of a single refrigerator for cases 1,2 , and 3 . 
TABLE VII

\section{PURCHASED COST OF A SINGLE REFRIGERATOR}

Case

Compressor

Cold Box Components:

Heat Exchangers

Adsorbers

Expander El

Expander E2

Expander E3

Cold Gas Pump C2

Subtotal (a)

Multiplier

Subtotal (b)

Vacuum Pumps:

$\mathrm{PI}$

P2

Subtotal (c)

Multiplier

Subtotal (d)

Total (b \& d)

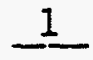

95

80

60

35

45

$-\cdot$

80

395

1.8

711

200

$\frac{90}{290}$

1.3

377

1088

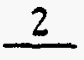

95

210

85

60

35

45

45

35

80

$\frac{80}{435}$

435

1.8

783

145

\begin{tabular}{|c|c|}
\hline 50 & $\cdots$ \\
\hline 120 & 145 \\
\hline 1.3 & 1.3 \\
\hline 156 & 190 \\
\hline 939 & 973 \\
\hline
\end{tabular}

It should be noted that case 3 does not compare on an equal base with cases 1 and 2 , because the refrigerator of case 3 does not require liquid helium from a central liquefier. If this liquid were to be provided, compressor flow will be reduced substantially. The allowance of $100 \mathrm{l} / \mathrm{hr}$ of liquid helium is probably worth $\$ 100,000-150,000$ and would bring subtotals $a$ and $b$ in case 3 to the lowest value. 
It should also be noted that the refrigerators have not been sized with a safety factor. It has been assumed that extra requirements for refrigeration would be met by providing extra liquid helium from the central liquefier. Also the extra refrigeration will be primarily supplied to the intermediate temperature shield. In that case $1 \mathrm{~g} / \mathrm{sec}$ of liquid helium used supplies approximately $80 \mathrm{~W}$ of refrigeration to the shield. Table VII shows that refrigeration equipment capable of providing the necessary refrigeration at $2.0^{\circ} \mathrm{K}$ costs approximately $50 \%$ more than that operating at $4.5^{\circ} \mathrm{K}$. Also, because of the required low pressure drop in the magnets, number of refrigerators will be 32 rather than 12 for the $4.5^{\circ} \mathrm{K}$ operation case. Therefore the individual cost of the refrigerators will be relatively higher. If we assume that the smaller refrigerator costs $(.375)^{.7}=.50$ of a full sized refrigerator, the cost comparison of refrigerators for the $\mathrm{D}$ magnet operating at $4.5^{\circ} \mathrm{K}$ and $2.0^{\circ} \mathrm{K}$ will be as shown in Table VIII.

It appears that the cost of the refrigeration system $j u s t$ about doubles when going from 4.5 to $2.0^{\circ} \mathrm{K}$.

TABLE VIII

NORMALIZED REFRIGERATOR COSTS FOR D MAGNETS OPERATING AT $4.5^{\circ} \mathrm{K}$ AND $2.0^{\circ} \mathrm{K}$

Temperature $\left({ }^{\circ} \mathrm{K}\right)$

Number of Refrigerators

Cost of Refrigerator

Cost of Vacuum Pumps

Total Cost

$\begin{array}{cc}4.5 & \frac{2.0}{12} \\ 1 & 32 \\ - & .5 \\ 12 & \frac{.25}{24}\end{array}$


B. Utility Requirements

The primary utility requirements for the refrigerators are electrical power and cooling water. These requirements are tabulated below for each of the 3 cases defined on page 41 .

B.I Power Requirements

TABLE IX

POWER REQUIREMENTS (KW/REFRIGERATOR)

Case

1

$\underline{2}$

3

Main Compressor $\mathrm{C} 1$

313

306

Vacuum Pump P1

391

130

298

Vacuum Pump P2

186

Cold Gas Compressor C2

$\frac{3}{893}$

64

Total

\section{2}

893

$\frac{3}{503}$

745

\section{B. 2 Cooling Water Requirements}

The main compressor and the vacuum pumps are oil lubricated screw machines. The heat of compression. is removed from the process gas by the lubrication oil which in turn is cooled against water in an external oil-water heat exchanger. For the purpose of this analysis, a closed loop cooling water system with a cooling tower has been assumed. The cooling water flowrates in $T a b l e ~ X$ are based on a cooling water temperature of $95^{\circ} \mathrm{F}$ and a temperature rise of $15^{\circ} \mathrm{F}$. 
TABLE X

COOLING WATER REQUIREMENTS (GPM)

$\begin{array}{lrrr}\text { Case } & 1 & 2 & 3 \\ \text { Main Compressor C1 } & 150 & 150 & 200 \\ \text { Vacuum Pump P1 } & 180 & 60 & 140 \\ \text { Vacuum Pump P2 } & \frac{80}{410} & \frac{30}{240} & - \\ \text { Total } & & \end{array}$

It should be noted that the refrigeration cycles have not been optimized. Some improvement in the utility requirements may be expected for an optimization program. 


\section{Space Requirements}

Figure 13 shows a facility arrangement for one refrigerator station for Case 1 . An enclosed area $40 \mathrm{ft} x$ $44 \mathrm{ft}$ will house the entire refrigerator station and will provide adequate space for routine maintenance, serviling and replacement of equipment, such as heat exchanger bundles. Case 1 requires the greacest floor area and hence is the controliing case. Case 2 and Case 3 could easily be accomodated in the $40 \mathrm{ft} \times 44 \mathrm{ft}$ area.

It is conceivable that initially refrigeration equipment may be provided to operate the collider at 15 TEV and magnets at $4.5^{\circ} \mathrm{K}$. This deletes the requirement for vacuum pumps initially. 
$-B 47-$

FIG. 13

CASE 1 EQUIPMENT LAYOUT

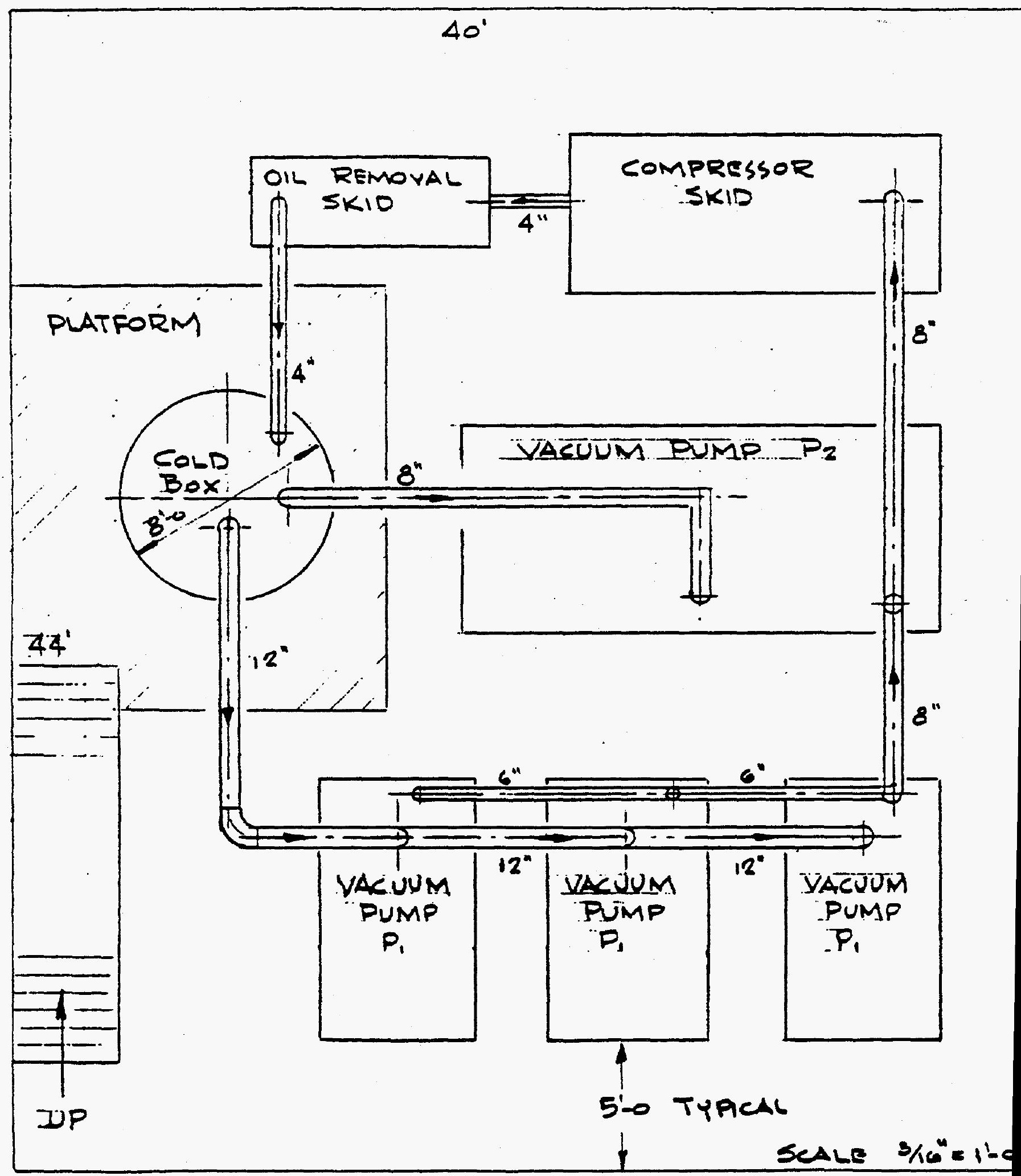


D. Size of Magnet Cryostat

Figure 14 shows the cryostat of the $D$ magnet (reference Fermilab Drawing 0102-ME-212366-Rev. A).

Figure 14 also shows the concept of a cryostat which will accomodate the larger magnet cross-section required for operation at $8 \mathrm{~T}$ and $2.0^{\circ} \mathrm{K}$.

The following should be noted:

1) The liquid helium transfer line carrying liquid around the ring is carried through the iron of the magnets. The line needs to be insulated from the $2.0^{\circ} \mathrm{K}$ environment. This is easily accomplished since the line normally is at $5.0^{\circ} \mathrm{K}$.

2) The $4.5^{\circ} \mathrm{K}$ vapor return line has disappeared. Instead vapor is carried between iron OD and magnet cryostat ID. Space allowance for this is $1 \mathrm{~cm}$ radially.

3) The intermediate shield line is now located on the outside of the shield. This saves space and does not affect overall heatleak very much. The line size is reduced to $2 "$, which allows for reasonable pressure drop, even in case of one refrigerator dropping out. At that time the adjacent refrigerators take up the load.

4) The 1iquid $\mathrm{N}_{2}$ remains the same on the assumption that the $\mathrm{N}_{2}$ distribution system has not changed.

Table XI shows a comparison of various diameters for the superfluid versus $4.5^{\circ} \mathrm{K}$ magnet operation, as shown in Figure 14. If we can achieve the various dimensions, cryostat outside diameter only grows by $3.95 \mathrm{~cm}$ or 1.56 inches, while $\mathrm{N}_{2}$ cooled suield and intermediate temperature shield only grow by approximately $5 \mathrm{~cm}$ or $2^{\prime \prime}$ each. 
$-849-$

$$
\frac{\text { COMPARISON FIG. } 14}{8 T \cdot 2^{\circ} \mathrm{K} \text { AND } 6 T \cdot 4.5^{\circ} \mathrm{K}}
$$
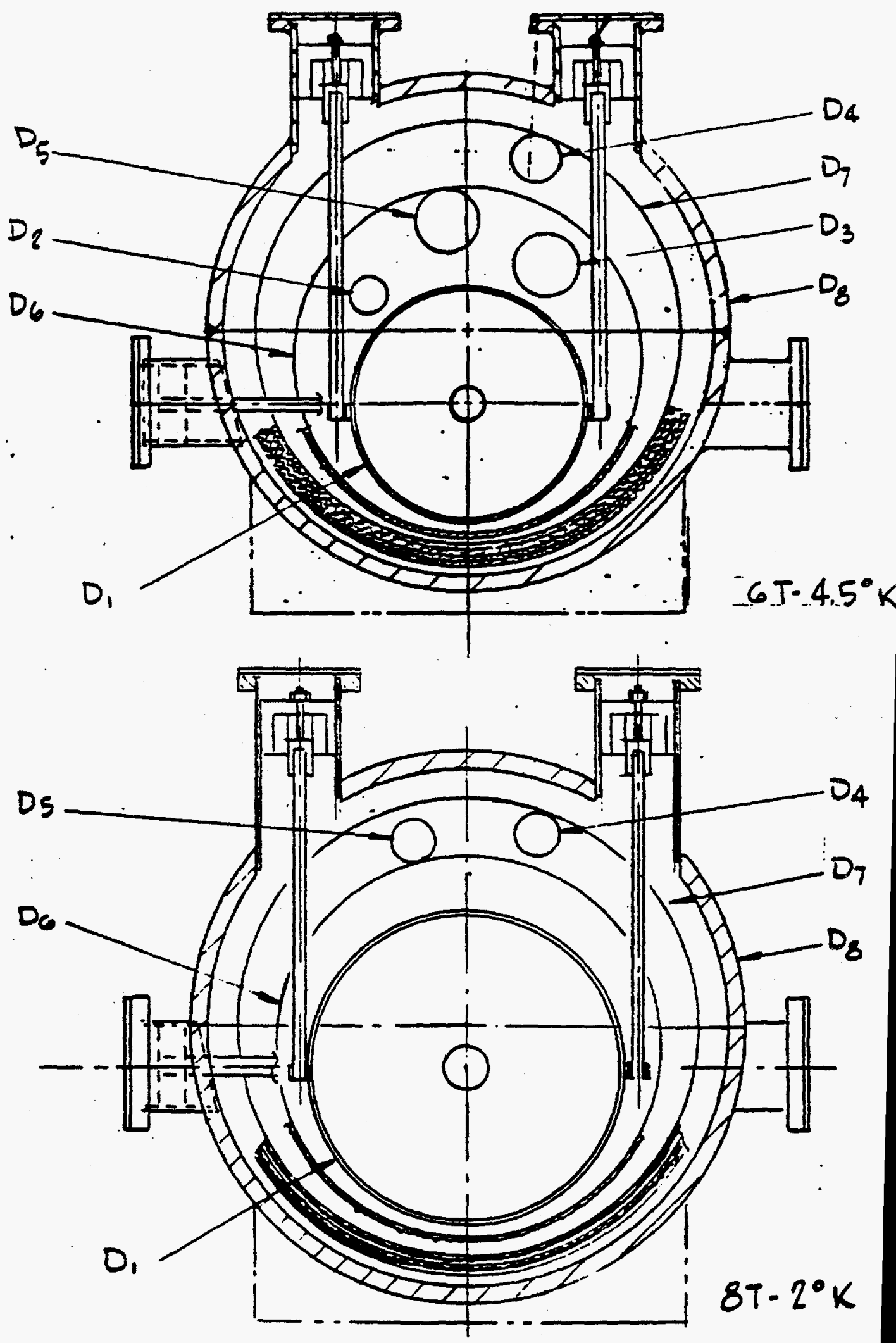
TABLE XI

COMPARISON OF PIPE AND VESSEL DIAMETERS FOR $6 \mathrm{~T}-4.5^{\circ} \mathrm{K}$ AND $8 \mathrm{~T}-2.0^{\circ} \mathrm{K}$ MAGNETS (IN CM)

$\begin{array}{lcc} & \frac{6 \mathrm{~T}-4.5^{\circ} \mathrm{K}}{27.3} & \frac{8 \mathrm{~T}-2.0^{\circ} \mathrm{K}}{35.7} \\ \text { DI } & 3.89 & 0 \quad * \\ \text { D2 } & 6.88 & 0 \quad * * \\ \text { D3 } & 5.72 & 5.72 \\ \text { D4 } & 7.62 & 5.08 \\ \text { D5 } & 40.64 & 45.86 \\ \text { D6 } & 40.53 & 54.75 \\ \text { D7 } & 60.96 & 64.91 \\ \text { D8 } & \\ \text { Dithin the iron envelope. } & \\ \text { now part of the magnet vessel. }\end{array}$




\section{REFERENCES}

1. Lambertson, G.R., Gilbert, H.S., and Rechen, J.B., Final Report on the Experimental Superconducting Synchrotron (ESCAR), DOE Contract No. W-7405-ENG-48, March 1, 1979

2. Vander Arend, P.C. and Fowler, W.D., S.C. Accelerator Magnet Coding Systems, IEEE Transactions on Nuclear Science, Vol. NS20, No. 3, 1973

3. Hassenzah1, W.V., The Effect on Magnet Material Requirements of Increasing the Design "D" Field From 6 to $8 \mathrm{~T}$ by Operating at a Temperature of About $2^{\circ} \mathrm{K}, \mathrm{SSC}-\mathrm{MAG}-37$, May 28, 1985 
$-B 52$

Blank Page 


\section{APPENDIX A}

\section{MAGNET QUENCH RECOVERY}

As sumptions:

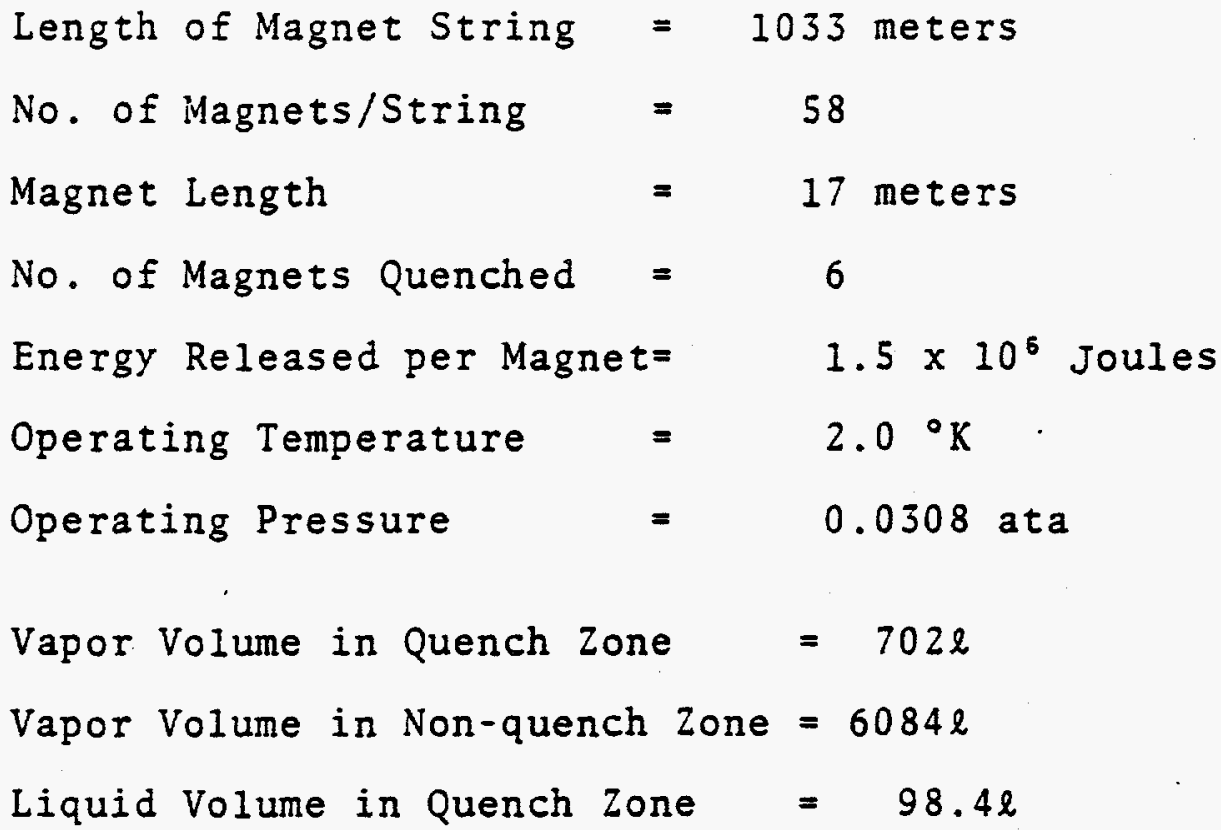

Mass LHe Vaporized During Quench

$=14,320$

Mass of Vapor in Quench Zone Prior to Quench

$=\quad 550$

Mass of Vapor in Non-quench Zone Prior to Quench $=4,760$

Mass of LHe in Non-quench Zone Prior to Quench $=124,160$

Mass of LHe per Magnet Prior to Quench

$=2,387$ 
The following calculations are based on the quench model described on page 24 of this report. Figure A-I shows the process circuits for magnet quench recovery.

a) Six magnets in a magnet string are driven normal. The thermal energy released $Q_{R}$, is,

$$
Q_{R}=\left(1.5 \times 10^{6} \mathrm{~J} / \text { magnet }\right)(6 \text { magnets })=9.0 \times 10^{6} \mathrm{Joules}
$$

This magnet string is isolated (Figure A-1) from the satellite refrigerator and the other three magnet strings.

b) 14,320 grams of LHe in the 6 quenching magnets are vaporized: Assuming only the heat of vaporization is supplied to the liquid, and that the subsequent vaporization results in an isentropic compression of the helium vapor in the magnet string, the vapor will equilibrate at approximately 0.3 ata and $5.11^{\circ} \mathrm{K}$. The before and after conditions are as follows:

\begin{tabular}{|c|c|c|}
\hline & $\begin{array}{l}\text { Before } \\
\text { Quench }\end{array}$ & $\begin{array}{l}\text { Following } \\
\text { Isentropic } \\
\text { Compression } \\
\end{array}$ \\
\hline Pressure, ata & 0.031 & .300 \\
\hline Temperature, ${ }^{\circ} \mathrm{K}$ & 2.0 & 5.1 \\
\hline Enthalpy, J/gm & 24.91 & 40.07 \\
\hline Entropy, $\mathrm{J} / \mathrm{gm}^{\circ} \mathrm{K}$ & 12.63 & 12.63 \\
\hline Specific volume, $c c / g m$ & 1278 & 333 \\
\hline Mass of He Vapor, gms & 5310 & 19630 \\
\hline Vapor Void Volume,ce & $6.79 \times 10^{6}$ & $6.79 \times 10^{6}$ \\
\hline Vapor Volume, cc & $6.79 \times 10^{6}$ & $6.54 \times 10^{6}$ \\
\hline
\end{tabular}




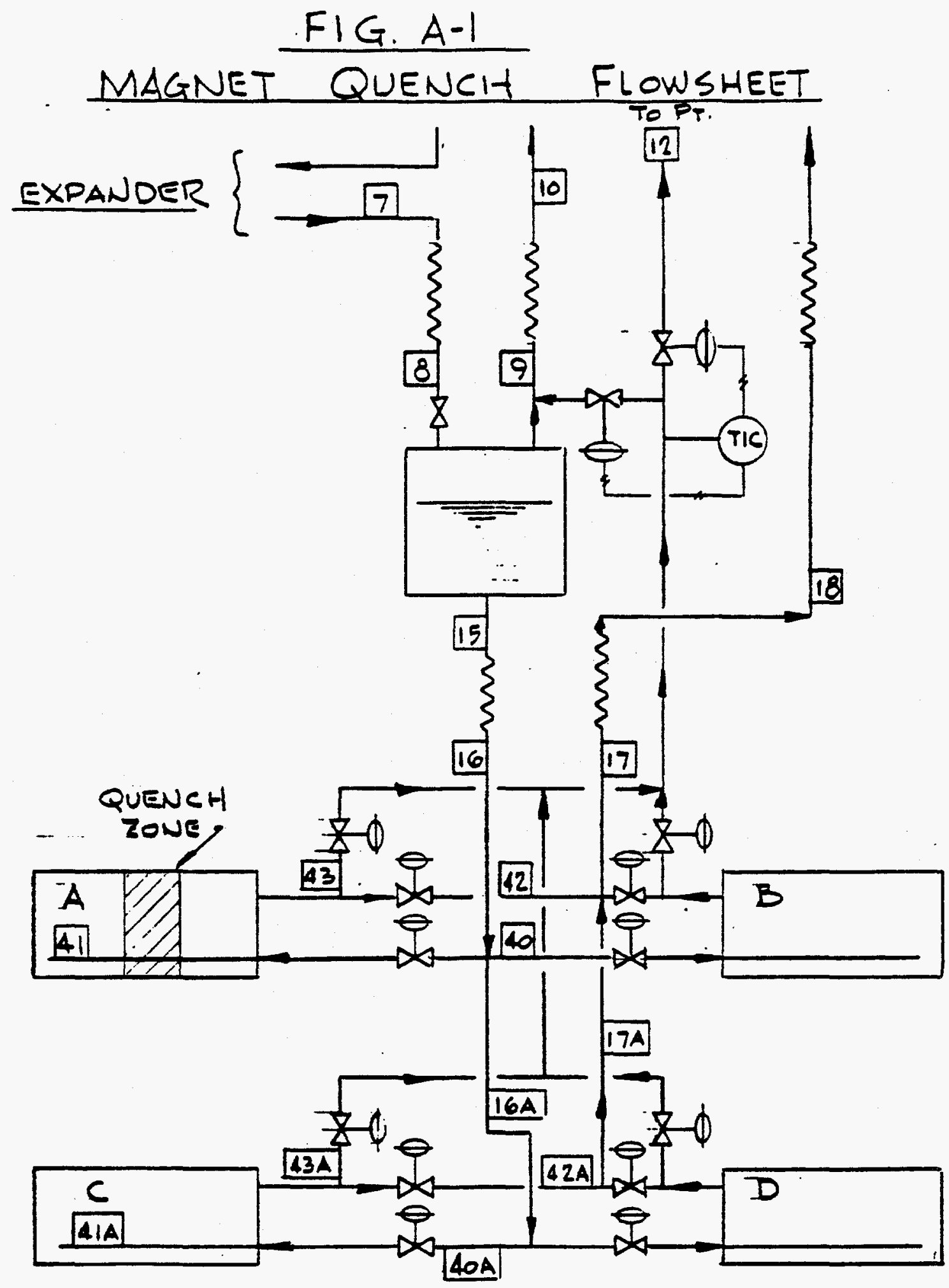


The $6.54 \times 10^{6} \mathrm{cc}$ is a little less than $6.79 \times 10^{6} \mathrm{cc}$ available which means the 0.3 ata and $5.1^{\circ} \mathrm{K}$ are slightly higher than needed to produce a balance.

e) To this point, the only heat transferred from the magnet is that required to vaporize the LHe in the 6 quenching magnets $Q_{v}$,

$$
q_{q}=14320 \mathrm{gms}(24.91-1.63) \mathrm{J} / \mathrm{gm}=0.33 \times 10^{6} \mathrm{Joules}
$$

Assume that there is no heat transferred from the quenched magnets, but that heat transfers from the helium vapor to the iron and LHe in the non-quenched magnets establishing an equilibrium between the iron, coils, helium vapor and LHe. The change in internal energy $(\Delta E)$ of the helium vapor equals the change in internal energy of the LHe plus the change in internal energy of the iron;

$$
\Delta E_{\mathrm{VHe}}=\Delta \mathrm{E}_{\mathrm{LHe}}+\Delta \mathrm{E}_{\mathrm{I}} \quad \text { (iron) }
$$

A trial-and-error solution yields a final equilibrium condition of $2.17^{\circ} \mathrm{K}$ and 0.05 ata. The heat balance is as follow's:

$$
\begin{aligned}
\Delta E_{\mathrm{VHe}}=18,280 \mathrm{gms}(29.92-21.10) \mathrm{J} / \mathrm{gm} & =161,230 \mathrm{~J} \\
\Delta \mathrm{E}_{\mathrm{LHe}}=124,160 \mathrm{gms}(2.80-1.63) \mathrm{J} / \mathrm{gm} & =145,270 \mathrm{~J} \\
\Delta \mathrm{E}_{\mathrm{I}}=5.04 \times 10^{8} \mathrm{gms}(.000216-.000181) \mathrm{J} / \mathrm{gm} & =\frac{17,040 \mathrm{~J}}{\Delta \mathrm{E}_{\mathrm{LHe}}+\Delta \mathrm{E}_{\mathrm{I}}}=162,910 \mathrm{~J}
\end{aligned}
$$


The quenched magnet string is at $2.17^{\circ} \mathrm{K}$ and .05 ata. If magnet quench recovery commences, the magnet string will be maintained at $0.1-0.2$ ata. If not, and the quenched magnet remains isolated, heat will be transferred from the quenched magnets to the vapor around them resulting in a pressure increase.

Quench recovery is accomplished by vaporizing liquid helium added to the quenched magnet string and recoverin the cold vapor via the 0.1 ata refrigerator circuit. Additional refrigeration could be supplied by $4.5^{\circ} \mathrm{K}$ LHe and returning that amount of vapor to the liquefier. The recovery requires that the $9 \times 10^{6}$ Joules of quench energy be removed, and the magnet returned to the initial superfluid condition, $2.0^{\circ} \mathrm{K}$ and 0.031 ata.

LHe will immediately vaporize when it reaches the warm magnets and the vapor will warm quickly to the magnet temperature (approximately $32^{\circ} \mathrm{K}$ ). This warm vapor enters the non-quenched zone where the temperature is $2.2^{\circ} \mathrm{K}$ and immediately transfers heat to the cold magnet and associated LHe causing some vaporization. This results in a temperature 
wave traveling through the magnet string. For sometime following the initiation of quench recovery, the refrigerator will see only cold helium vapor returning from the quenched string. At some point the temperature wave will exit the magnet string and pass through the refrigerator, after which the cooldown will be completed.

The heat transfer coefficient between the He vapor and the magnet during cooldown was estimated to be $30 \mathrm{Btu} / \mathrm{hr} \cdot \mathrm{ft}^{2} \cdot{ }^{\circ} \mathrm{F}$ at a He vapor rate of $75 \mathrm{~g} / \mathrm{sec}$. At this rate the temperature wave fronts will initially be sharp. However, as the temperature wave travels through the magnet string, the wave fror. will spread out increasing the length of the temperature wave. For all practical purposes, the refrigeration available is the heat of vaporization of the LHe at 0.1 ata,

$$
\left.\left.\Delta H_{v}=\right) 26.66-4.036\right) \mathrm{J} / \mathrm{gm}=22.62 \mathrm{~J} / \mathrm{gm}
$$

At a LHe flowrate of $75 \mathrm{gm} / \mathrm{sec}, 1697 \mathrm{~J} / \mathrm{sec}$ is removed. Cooldown will then require 5300 seconds, or 1.47 hours (2745 1iters of LHe will be vaporized). The calculations required to define the character of this temperature wave are beyond the scope of this study and are not essential to the basic analysis. 
A calculation was made to estimate the maximum pressure which could be generated if all the magnets in a magnet string quenched simultaneously and the vapor and the iron reach thermal equilibrium. Consider a single magnet at equilibrium conditions of $2.0^{\circ} \mathrm{K}$ and .031 ata before quench, and having the following parameters:

Quench Heat

Vapor Volume before Quench

Vapor Mass before Quench

Liquid Volume before Quench

Liquid Mass before Quench

Total Mass of Helium

Internal Energy of LHe before Quench

Internal Energy of GHe before Quench

Mass of Magnet Iron
$=1.5 \times 10^{6}$ Joules

$=117$ liters

$=91.6 \mathrm{gms}$

$=16.4$ liters

$=2387 \mathrm{gms}$

$=2479 \mathrm{gms}$

$=1.63 \mathrm{~J} / \mathrm{gm}$

$=20.79 \mathrm{~J} / \mathrm{gm}$

$=9.70 \times 10^{6} \mathrm{gms} / \mathrm{magn}$

Internal Energy of Iron before Quench $=.000181 \mathrm{~J} / \mathrm{gm}$ Following quench, the change in internal energy $(\triangle E)$ of the helium vapor, helium liquid, and magnet iron must equal the quench energy released,

$$
m_{V}\left(E_{V f}-E_{V i}\right)+m_{I}\left(E_{L f}-E_{I I}\right)+m_{I}\left(E_{I f}-E_{I I}\right)=1.5 \times 10^{6} \mathrm{~J}
$$

substituting

$$
\begin{array}{r}
91.6\left(E_{V f}-20.79\right)+2387\left(E_{L f}-1.63\right) \cdot 9.7 \times 10^{6}\left(E_{I f}-.000181\right) \\
\\
=1.5 \times 10^{6} \mathrm{~J}
\end{array}
$$

Also, $E_{V f}=E_{L f}$ 
The solution is trial and error. Select an equilibrium temperature and solve; repeat until the change in internal energy of the helium and the iron equals $1.5 \times 10^{6}$ Joules.

$$
\text { A.t } 31.2^{\circ} \mathrm{K}, \quad \begin{aligned}
& E_{V f}=108.2 \mathrm{~J} / \mathrm{gm} \quad(\text { at } 12 \mathrm{ata}) \\
& E_{I f}=0.127 \mathrm{~J} / \mathrm{gm}
\end{aligned}
$$

Solving the left hand side of the equation,

$$
\begin{aligned}
& 91.6(108.2-20.79)=2387(108.2-1.63)+9.7 \times 10^{6}(.127-.00018) \\
& =8,010+254,380+1,230,140=1.493 \times 10^{6} \mathrm{~J}
\end{aligned}
$$

Therefore, the equilibrium temperature is,

$$
\mathbf{t}=31.2^{\circ} \mathrm{K}
$$

The specific volume,

$$
\checkmark=\frac{117.0+16.4}{2479}=0.0538 \frac{\mathrm{l}}{\mathrm{gm}}=53.8 \mathrm{cc} / \mathrm{gm}
$$

The equilibrium pressure at $31.2^{\circ} \mathrm{K}$ is,

$$
\mathrm{P} \cong 12.2 \mathrm{ata}
$$

This is the maximum pressure attainable in a magnet string as a result of a magnet quench. 
Appendix $C$

\section{SYNCHROTRON RADIATION HEAT REMOVAL}

FROM SSC MAGNETS AND BEAM TUBE

ISOLATION WITH LINERS

By

R.P. Shutt

Brookhayen Motional Laboratory 


\section{Syachrotron Radiation Heat Removal from SSC Magnets and Bean Tube Isolation with Liners.}

Sumary

The synchrotron radiation heat in the Design $D$ magnet SSC amounts to $2 \mathrm{~W} / \mathrm{dipole}$, or $0.0012 \mathrm{~W} / \mathrm{cm}$, which constitutes by far the largest fraction of the total magnet heat load, if a heat shleld operated at $20^{\circ} \mathrm{K}$ is used. For economic reasons $1 t$ would be of Interest to remove this heat also at a temperature well above the magnet operating temperature. In fact, this would become quite necessary if one wanted to operate the magnets at a lowe I temperature than $4.4^{\circ} \mathrm{K}$, near $1.8^{\circ} \mathrm{K}$. Furthermore, if the beam tube vacuum should be adversely affected by fons or gases desorbed from the cold beam tube wall by the impinging radiation, it has been suggested to absorb the radiation locally by projections inserted fnto the beam tubes. Fabrication of a beam tube with projections may be difficult. Finally, it may become possible to increase the beam intensity, by factors of 2,3 or more, in the future, which would require conslderably more refrigeration power and could not be accommodated by the present magnet cooling method.

For the given reasons it has been suggested to consider installation of Iiners inside the beam tubes from which the synchrotron radiation heat could be removed at a higher temperature. Obviously, one would then have to be . willing to give up physical aperture avallable for the beam or to increase the magnet aperture. Consideration must be given to the copper plating that Is required on the beam tube surface, and which would have to be transferred to the inside of the liner. If the iner temperature exceeds $\sim 30^{\circ} \mathrm{K}$, it may not be possible that even high purity copper will retaln the required high 
resistivity ratio. Furthermore, Lorentz forces produced during magnet quenches in copper plating or liner wall, if made of high conductivity material, are so high that the liner would have to be supported through the magnet cold bore and correction coll against the main magnet coils. The required extensive supports would leak too much heat to the magnet. Therefore, the liner wall thickness has to be large enough to be self-supporting, reducing avallable apercure further.

The first Iiner that might satisfy the various mentioned constraints would consist of a stainless steel tube with sufficlent wall thickness, with approximately one third of its wall consisting of holes for vacuum pumping, and with copper plating on the 1nside. Near the poles, thick strips of high thermal conductivity material are well-attached. Heat is conducted towards the magnet ends where it is exchanged at, say, $20^{\circ} \mathrm{K}$. Attaching the strips to the long stainless steel tubes is not a simple matter if one wants to avoid (a) obtaining a very warped assembly or (b) reducing the high conductivity of the strips. If the magnet aperture is not to be increased, the Iiner has to be made oval (vertically flattened). It is most likely not feasible with this method to increase the beam intensity, except by reducing the magnet length by, say, $50 z$.

Next, a helium-cooled Iner has been considered. An oval stainless steel tube is now welded to (or extruded with) two stainless steel cooling tubes located at the poles and passing helfum at temperatures between 20 and $<40^{\circ} \mathrm{x}$. The helium is recooled every 3 to 6 magnet cells. This method could accomodate heat loads up to 3 times as large as the present design load whout increasing the cooling tube size substantially beyond the cross sections of the therral conductors discussed in the previous paragraph. 
Again, the liner has many holes, is copper-plated, and has sufficlent wall thickness to withstand the forces on the copper during a magnet quench.

A third, less economical in operation, but perhaps advantageous method. consists of a thermally and mechanically falrly independent beam tube assembly which is operated at the highest temperature that is allowed for cryopumping $\left(\leq \sim 8^{\circ} \mathrm{K}\right)$. This "warm bore" assembly would be isolated by the vacuum chamber vacuum $\left(\sim 10^{-6}\right.$ Torr) from the magnet cold bore which can then be operated independently at any low temperature. The copper-plated, circular, sufficiently thick-walled beam tube is cooled by helium flowing through a jacket surrounding the beam tube. Here the beam tube. may again need projections for localized synchrotron heat removal. Increased synchrotron radiation heat is fairly easily accommodated, copper plating resistivity ratio is not lost, correction colls are not exposed to heat spikes, and fabrication would probably be simpler than for the other methods.

It must be emphasized that all three methods require much design and installation work to provide connectlons between magnets and recoolers for helium flow or cooling near the magnet ends for the diffusion method. Obviously, resulting cost increases and possibly increased operating risks must be weighed against savings in magnet and refrigeration costs and other advantages when considering operation at a very low temperature. 
For the presently anticipated beam intensitles and maximum energy of 20 IeV in the SSC, the synchrotron radiation energy will be about $2 \mathrm{~W}$ per 17m long dipole. With the introduction of a second heat shield, operating near $20^{\circ} \mathrm{K}$, around the SSC magnets, the additional heat load per dipole has been estimated to amount to only $0.3 \mathrm{~W}$ or perhaps somewhat more. Thus, synchrotron radiation now produces by far the major portion of the total load. Removing heat at, say, $20^{\circ} \mathrm{K}$ rather than near $4^{\circ} \mathrm{K}$ from a cryogenlc system could, theoret1cally, reduce required refrigeration power, for a given load by a factor of about 5. Furthermore, it has been suggested to consider magnet operation at 1.8 to $2^{\circ} \mathrm{K}$, which, besides resulting in various additional complexities for the refrigeration system, would make reduction of the total magnet heat load imperative.

In the future, it may also becone desirable, and possible, to increase the beam intensity of the machine at maximum beam energy. The presenty concefved cooling system does not allow for a very substantial heat load increase; refrigeration power would be insufficient and cemperature increases in the magnets may become too large for stable operation.

Finally, at the present time experiments are beginning at BNL's National Synchrotron LIght Source (NSIS) to test, with electron beams, the effects on the vacuum of the synchrotron radiation 1mpinging on the beam tube wall. The vacuum must be kept at $<10^{-1} 1$ Torr. The cold beam tube is to act as a cryogenic pump. Thus, adsorbed gases should essentially not be removed from the tube surface by excitation due to the radiation. In case the vacuum is Indeed affected adversely, in a recent SSC Technical Note (No. 26) at BNL a "clean- up" method was considered that had been suggested as a possibility for the SSC. This consisted of providing small projectlons into the beam 
tube at 1ntervals of 30 to $100 \mathrm{~cm}$. With the proper geometry, the radiation would almost exclusivelg lmpinge on the projections and be absorbed there. Therefore, only these small surfaces would have to be freed of adsorbed gases. which would then be adsorbed elsewhere in the beam tube. In addition, since the radiation heat is more concentrated locally, the temperature of the projections would Increase somewhat. The effect of these "heat spikes" on the magnet coils was Investigated in the mentioned Technical Note, and it was found that allowable coll temperatures were nowhere exceeded. The allowed synchrotron radiation heat load could also be increased (somewhat only) by adjusting the chosen geometry. However, the projections will of course reduce the physical aperture of the beam tubes and may be difficult to produce.

Overall, the cooling wethods that have been consldered so far for the SSC magnets have been shown to be adequate (although not with very much margin). They are also basically simple, requiring only a few straight helfum flow passages through the magnets.

If adverse effects on the beam vacuum cannot be remedied by the discussed projections into the beam tube, if possible future beam intensity increases should be taken into account, if refrigeration power should be decreased (with savings in both the cost of the refrigeration plant and its operation), or if magnet operation at about $2^{\circ} \mathrm{K}$ is considered desirable (with savings in superconductor cost at the present operating field near $6.5 T$ or, possibly, in magnet and tunnel cost at a higher field), In these cases it has been suggested to consider installation of metallic liners in the beam tubes. If one merely wanted to protect the cold beam tube from the synchrotron radiation, one could mount a thin-walled stainless steel tube as a Iner, 
supported by occasional very small, low heat conductivity spacers (of a material that is compatible with the high vacuum). The 11ner would then warm up to a temperature around $100^{\circ} \mathrm{K}$, depending on surface emissivities, and radiate the heat $10 a d$ of $2 \mathrm{~W} /$ dipole to the magnet. According to an estimate by P. A. Thompson, in order to maintain a uniformly high vacuum, approximately one-third of the tube wall surface has to consist of holes. However, if the inside of the liner has to be plated with copper (now 0.2 mn thick, with resistance ratio of 200 ) for impedance matching, then this method is not feasible because at temperatures above $\sim 30^{\circ} \mathrm{K}$ copper cannot have a resistance ratio of 200 according to avallable data. It is not particularly useful to increase the copper thickness correspondingly if the resistivity is larger than prescribed, since the skin depth $\sim \rho^{1 / 2}$ and therefore the wall resistance is still $\sim \rho^{1 / 2}$. (So far it does not seem to be clear whether a value of 200 can be obtained at all for copper that is plated to the Inside of a tube by available methods.) Similar facts appiy to aluminum, to be considered below; depending on resistance ratio $R(T)$, resistivities remain flat up to 15 to $25^{\circ} \mathrm{K}$, and above that they increase rapidly. The presence of a magnetic field increases the resistivity, especlally for large $R(T)$. This effect can be represented for copper with good approximation over a wide range in resistivity ratios $R(T)$ and fields $B$ by,

$$
\rho(T, B)=\rho(273,0)\left(3 \times 10^{-3} R B+1\right) R^{-1}
$$

Thus the wall resistance is proportional to $(P(T, B) 1 / 2=\sigma$. 
Using $B=6.5 \mathrm{~T}, \rho(273,0)=1.55 \times 10^{-6} \Omega \mathrm{cm}$ we calculate for $\sigma$ :

\begin{tabular}{c|c}
$R$ & $\sigma$ \\
\hline 1 & $12.6 \times 10^{-4}$ \\
25 & 3.04 \\
50 & 2.47 \\
100 & 2.14 \\
200 & 1.95 \\
400 & 1.85 \\
800 & 1.79
\end{tabular}

One sees that $\sigma$ varies very slowly above $R=100$, by $14 \%$ between 100 and 400 , and Increases more rapidly below this value, for instance, by $\sim 40 \%$ between $R=100$ and 25 . Depending on the accuracy required for $\sigma$, there must certainly be a range of values permitted for $R$. Note that these remarks apply only to copper. For aluminum the magneto-resistance effect is strongly non-I1near.

Copper-plating the liner leads to induction of large currents during a magnet quench. Interaction with the fleld leads to large stresses and deflections of the tube wall unless it is well supported and/or quite thlck-walled ( $\geq 0.15 \mathrm{~cm}$ ). Numerous strong supports between liner and beam tube are not feasible because of the resulting heat conduction. Therefore a sufficlently thick-walled self-supporting stainless steel liner would be Indfcated. The required wall thickness and the thickness of the supports add up to a considerable reduction of the physical aperture avallable to the proton beam. 
The high electrical conductivity materlal most likely required to be located on the wall of the liner, and resulting forces, present a problem that has to be dealt with, whatever type of liner is to be used.

In order to reduce the heat load to be removed from the magnet, operating at a temperature of 4.3 to $4.5^{\circ} \mathrm{K}$ or less, three possibllities have been considered. The first employs a liner of high thermal conductivity materlal, such as a high purity aluminum or copper, which is to conduct the heat to the ends of a magnet where it can be exchanged at, say, $20^{\circ} \mathrm{K}$. The second possibility makes use of helium (entering at a temperature near $20^{\circ} \mathrm{T}$ ) flowing through small tubes attached to the liner, heat being exchanged after every few cells of magnets. Finally, a third, perhaps most suitable, but less eccnomical method suggests itself, namely, to make the beam tube mechanically and thermally independent of the magnet, operating it at whatever temperature is feasible for cryopumping. We shall flrst consider the high conductivity liner.

High Thermal Conductivity Liner Cooled at Ends.

Assume that synchrotron radiation heat is generated at a rate $q(W / c r i)$ per unit length of a dipole. The cross sectional area of the liner is to be $a$ and its strongly temperature-dependent heat conductivity $k(T)$. Heat w111 be radiated towards the cold beam tube at the rate $S(T)$ per unit length. Then the equation for the temperature distribution along length $z$ due to heat diffusing toward the cooled ends of the liner 1s,

$$
\frac{d}{d z}\left(k(T) \frac{d T}{d z}\right)=\left(-q+s(T) \frac{1}{a}\right.
$$


Assuming symmetry, we have the boundary conditions,

$$
\begin{aligned}
& z=0: T=T_{0} \\
& z=\frac{l}{2}: \frac{\mathrm{dT}}{\mathrm{d} z}=0
\end{aligned}
$$

For heat radiation:

$$
S(T)=D\left(T^{4}-T_{b}^{4}\right)
$$

where $T_{b}$ is the operating cemperature of the magnet $\left(2 \leq T_{b} \leq 4.5^{\circ} \mathrm{K}\right)$ and

$$
\begin{aligned}
& D=A E_{1} E_{2} K \\
& E_{1}=\text { emissivity of liner surface at } T \text {. } \\
& E_{2}=\text { emissivity of beam tube surface at } T_{b} \text {. }
\end{aligned}
$$

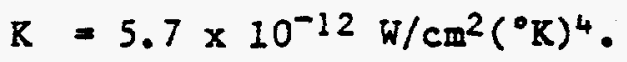

$$
\begin{aligned}
& A=2 \pi r\left(\mathrm{~cm}^{2} / \mathrm{cm}\right) \quad=\text { average of surface areas per } \mathrm{cm} \\
& \text { length of liner and beam tube. } \\
& r \text { = "average radius" }=1.6 \mathrm{~cm} \text {, which is here set equal to } \\
& \text { the outer radius of the liner, assuming } \\
& \text { that the spacers to the beam tube are } \\
& \text { small. }
\end{aligned}
$$


Liner Cross Section:

$$
\begin{aligned}
a= & 2 \pi\left(r-\frac{-t}{2}\right) \text { ft } \\
t= & \text { Iner wall thickness }=0.1 \\
f= & 2 / 3 \text { takes into account, as an average, that } 1 / 3 \text { of the } \\
& \text { Ilner wall area consists of holes. f is not used to } \\
& \text { determine } A \text { because heat is also radiated frow the IIner } \\
& \text { through the holes in the wall. }
\end{aligned}
$$

A computer program to solve eq. (1) was assembled and operated by kurt Jellet who overcame successfully a number of problems caused by the. particular constraints and by the very strong non-linear dependence of $S(T)$ and $k(T)$ on $T$. His contributions are highlg appreclated.

For the liner, we have flrst chosen a falrly high purity aluminum tube with a resistance rat10 $R(T) \approx 1000$ between $2 \leq T \leq \sim 20$, such as an AI-1100. The magneto-resistance effect for aluminum is non-1inear, Iising fast up to $\sim 1 \mathrm{~T}$ and then almost leveling of at a factor of about 3, fncreasing the resistivity at the magnetic fields of interest to us. Without application of a magnetic field the heat conductivity could very simply be inferred from the Wedemann-Franz law that $k(T) \rho(T)=\lambda T$, were $\lambda \approx 2 \times 10^{-8}$ for most metals. However, testing this relation at low temperature and in the presence of a magnetic fleld, using avallable data for copper, shows that it is not well sacisfied; $k(T)$ would have to be considerably lower then the data show. For the aluminum IIner we have chosen a heat conductivity function that is as consistent as possible with these indications and also have taken into 
account that we are to operate the 1 iner in a temperature region $\left(>20^{\circ} \mathrm{K}\right.$ ) where $R(T)$ decreases ( $(T)$ increases) and therefore $k(T)$ is expected to decrease. Expressing $k(T)\left(1 \mathrm{~W} / \mathrm{cm}^{\circ} \mathrm{K}\right)$ as a function of $T$,

$$
\begin{array}{ll}
k(T)=5.3 T & \text { for } T \leq 10^{\circ} \mathrm{K} \\
k(T)=62 & \text { for } 10<T<18 \\
k(T)=59.6 \mathrm{e}^{-B(T-18)}+2.4 \text { for } 18 \leq T
\end{array}
$$

where $B=0.064$.

Results from this calculation are shown in Table I. There we show:

(1) q = synchrotron radiation heat per cm length

(2) $T_{0}=$ liner temperature at cooled end

(3) $E_{1} E_{2}=$ product of emfssivities of liner and beam tube surfaces (at their respective temperatures). $E_{1}$ and $E_{2}$ depend strongly on the surface conditions and cannot be predicted with any degree of certainty or, probably, maintained for a great length of time. We have therefore started with the conservative value of 0.4 and then show also results for smaller values.

(4) $T_{\max }=$ maximum temperature calculated at $z=2 / 2=830 \mathrm{~cm}$, at center of the dipole. 
Table I

\begin{tabular}{|c|c|c|c|c|c|c|c|}
\hline $\begin{array}{c}(1) \\
q \\
w / c m \\
10^{-3} x\end{array}$ & $\begin{array}{l}(2) \\
T_{0} \\
{ }^{\circ} \mathrm{K}\end{array}$ & $\begin{array}{c}(3) \\
E_{1} E_{2}\end{array}$ & $\begin{array}{l}(4) \\
T_{\max } \\
{ }^{\circ} \mathrm{K}\end{array}$ & $\begin{array}{l}(5) \\
S_{\max } \\
W / \mathrm{cm} \\
10^{-3} \mathrm{X}\end{array}$ & $\begin{array}{c}\text { (6) } \\
s_{\max / q}\end{array}$ & $\begin{array}{c}(7) \\
Q_{I} \\
W\end{array}$ & $\begin{array}{l}(8) \\
Q_{t s} \\
W\end{array}$ \\
\hline 1.2 & 20 & $\begin{array}{l}0.4 \\
0.2 \\
0.1 \\
0.05 \\
0.025\end{array}$ & $\begin{array}{l}38.6 \\
39.1 \\
39.4 \\
39.5 \\
39.6\end{array}$ & $\begin{array}{l}0.051 \\
0.027 \\
0.014 \\
0.007 \\
0.004\end{array}$ & $\begin{array}{l}0.043 \\
0.023 \\
0.012 \\
0.006 \\
0.003\end{array}$ & $\begin{array}{l}0.043 \\
0.022 \\
0.011 \\
0.006 \\
0.003\end{array}$ & $\begin{array}{l}2.0 \\
2.0 \\
2.0 \\
2.0 \\
2.0\end{array}$ \\
\hline 2.4 & 20 & $\begin{array}{l}0.4 \\
0.1 \\
0.025\end{array}$ & $\begin{array}{r}85.2 \\
114.1 \\
.145 .8\end{array}$ & $\begin{array}{l}1.21 \\
0.97 \\
0.65\end{array}$ & $\begin{array}{l}0.50 \\
0.40 \\
0.27\end{array}$ & $\begin{array}{l}0.59 \\
0.42 \\
0.27\end{array}$ & $\begin{array}{l}4.0 \\
4.0 \\
4.0\end{array}$ \\
\hline 3.6 & 20 & $\begin{array}{l}0.4 \\
0.1 \\
0.025\end{array}$ & $\begin{array}{l}107.4 \\
148.6 \\
201.6\end{array}$ & $\begin{array}{l}3.05 \\
2.79 \\
2.37\end{array}$ & $\begin{array}{l}0.85 \\
0.78 \\
0.66\end{array}$ & $\begin{array}{l}1.72 \\
1.50 \\
1.24\end{array}$ & $\begin{array}{l}6.0 \\
6.0 \\
6.0\end{array}$ \\
\hline 3.6 & $\begin{array}{r}16 \\
12 \\
8 \\
4\end{array}$ & 0.4 & $\begin{array}{r}103.4 \\
96.1 \\
83.6 \\
72.3\end{array}$ & $\begin{array}{l}2.62 \\
1.95 \\
1.12 \\
0.63\end{array}$ & $\begin{array}{l}0.73 \\
0.54 \\
0.31 \\
0.17\end{array}$ & $\begin{array}{l}1.23 \\
0.77 \\
0.40 \\
0.23\end{array}$ & $\begin{array}{l}6.0 \\
6.0 \\
6.0 \\
6.0\end{array}$ \\
\hline
\end{tabular}


(5) $S_{\max }=$ maximum power radiated per $\mathrm{cm}$ length from liner to beam tube.

(6) $s_{\max } / q=$ maxlmum fraction of synchrotron radiation power reaching beam tube and therefore still having to be removed at magnet operating temperature.

(7) $Q_{I}=$ total power still to be removed from dipole at operating temperature.

(8) $Q_{t s}=$ Total synchrotion radiation power in dipole, for comparison with $Q_{I}$.

It is important to consider $S_{\text {max }}$ separately from $Q_{I}$ because we shall see (Fig. 1) that the maximum for $T(z)$ is rather flat around $z=830$, and therefore, if one expected heat diffusion in the beam tube/correction coil assembly (where the diffusion decay length is only $2.4 \mathrm{~cm}$ as shown in SSC Technical Note No. 26) to reduce $S_{\max }$, the 1mprovement would be very small. Thus magnet operation at $2^{\circ} \mathrm{K}$ would be difficult even if $Q_{I}$ were adequately small. For the "design" heat load of $q=0.0012 \mathrm{~W} / \mathrm{cm}\left(Q_{t s}=2 \mathrm{~W} / \mathrm{d}\right.$ pole $)$, the table shows that we are not exceeding $40^{\circ} \mathrm{K}$ for $0.4 \geq \mathrm{E}_{1} \mathrm{E}_{2} \geq 0.025, \mathrm{~S}_{\max } / \mathrm{q} \leq$ 4.3\%, and that $Q_{z} \ll Q_{\text {ts. Also }} S_{\max } / q$ and $Q_{r}$ decrease almost linearly with decreasing $E_{1} E_{2}$, since here $T(z)$, essentially, does not change with $E_{1} E_{2}$.

Increasing $q$ by only a factor of two (corresponding to $Q_{\text {ts }}=4 \mathrm{~W} / \mathrm{d}$ pole), due, for Instance, to doubling the beam intensity, changes the results drastically. $T_{\text {max }}$ now increases conslderably whth decreasing $E_{1} E_{2}$, and $S_{\max }$ and $Q_{5}$ decrease only slowly with $E_{1} E_{2}$. For even smaller $E_{1} E_{2}, S_{\max }$ and $Q_{I}$ 


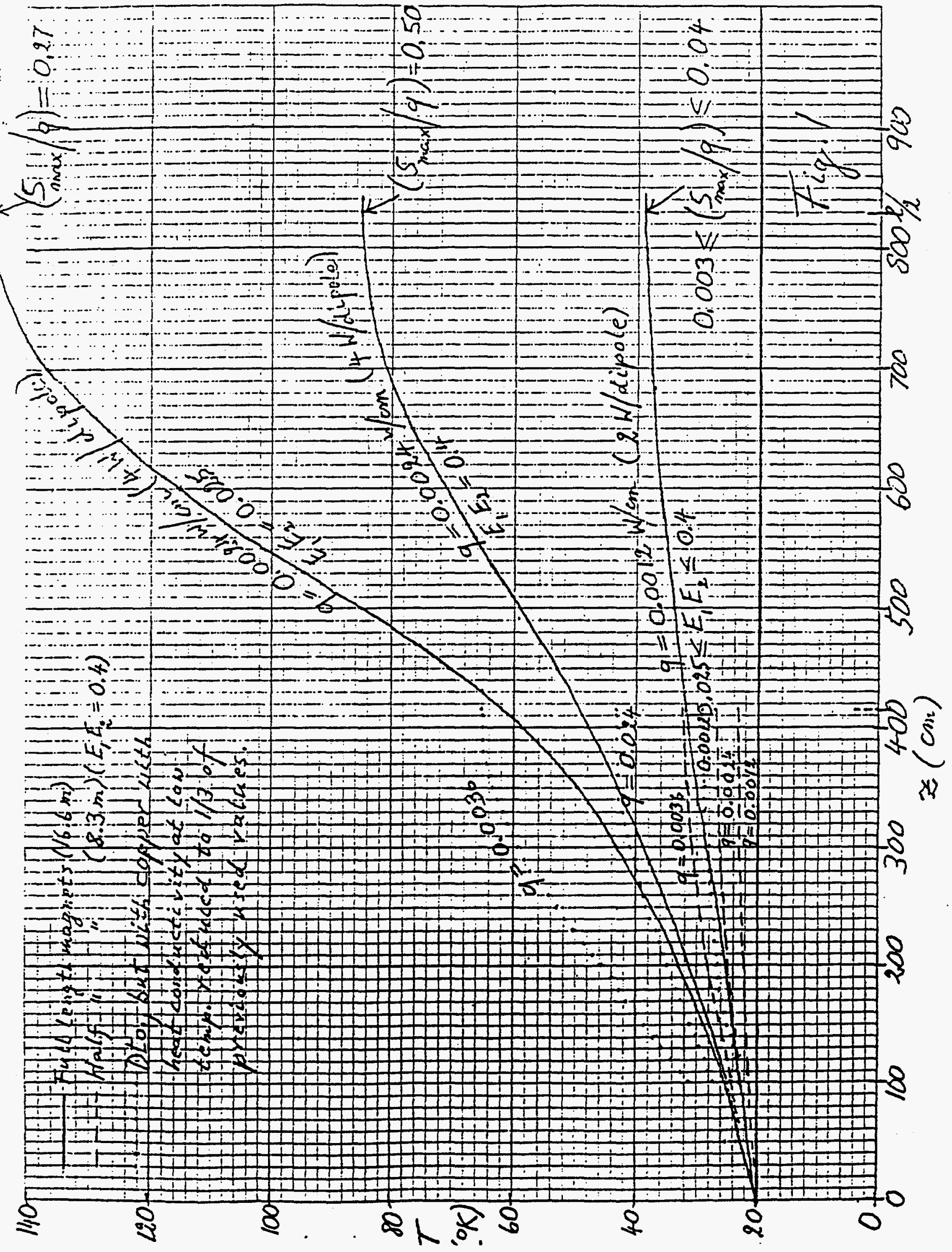


would, of course, decrease faster, but we cannot easily justify reducing $E_{1} E_{2}$ below 0.025 in the present application. $S_{\max }$ is here at least $27 \%$ of $q=0.0024$ which may be too high for magnet operation at $2^{\circ} \mathrm{K}$. Total load on a dipole excluding external loads would be $0.27 \mathrm{~W}$.

The situation deteriorates further for $q=0.0036\left(Q_{t s}=6\right)$. Now $s_{\max } \geq$ $0.0024 \mathrm{~W} / \mathrm{cm}$ or $S_{\max } / q \geq 66 \%$, and $Q_{r} \geq 1.24 \mathrm{w}$. For this case we have reduced the cooling temperature $I_{0}$ from 20 to $4^{\circ} \mathrm{K}$ (Table I). This might then still permit magnet operation at $2^{\circ} \mathrm{K}$, although at much increased costs for refrigeration. We find substantial Improvement even for the value of 0.4 here chosen for $E_{1} E_{2} \cdot S_{\max } / q$ has decreased from $85 \%$ to $17 \%$ and $Q_{I}$ from 1.72 to 0.23 W/dipole.

Sone of the results are also shown in Fig. 1, where $T(z)$ is plotted for $q=0.0012$ and $0.0024 \mathrm{w} / \mathrm{cm}$. As mentioned above, $T(z)$ essentially does not change with $E_{1} E_{2}$ for $q=0.0012$, but changes considerably for $q=0.0024$; for smaller $E_{1} E_{2}, T(z)$ merely 1ncreases so that the radiated heat $\left(\sim T^{4}\right)$ cannot change much.

We conclude, so far, that for the design value of $q=0.0012$ the aluminum Ilner considered here would provide the desired result, namely reducing the heat load so that the magnet could be operated at $2^{\circ} \mathrm{K}$ without difficulty. However, Increasing the heat load by only a factor of two would seem to make this very difficult and costly, unless a way can be found to decrease the surface emissivities to quite small values, and to ensure that they will remain low.

Since it seems somewhat deplorable to limit the machine intensity so that it could not be increased in the future without great effort and cost, one might consider, for Instance, hal ving the length of the dipoles. This would require 
a relatively small additional amount of construction money, but would have the desired effect. F1gure 1 shows the result for $E_{1} E_{2}=0.4$; even for $q=0.0036$ $\left(Q_{\text {ts }}=6 \mathrm{~W} /\right.$ dipole) $\mathrm{T}_{\max }$ is only $33^{\circ} \mathrm{K}$, and therefore $\mathrm{S}_{\max }$ and $\mathrm{Q}_{\mathrm{I}}$ are very small $\left(2.4 \times 10^{-5} \mathrm{~W} / \mathrm{cm}\right.$ and $0.024 \mathrm{~W}$, respectively).

Using high conductivity aluminum for the liner leads to various technical difficulties. Copper would be more suitable in several respects (thermal expans1on, easy fusibility to stainless steel) but may not be easily obtainable with the high resistivity ratio (>1000) used here for the aluminum. For half-length magnets, heat load values are sufficiently decreased that one could consider copper with, for instance, resistivity ratio of about 300 . The result has also been shown on Fig. 1. For $q=0.0024, T_{\text {max }}$ is still only half as large as with the high conductivity aluminum in the long magnets and $S_{\max }=8.3 \mathrm{x}$ $10^{-5}, Q_{I}=0.066$, and for $q .=0.0036, s_{\max }=4.2 \times 10^{-4}, Q_{r}=0.27$.

While it appears that, from a point of view of desirable magnet heat loads, operation at $q=0.0012 \mathrm{~W} / \mathrm{cm}$, but probably not 0.0024 , is feasible with fulllength magnets if a high conductivity aluminum liner is used, or operation with half length to 0.0036 with aluminum or with copper to 0.0024 or somewhat more, we must recall that the liner most likely must be plated with or consist of a material with resistivity ratio of about 200 which, as mentioned above, way not be obtalnable at $\mathrm{T}>\sim 30^{\circ} \mathrm{K}$. In this case even the aluminum liner at full magnet length wight not suffice with $q=0.0012\left(T_{\max } \approx 40\right)$. With half length, aluminum could accommodate even $q=0.0036$, since $\mathrm{T}_{\max }$ then only $33^{\circ} \mathrm{K}$. Or with copper liner $q=0.0012\left(T_{\max }=29\right)$ is acceptable. If resistance ratios could be averaged over dipole lengths for proper wall impedance matching, the range of acceptable possibilities could be increased, since temperatures conslderably less than $T_{\max }$ are of course encountered as the magnet ends are 
approached. Finally, temperatures could be substantlally decreased by increasing liner wall thickness $t$. For instance, with copper, $q=0.0036$, and $t=0.2 \mathrm{~cm}$ we would obtain $I_{\max }=36.3, S_{\max }=4.0 \times 10^{-5}, Q_{r}=0.018^{\circ}$ Here $T_{\max }$ Is almost acceptable. However, now we have Increased a parameter ( $t$ ) which we have tried to malntain in order not to lose further machine aperture. Furthermore, the following consideration of effects due to magnet quenches will show that addition of high conductivity material to the iner results in very awkward construction detalls.

As shown in recent Magnet Division Notes No. 134-20 (SSC-MD-102) and 141-20 (SSC-MD-107), when fleld B (in units of Tesla) changes, current

$$
I=2 \times 10^{-4} \frac{\dot{B}}{\mathrm{ta} r^{2}}
$$

is induced. For possible eventual maximum quench field of 7.5 and quench decay time of $0.3 \mathrm{sec}, \dot{B}=7.5 / 0.3=25 \mathrm{~T} / \mathrm{sec}$. Resistivity $\rho$ for our aluminum, towards the ends of the magnets, is $2.5 \times 10^{-9} \Omega \mathrm{cm}$ at low fleld and $7 \times 10^{-9}$ for fields $>\sim 2 T$. Therefore

$$
I=1.2 \times 10^{5} \mathrm{~A}
$$

during a quench. (Near injection, with ramp-up time of $900 \mathrm{sec}, I=100 \mathrm{~A}$, resulting in an induced fleld of $B_{I}=10^{-5} \pi I / I \equiv 20$ Gauss. Heat produced per dipole is

$$
\mathrm{B}=10^{-8} \pi \frac{\dot{B}^{2} t \mathrm{r}^{3} L}{\rho}=0.3 \mathrm{~W} / \mathrm{d} \text { pole }
$$

at end of ramping: $\mathrm{B}=0.1 \mathrm{~W}_{\text {.) }}$ 
The simple equation 5 does not take Into account that I produces a fleld B (1deally uniform). The decay time for I can be found from

$$
\tau=2 \pi \times 10^{-8} \times \frac{t r}{\rho}=0.1 \mathrm{sec}
$$

which is substantially smaller than the assumed quench decay time of $0.3 \cdot \mathrm{sec}$ which is here assumed as a lower limit. Therefore, for these estimates we neglect the induced field which would be $B_{I}=B T=2.5 T$. (Expressions that can be used for corrections can be found In ISA Technical Note No. 52.)

Near the midplane $(\theta=0)$ of the magnet, current distribution $L(\theta)=I \cos \theta / 2 r$, Interacting with $B$, produces a maximum outward pressure during a quench of

$$
P_{\max }=g \frac{B I}{\Gamma}=4100 \text { psi }
$$

$(g=0.0072)$ and a maximum deflection, if the liner is not supported, of

$$
w_{\max }=6.6 \times 10^{-6} \frac{g^{5}{ }^{5} B \dot{B}}{E I_{M} \rho}(1 \mathrm{nch})
$$

where $E=$ elastlc modulus of tube material ( $=10^{7} \mathrm{psi}$ ), $I_{M}=\mathrm{ft}^{3} / 12$. We obtain the, of course, absurd value of $w_{\max }=1.6 \%$ (In all the above calculations we 
use centimeters for $t$ and $I$, but have given special results in the Indicated units.) The maximum stress would be given by the equally absurd maximurr

$$
\sigma_{\max }=3.8 \frac{E}{\tau^{2}} t w_{\max }=2.4 \times 10^{6} \mathrm{psi}
$$

Increasing $t$ would decrease $\sigma_{\max }$ only inversely with $t$. Supporting the liner is not feasible because (1) $P_{\text {max }}$ is rather high to be allowed to act through the beam tube wall on correction coll and main colls, (2) supports would have to be continuous and of substantial width and therefore constitute a large heat leak to the magnet, (3) even with support near the midplane (at the poles the liner is deflected inward) $\sigma_{\max }$ could not be decreased by the two orders of magnitude required.

We consider making a thin-walled liner of stainless steel and concentrating the aluminum (or copper) near the poles, insuring that the materials are well joined to each other. For clrcular segments we can calculate (see ISA Technical Note No. 364),

$$
\sigma_{\max }=9.4 \times 10^{5} \frac{\phi\left(\theta_{0}\right)}{\tau_{s}}
$$

where

$$
\phi\left(\theta_{0}\right)=1-\frac{\pi}{4}-\sin \theta_{0}+\frac{1}{4} \sin 2 \theta_{0}+\frac{\theta_{0}}{2}
$$


with $\theta_{0}=$ angle where segments begin. The total induced current becomes

$$
I=2 \times 10^{-4} \frac{\dot{B} t_{s} I^{2}}{\rho}\left(1-\sin \theta_{0}\right)
$$

of course, the induced field can no longer be unfform. We must maintain the cross sectional heat conduction area obtalned previously. Therefore

$$
\tau_{s} \approx f t /\left(1-\frac{2 \theta_{0}}{\pi}\right)
$$

In Table II we Ifst $I, t_{s}, b(=$ azimuthal length of segment), $s$ ( = sagitta of segment), $\phi_{0}$, and $\sigma_{\max }$.

Table II

\begin{tabular}{|c|c|c|c|c|c|c|}
\hline$\theta$ & $\begin{array}{c}I \\
\mathrm{~A} \\
10^{4} \mathrm{X}\end{array}$ & $\begin{array}{l}\mathrm{c}_{\mathrm{S}} \\
\mathrm{cm}\end{array}$ & $\begin{array}{l}\mathrm{cm} \\
\mathrm{cm}\end{array}$ & $\begin{array}{l}\mathrm{s} \\
\mathrm{cm}\end{array}$ & $\phi_{0}\left(\theta_{0}\right)$ & $\begin{array}{l}\sigma_{\max } \\
\mathrm{psi} \\
106 \mathrm{X}\end{array}$ \\
\hline 45 & 9.1 & 0.10 & 2.8 & 0.6 & 0.193 & 1.8 \\
60 & 7.1 & 0.13 & 2.3 & 0.4 & 0.150 & 1.1 \\
\hline 65 & 5.1 & 0.20 & 1.6 & 0.2 & 0.089 & 0.42 \\
70 & 3.3 & 0.30 & 1.1 & 0.09 & 0.046 & 0.14 \\
75 & 2.5 & 0.40 & 0.8 & 0.05 & 0.028 & 0.07 \\
\hline
\end{tabular}


One sees that $\sigma_{\max }$ is still unacceptably high up to $\theta_{0}=75^{\circ}$. However for $\theta_{0}>$ $60^{\circ}$ sagitta $s$ becomes smaller than $t_{s}$ and also azimuthal length $b$ approaches $t$. We therefore have overestimated $\theta_{\max }$ for $\theta_{0} \geqslant 60^{\circ}$ and could begin to treat the segments merely as rectangular blocks exposed to a tensile force. We find, for $\theta_{0}=70^{\circ}, \sigma_{\max }=1.8 \times 10^{4}$, and, for $\theta_{0}=75^{\circ}, \sigma_{\max }=10^{4} \mathrm{ps} 1$ which may be acceptable, although high purfty, annealed materlals usually exhibit zather low yield points. $t_{s}$ now has to be $20.4 \mathrm{~cm}$, either requiring an increase in magnet diameter or a vertically flattened (oval) Iiner. It thus may be just possible to make use of a high thermal conductivity liner cooled at the magnet ends. But the constraints are very tight. One still has to provide the required cooling at the ends of every magnet by means of small heat exchangers connected to the liners through the high vacuun beam tube.

\section{Winers With Direct Hellum Cooling}

Since helium cooling is required for the magnet, it would appear that cooling a stainless steel liner with hellum flowing through, say, two attached stainless steel tubes would be the most strafghtforward approach. However, this requires introducing a hellum system 1nto the beam vacuum, which must operate at inlet pressures around 15 atm, with large pressure drop in order to keep the cooling tube cross section small. Connections between magnets must be made with double bellows, with the space between them evacuated to ensure that the high 
beam vacuum is not disturbed. (Operation at $\leq 2^{\circ}$ becomes especially risky concerning leaks because of the well-known hellum properties.) Such interconnections will occupy space that is not easily avallable, and require additional painstaking labor for installation. After traversing several magnet cells the hellum must be recooled, requiring a heat exchanger simllar to the recooler needed after every cell for cooling the magnet, but here to be connected through the beam tube to the 11ner. Nevertheless, this cooling method is not fraughe with the dangers of collapse during a quench or the necessity to fuse long strips of highly conducting material to stainless steel. The stainless steel cooling tubes, In this case, also have to be well fused to the liner wh1ch will require R\&D work in order to produce straight assemblies. But fusing aluminum strips or even copper to long lengths of stainless steel tubes appears to be very much more difficult. Space occupied by the cooling tubes will turn out to be about equal to that occupled by the aluminum or copper strips. Surrounding the liner with a cooling jacket Instead of attaching separate tubes is not feasible because of the above-mentioned large number of holes required for vacuum pumping. Extruding a liner in combination with the cooling tubes located around the poles would, of course, be very desirable, if possible. This would probably be the best way to avoid warping problems. In any case, whether fusing or extruding is employed, the required copper plating should be applied in the finished assembly in order not to spoil the properties of the plating.

We proceed to calculate the required size of the cooling tubes in the following simple manner. The pressure difference $\Delta p$ along a tube can be found from,

$\Delta p=10^{-6}\left(\left(0.0014+\frac{0.125}{\left(R_{r}\right)^{0} \cdot 32}\right) \frac{32 m^{2} L}{\pi^{2} d^{5} D}+\frac{8 m^{2} n}{\pi^{2} d^{4} D}\right)(a t m)$ 


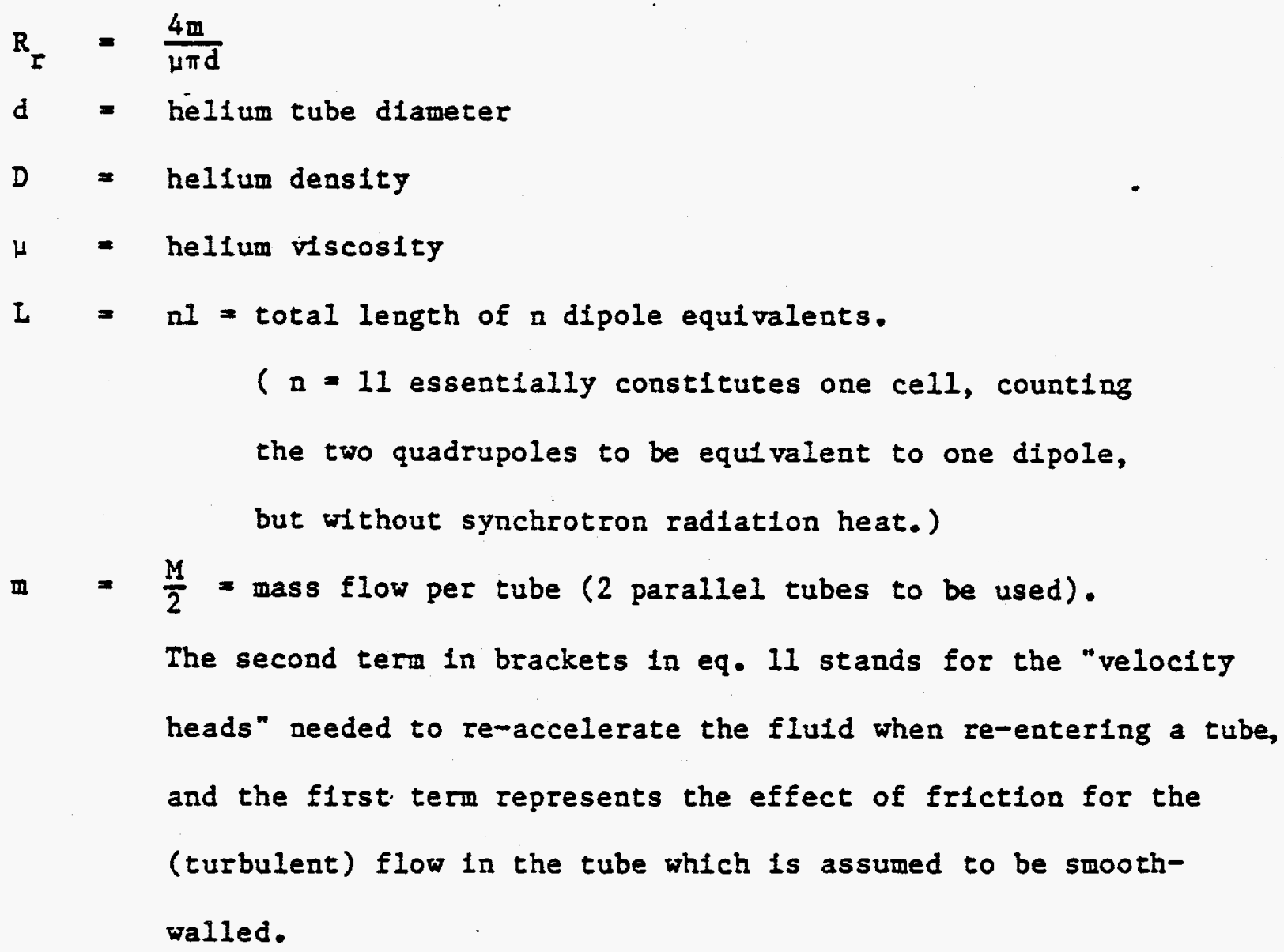

$$
M c_{p} \Delta T=(L-\ell) q=2(n-1) q
$$

having excluded synchrotron radiation heat from the quadrupoles.

$c_{p}=$ helium heat capacity

$\Delta T=$ temperature increase of hellum

$c_{p}, \mu$, and especially, $D$ depend on the temperature.

We have merely used values for these quantities at the average of the

temperature range considered: A better procedure would to be solve equations 11 and 12 for short segments $\Delta L$. Donald $P$. Brown has a program avallable for this 
purpose and conflrmed that only very small adjustments would be necessary in the values for $d$ and $M$ found here.

Based on present concepts for the SSC refrigeration system, D.P. Brown has suggested to alm for a total pressure drop of 6 atm, starting with 15 atm, and a starting cemperature of $24^{\circ} \mathrm{K}$. It also would be desirable to minimize the number of required recoolers. We have almed for $\mathrm{n}=66$ magnets, or 6 cells which is about one-third of the 17 cells cooled per refigerator. Table III gives the results.

Table III

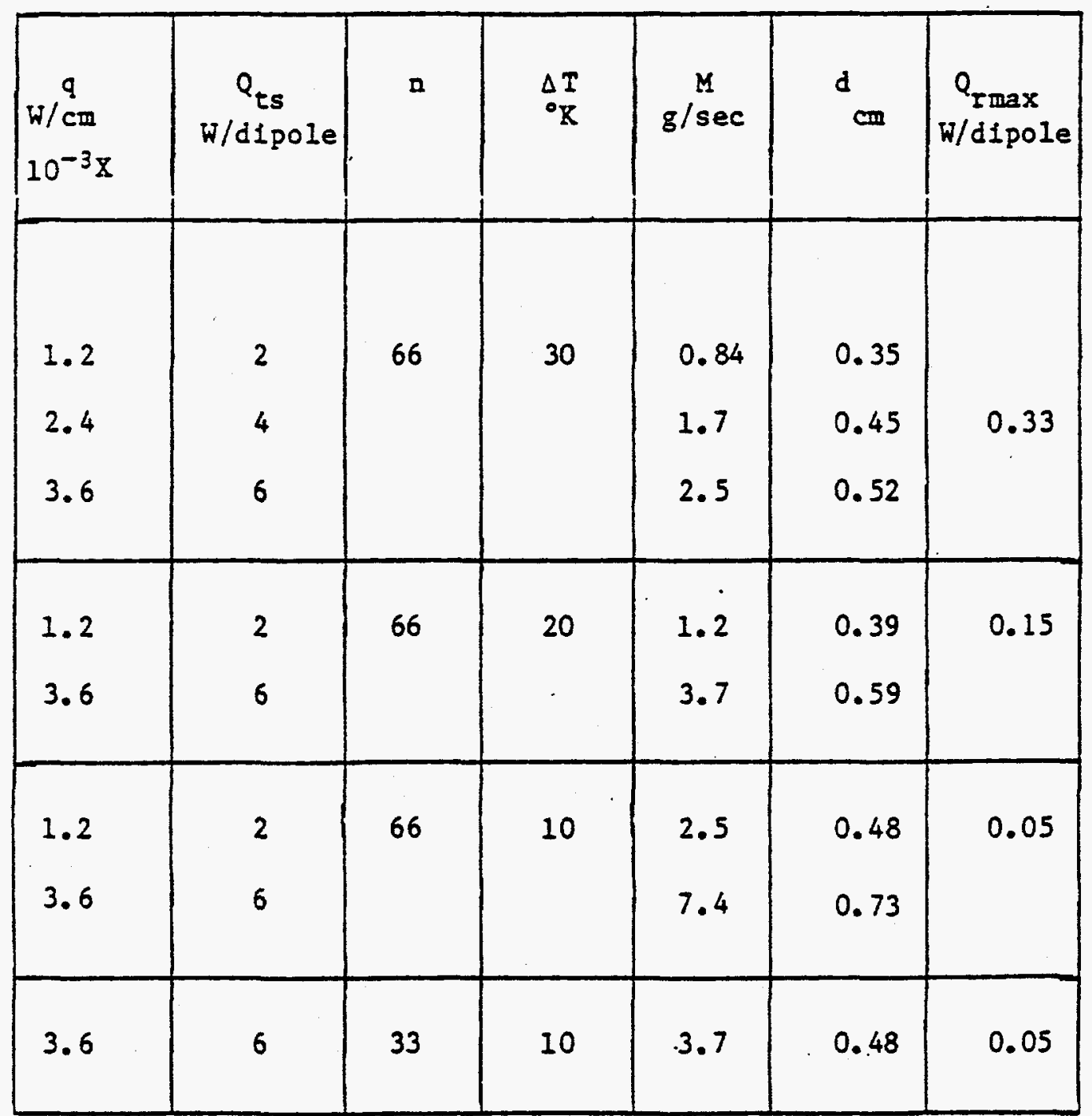


We have again Included results for total heat loads $Q_{t s}>2 \mathrm{~W} / \mathrm{d}$ pole. We have varled helfum temperature increase $\Delta T$ and listed resulting maximum heat radiation $Q_{\text {rmax }}$ to the beam tube in the last column. If one wishes to keep the magnet heat load very small one has to decrease $\Delta T$. This is also necessary in order to retain the high resistivity ratio for the copper plating. As stated previously, a temperature of $30^{\circ} \mathrm{K}$ should probably not be much exceeded. For $\Delta \mathrm{T}$ $=10$ we have a maximum temperature of $34^{\circ} \mathrm{K}$. This results in a tube diameter of $d \approx 0.5 \mathrm{~cm}$. Adding a wall thickness of $0.06 \mathrm{~cm}$ results in an outer diameter of about $0.62 \mathrm{~cm}$, or $0.25^{\circ}$. Increasing $Q_{\text {ts }}$ to $6 \mathrm{~W}$ would require $d=0.73 \mathrm{~cm}$, leading to an outer diameter of about $0.9 \mathrm{~cm}$ or almost $3 / 8^{\text {" which }}$ is excessive. Even accommodation of two 0.25 " tubes would require very considerable flattenting of the 11ner. In the last row of Table III a has been reduced to 33 , resulting again in $d=0.5 \mathrm{~cm}$. $n$ could be reduced further but the galn is slow. Decreasing the starting temperature increases D, thus allowing smaller d for given $\Delta \mathrm{p}$. For starting at a temperature of $14^{\circ} \mathrm{K}$ and $\Delta \mathrm{T}=10$, d becomes $0.32 \mathrm{~cm}$ for $n=33$. A further small galn could be made by increasing $\Delta T$ somewhat. of course, reducing the starting temperature makes the cooling less economical. We can conclude that, except for the added difficulties of fabrication and Installation, the helium cooling method may well be feastble, at least more so than the prevlously discussed heat diffusion method. Cold "Warm Bore" Beam Tube?

If operation at $\sim 2^{\circ} \mathrm{K}$ is demanded, the simplest method, that may be most compatible with various critical requirements, would probably be a "warm" copper-plated beam tube (with projections if needed for vacuum maintenance), cooled to a temperature that is sufficlently effective for cryopumping 
( 4 to $8^{\circ} \mathrm{K}$ ). The tube is surrounded by a cooling jacket admitting sufficient mass flow so that recooling is not needed more frequently than considered above $(n=33$ to 66). By still solving eqs. 11 and 12 and then converting the obtained value for $d$ to the radial width of the jacket by means of

$$
W=\left(d^{5} / 32 r^{2}\right)^{1 / 3}
$$

where r still $=1.6 \mathrm{~cm}$, we obtain Table IV.

Table IV. Coollng with helium jacket.

\begin{tabular}{|c|c|c|c|c|c|c|}
\hline $\begin{array}{c}q \\
w / c m \\
10^{-3} x\end{array}$ & $Q_{\text {ts }}$ & n & $\begin{array}{l}\Delta \mathrm{T} \\
{ }^{\circ} \mathrm{K}\end{array}$ & $\begin{array}{l}\Delta p \\
\text { atm }\end{array}$ & $\begin{array}{c}M \\
g / \sec \end{array}$ & $\mathrm{cm}$ \\
\hline $\begin{array}{c}0.0012 \\
0.0036\end{array}$ & $\begin{array}{l}2 \\
6\end{array}$ & 66 & 1. & 6 & $\begin{array}{r}34 \\
103\end{array}$ & $\begin{array}{l}0.18 \\
0.34\end{array}$ \\
\hline $\begin{array}{l}0.0012 \\
0.0036\end{array}$ & $\begin{array}{l}2 \\
6\end{array}$ & 33 & 1 & 6 & $\begin{array}{l}17 \\
51\end{array}$ & $\begin{array}{c}0.09 \\
0.18\end{array}$ \\
\hline $\begin{array}{l}0.0012 \\
0.0036\end{array}$ & $\begin{array}{l}2 \\
6\end{array}$ & 33 & 2 & 2 & $\begin{array}{r}9 \\
26\end{array}$ & $\begin{array}{c}0.08 \\
0.17\end{array}$ \\
\hline
\end{tabular}

We see that, for $n=33, \Delta T=1$, and $\Delta p$ still $=6$, the value for $w$ is only 0.09 cm which is acceptable, when compared to the space occupied by the previousiy discussed methods. Decreasing $\Delta p$ to 2 atm in order to decrease refrigerator power but increasing $\Delta T$ to $2^{\circ} \mathrm{K}$ results in $w=0.08 \mathrm{~cm}$. 
The wall thickness of the copper-plated 1nner (beam) tube must be thick enough ( $0.2 \mathrm{~cm})$ to withstand the stress produced during a magnet quench, as well as the external hellum pressure of $\leq 15$ atm. The outer tube of the. assembly can be very thin. The copperplating here will not tend to lose its high resistivity ratio. The correction colls are not exposed to heat spikes due to synchrotron radiation concentrating profections. The magnets are practically completely protected from heat radiated from the liner. Fabrication of the Iner assembly is relatively quite simple.

The price one pays is that the assembly occupies valuable magnet space, but probably not significantly more than the other assemblles considered; for any solution it may becone necessary to increase the magnet aperture somewhat. Certainly, this solution is, less economical than the others with regard to refrigerator power. But we would gain virtual mechanical and thermal Independence of the IIner assembly from the magnets. 
Appendix D

\section{IRIAL HELIUM-COOLED BORE LINER}

BY

M.S. McAshan

Stanford University 


\title{
Appendir D
}

\section{Trial Hellum-Cooled Bore Liner}

\author{
M. S. McAshan
}

\section{Introduction:}

The concept to be investigated here is a bore liner with the section illustrated in Figure 1. The liner is a stainless steel tube $3.3 \mathrm{~cm}$. inside diameter with a wall thickness of $.05 \mathrm{~cm}$. It is cooled by fluid flowing in the small passage on the right hand side, and it is supported in the cryostat bore by springs of an unspecified design. The cooling passage is imagined as being formed from $.025 \mathrm{~cm}$. thickness stainless sheet and welded to the liner tube either by automatic IIG or by electric resistance method, but other constructions are possible. Dimensions are tabulated below:

Table I

Mode1 Dimensions

$\begin{array}{ll}\text { Magnet bore } & 4.5 \mathrm{~cm} . \\ \text { Cryostat bore } & 3.8 \mathrm{~cm} . \\ \text { Liner } 0 . d . & 3.4 \mathrm{~cm} . \\ \text { Liner i.d. } & 3.3 \mathrm{~cm} . \\ \text { Cooling passage } & 0.1 \mathrm{~cm} . \text { by } 0.6 \mathrm{~cm} . \text { about } \\ \text { Length of magnet } & 1.600 \mathrm{~cm} .\end{array}$

Coolant flow:

In this example the cooling is to be by means of helium gas entering the cooling passage in the liner at $15 \mathrm{~B}$ and $4 \mathrm{~atm}$. pressure. The synchrotron radiation heat load for an $8 \mathrm{I}$ magnet is $2 \times 10^{-3}$ watts $/ \mathrm{cm}$. or 3.2 watts for the 16 meter length. Assembled in Table II are relevant parameters for the cooling scheme: 
Table II

Coolant Flow Parameters

Coolant properties:

entering temperature

flow rate

heat capacity, $c_{p}$

heat load

temperature rise

7iscosity

specific $\nabla$ olume, $\nabla$

pressure

pressure drop

Coolant passage:

area

hydraulic radius, $I_{h}$

length, $I$
15B

$.125 \mathrm{~g} / \mathrm{sec}$.

$5.2 \mathrm{~J} / \mathrm{gR}$

3.2 甲

$5 \mathrm{~B}$

31 micropoise

$75 \mathrm{~cm} .3 / \mathrm{g}$

$4 \mathrm{~atm}$.

$.046 \mathrm{~atm}$. or $.67 \mathrm{psi}$.
$.06 \mathrm{~cm}^{2}$

$.043 \mathrm{~cm}$.

$1,600 \mathrm{~cm}$.

Flow:

G

Regnolds number, $\mathrm{N}_{\mathrm{BE}}$ friction factor, 1 heat transfer coefficient, $\mathrm{h}$
$2.08 \mathrm{~g} / \mathrm{cm}^{2} \mathrm{sec}$.

11,430

.0077

$.053 \mathrm{~F} / \mathrm{cm} .^{2} \mathrm{~B}$

In completing this table the following standard correlations for fully developed turbulent flow were used:

$$
\begin{aligned}
& f=.0014+.125 / \mathrm{N}_{\mathrm{BE}} .32 \\
& \text { pressure drop }=7 \cdot \mathrm{G}^{2} \cdot f \cdot \mathrm{L} /\left(2 \cdot \mathrm{I}_{\mathrm{h}}\right) \\
& \mathrm{h}=\mathrm{C}_{\mathrm{p}} \cdot \mathrm{G} \cdot \mathrm{f} /\left(2 \cdot \mathrm{N}_{\mathrm{PB}}{ }^{2 / 3)}\right.
\end{aligned}
$$

\section{Copper plating:}

In order to minimize the microware impedance of the bore, it is expected that the liner will be copper plated on the inside. The plating should be no thicker than necessarv, however, because the magnetic pressure on the tube during magnet quench must be 
controlled. Assume for the present purposes that the plating is to be the thickness of one skin depth at $10 \mathrm{KJHz}$. The skin depth varies directly with the square root of the resistivity of the surface and inversely with the square root of the frequency, and thicknesses are given in Table III for two values of the resistivity ratio. The resistivity ratio of the copper plating should fall in this range. The room temperature resistivity value for copper, $r_{a}$ is 1.7 micro-ohm $\mathrm{cm}$.

A standard semi-empirical model of the thermal conductivity at low temperatures of the plating can written as follows:

$$
1 / B=r_{y} /\left(I_{z} \cdot T\right)+(T / 12)^{2} / 140
$$

Here $\mathrm{B}$ ia the thermal conductivity in $\mathrm{T} / \mathrm{cm} . \mathrm{B}$. The first term on the right expresses the impurity scattering using the Fiedemann-Franz law. $L_{2}$ is the Lorenz number, $2.4 \times 10^{-8}$ Patt-ohm $/ \mathrm{R}^{2}$, and $r_{r}$ is the residual resistivity. The second term includes the phonon scattering, which varies as $T^{2}$. The coefficients in this term come from the observation that for copper of perg high resistance ratio, the thermal conductivity is about 140 $\overline{7} / \mathrm{cm} \mathrm{B}$ at $12 \mathrm{~B}$. Using a model rather than tabulated values for thermal conductivity assures that the electrical and the thermal conductivities assumed for the plating are consistent. Table III contains ralues calculated from this formula.

Table III

Characteristics of Copper Plating

Resistance ratio, $I_{0} / r_{5}$

Skin depth at $10 \mathrm{KHHz}$

Thermal conductipity at $15 \mathrm{~B}$
10

$.0208 \mathrm{~cm}$.

$2 \mathrm{P} / \mathrm{cms}$
100 $0.00656 \mathrm{~cm}$.

$17 \mathrm{~F} / \mathrm{cms}$

\section{Thermal resistances transperse to the bore:}

As a worst-case scenario, let it be supposed that the whole SR neat load (2 milliwatt/cm.) is applied to the liner on the side diametrically opposite to the coolant channel. The heat then would have to be conducted through the copper plating, the stainless liner wall, and then into the helium. In Table IV are listed the temperature drops associatod with these thermal resistances. 
Table IV

Temperature Drops for Transverse Conduction

$\begin{array}{ll}\text { Copper ( } 5 \mathrm{~cm} \text {. thick, } 2 \times .02 \mathrm{~cm}^{2} \text { per } \mathrm{cm} .0 \text { bore) } & 0.125 \mathrm{~B} \\ \text { Stainless steel }\left(.05 \mathrm{~cm} \text {. thick, } 6 \mathrm{~cm} .{ }^{2} \text { per cm.) }\right. & 0.011 \mathrm{R} \\ \text { Film coefficient }\left(.6 \mathrm{~cm} .{ }^{2} \text { per } \mathrm{cm} \text {. of bore }\right) & 0.063 \mathrm{~B}\end{array}$

It is clear that these thermal resistances are negligible. Also negligible is the longitudinal heat flux in the copper. Therefore considerable flexibility is available in the placement and the design of the cooling passage; it could bealized as a number of paralle! Ilattened tubes brazed to the liner, for example, or it could be of greater or smaller cross section as required by pressure drop considerations. Also there is considerable operload capability.

Spstom integration:

The question now to be dealt with is how to use the bore liners described above in a complete system. There are many possibilities and at this stage one ned not to to specific. Assuming that the $8 \mathrm{~T}$ ring is to be cooled in the way described in the body of this report, the magnets in each ring are to arranged cryogenically in 64 groups of 60 units each group being about $1 \mathrm{kM}$ long. In this scheme there would be 32 refrigerators. The 60 bores in one of the groups could be connected in the following way: At the midpoint then refrigerators two streams of $0.125 \mathrm{~g} / \mathrm{sec}$. are withdrawn from the $15 \mathrm{~B}$ shield flow and used for bore cooling. In each magnet there would be two streams. One would be cooling the bore and the other would be flowing in a 1/4 inch 0.d. line connected thermally to the $15 \mathrm{~B}$ shield flow. At each magnet interconnection, the warm stream from the bore would be interchanged with the recooled stream from the shield. In this way the SR heat would be taken by the $15 \mathrm{~B}$ shield flow. At the refrigerator end of the group of 60 magnets, both flows would be dumped into the process at some convenient point. The pressure drop in a 30-bore string would bo 20 psi. Allowing an additional $20 \%$ for the drop in the recooling tubes and interconnections, the total drop would be 24 psi. or $1.6 \mathrm{~atm}$. It is clear that strings twice as long could be operated in the same way.

Magnetic pressure during quench:

The magnitude of this pressure can be estimated by the following argument: 
The thickness of the copper on the bore is assumed to be one skin depth at $10 \mathrm{KHiz}$. Therefore it is 0.01 skin depth for a frequency of $1 \mathrm{~Hz}$, which is about the rate of decay of the quenching magnet. The magnetic pressure is proportional to the difference of the squares of the field inside and outside the tube, so the peak magnetic pressure at the equator of the tube will be about 28 of that due to the full $8 \mathrm{~T}$. A useful number to remember is that $0.5 \mathrm{~T}$ exerts a pressure of $1 \mathrm{~atm}$. at a perfectiy conducting boundary. Thus in this case there will be a pressure of 28 of $256 \mathrm{~atm}$. or about $5 \mathrm{~atm}$. The liner tube with a $.05 \mathrm{~cm}$. thick wall is pretty ragged, but this pressure is enough to be of concern. It will cause the tube to bulge outward; and rather than trying to design a rigid support strong enough to contain the pressure, the concept being considered here is to use spring supports that will deform and then return. If the deformation is large enough the tube can bulge out against the cryostat bore for support, and then spring back.

For completeness it should me mentioned that the restivity of stainless at $20 \mathrm{~B}$ is 50 micro-ohm $\mathrm{cm}$, and the skin depth at $1 \mathrm{~Hz}$ is $36 \mathrm{~cm}$. Thus the pressure acts almost entirely on the plating.

Heat leak through the supports:

Assume that the bore tube can supported on a system equivalent to 2 square centimeters of stainless $1 \mathrm{~cm}$ long. To make this plausible inagine it as a set of 6 springs each $0.5 \mathrm{~cm}$. long and $.025 \mathrm{~cm} . \times .2 \mathrm{~cm}$. in section ererg $50 \mathrm{~cm}$. along the bore. The optimum configuration will bave to be found, but this would surely hold the tube securely in place. The thermal conductivity integral for stainless is approximated by the expression $2 \times 10^{-4} \cdot \mathrm{T}^{2.25} \mathrm{~T} / \mathrm{cm}$. ( $\mathrm{T}$ in $\mathrm{K}$ ) for tomperatures up to $50 \mathrm{~B}$. Assuming that one end of the bore is at $15 \mathrm{~B}$ and the other at $20 \mathrm{~B}$ the heat leak comes to 0.25 watts atmost independent of wheather the cryostat is operated at $4.2 \mathrm{~B}$ or $2 \mathrm{~B}$. Thus even with some allowance for heat leak at the cryostat ends, the total is no more than 108 of the synchrotron radiation heat load.

\section{Bore interconnections:}

A problem that has not yet been considered is getting the fluid flow off and on to the bore at the magnet ends. At first sight this does not seem to be too difficult: The flow passage or passages could terminate in a band around the liner. This band could be thin enough to pass through the cryostat bore, but thick enough to allow the welding on of bellows rings after installation in the magnet. Such a ring would be particularly easy to use in the case of a brazed liner assembly, however, it could be put on to a welded liner by local RF brazing. The magnet interconnection regions are likely to be crowded, and a 
consistent design of the whole system must be made with all of the testing and assembly steps considered.

\section{Conclusion:}

The design exercise carried out here has shown no real problems with a fluidcooled bore liner in the space allowed, $0.25 \mathrm{~cm}$. radius. In lact the system seeme to have considerable flexibility and an important margin for overload. In addition it requires no actipe control.

In considering a bore liner it should be kept in mind that this is a system that intercepts two-thirds of the lowest temperature heat load and has the potential of reducing the refrigerator operating cost by a factor of two. Thus it should not be looked on as a tripial add-on. It is worth significant design and spstem integration effort. 


\section{Appendix D}

Figure I

Model Helium-Cooled Bore Liner

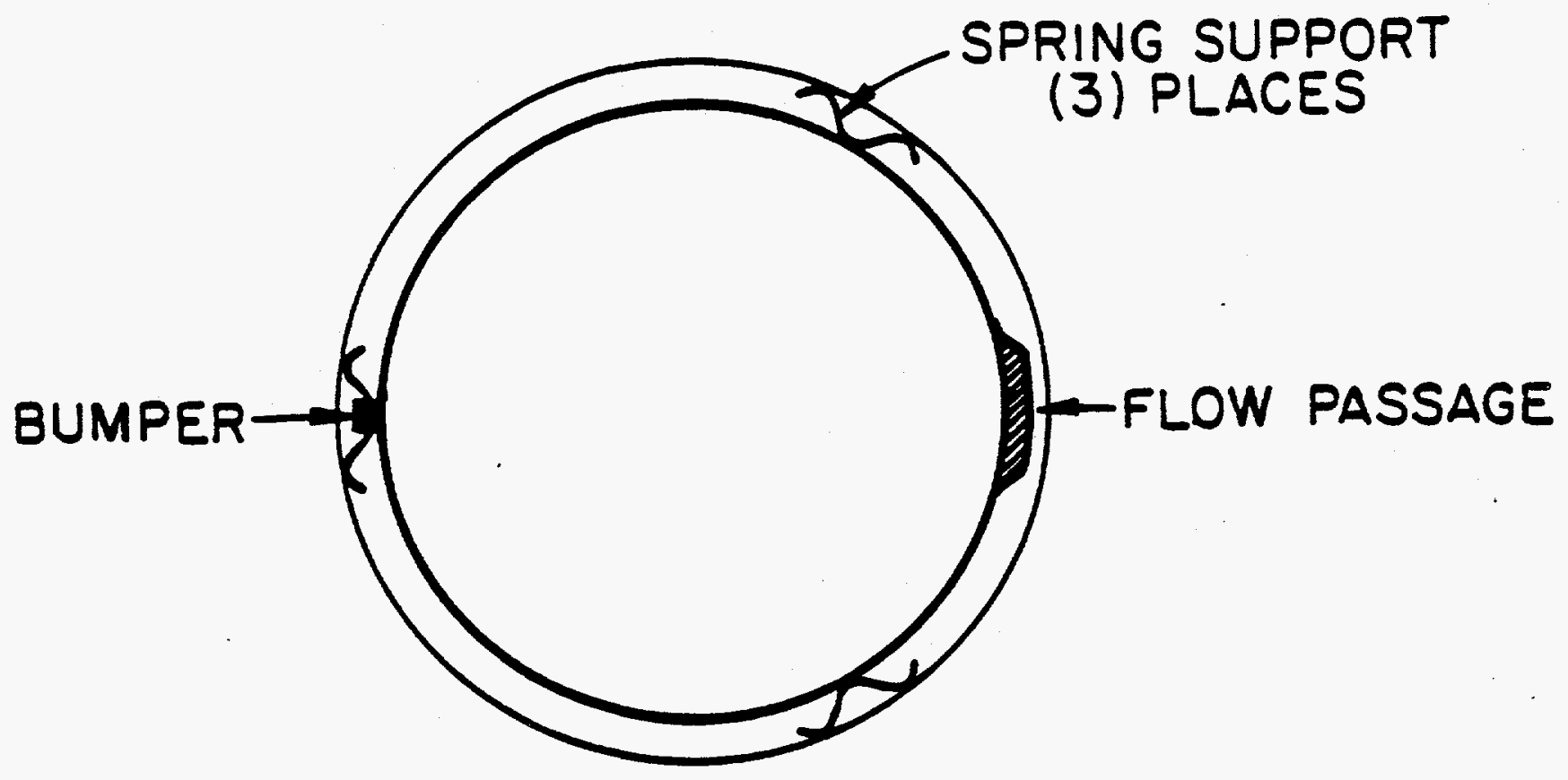

\section{Model Dimensions}

Magnet bore

Cryostat bore

Liner $0 . d$.

Liner i.d.

Cooling passage

Length of magnet
$4.5 \mathrm{~cm}$.

$3.8 \mathrm{~cm}$.

$3.4 \mathrm{~cm}$.

$3.3 \mathrm{~cm}$.

$0.1 \mathrm{~cm}$. by $0.6 \mathrm{~cm}$. about

$1,600 \mathrm{~cm}$. 


\section{Appendiн E}

\section{Membership of the Task Force on Low Temperature Operation}

The task force was appointed by by Maury Tigner, Director of the SSC, Phase 1, in March, 1985. Its membership includes:

W. Fowler

W. Hassenzahl

M. McAshan

R. Shutt

P. Vander Arend

Ex officio:

P. Limon

C. Taylor

M. Tigner
Fermi National Accelerator Laboratory Lawrence Berkeley Laboratory Stanford University, HEPL Brookhaven National Laboratory Cryogenic Consultants, Inc.

SSC, Central Design Group

Lawrence Berkeley Laboratory

SSC, Central Design Group

The task force met in three all-day sessions on April 11, May 17, and June 14, with all attending except $R$. Shutt. 
Appendix E

MEMBERSHIP OF TASK FORCE

ON LOW TEMPERATURE OPERATION

Membership list was not attached. 